NUREG/CR-1606 BNL-NUREG-51248

\title{
An Evaluation of Condensation-Induced Water Hammer in Preheat Steam Generators
}

Prepared by P. Saha, T. Ginsberg, B. J. C. Wu, O. C. Jones, Jr.

Department of Nuclear Energy

Brookhaven National Laboratory

Prepared for

U.S. Nuclear Regulatory

Commission

\section{DO NOT MICROFILM \\ COVER}




\section{DISCLAIMER}

This report was prepared as an account of work sponsored by an agency of the United States Government. Neither the United States Government nor any agency Thereof, nor any of their employees, makes any warranty, express or implied, or assumes any legal liability or responsibility for the accuracy, completeness, or usefulness of any information, apparatus, product, or process disclosed, or represents that its use would not infringe privately owned rights. Reference herein to any specific commercial product, process, or service by trade name, trademark, manufacturer, or otherwise does not necessarily constitute or imply its endorsement, recommendation, or favoring by the United States Government or any agency thereof. The views and opinions of authors expressed herein do not necessarily state or reflect those of the United States Government or any agency thereof. 


\section{DISCLAIMER}

Portions of this document may be illegible in electronic image products. Images are produced from the best available original document. 


\section{The following pages are an exact representation of what is in the original document folder.}




\section{NOTICE}

This report was prepared as an account of work sponsored by an agency of the United States Government. Neither the United States Government nor any agency thereof, or any of their employees, makes any warranty, expressed or implied, or assumes any legal liability or responsibility for any third party's use, or the results of such use, of any information, apparatus product or process disclosed in this report, or represents that its use by such third party would not infringe privately owned rights.

\section{DO NOT MICROFILM COVER}

Available from

GPO Sales Program

Division of Technical Information and Document Control

U. S. Nuclear Regulatory Commission

Washington, D. C. 20555

Printed copy price: $\$ 3.75$

and

National Technical Information Service

Springfield, Virginia 22161 


\section{An Evaluation of Condensation-Induced Water Hammer in Preheat Steam Generators}

NUREG/CR--1606

TI85 015921

Manuscript Completed: June 1980

Date Published: September 1980

Prepared by

P. Saha, T. Ginsberg, B. J. C. Wu, O. C. Jones, Jr.

Nuclear Safety Programs

Department of Nuclear Energy

Brookhaven National Laboratory

Upton, NY 11973

\section{Prepared for}

Division of Systems Safety

Office of Nuclear Reactor Regulation

U.S. Nuclear Regulatory Commission

Washington, D.C. 20555

NRC FIN No. A3115

\section{DISCLAIMER}

This report was prepared as an account of work sponsored by an agency of the United States Government. Neither the United States Government nor any agency thereof, nor any of their employees, makes any warranty, express or implied, or assumes any legal liability or responsibility for the accuracy, completeness, or usefulness of any information, apparatus, product, or process disclosed, or reprosents that its use would inot inf finge privately uwried rights. Reference herein to any specific commercial product, process, or service by trade name, trademark, manufacturer, or otherwise does not necessarily constitute or imply its cndorsement, recon!mendation, or favoring by the United States Government or any agency thereof. The views and opinions of authors expressed herein do not necessarily state or reflect those of the United States Government or any agency thereof. 


\section{THIS PAGE}

\section{WAS INTENTIONALLY \\ LEFT BLANK}


ABSTRACT

At the request of trie Division of Systems Safety of USNRC, a project to evaluate the potential of condensation-induced water hammer in preheat type steam generators was undertaken at BNL. The results of this project are presented in this report.

A review of Westinghouse 1/8-scale water hammer tests and data analysis was carried out. BNL has concluded that water hammers occurred in the feedwater line during many of the 1/8-scale tests. These events were probably caused by steam bubble entrapment and collapse in the partially-filled feedwater line. Recorded vessel pressure pulse activity under two-phase operating conditions was rare and, in those cases where pulses were recorded, the pressure pulse amplitudes were small. Either void collapse water hammers are unlikely events under these two-phase conditions, or events that did occur were attenuated in magnitude by the two-phase medium and internal structures before the pulse reached the pressure transducer. Pressure pulse attenuation in two-phase air-water media was studied experimentally at BNL. It was found that no significant attenuation could be detected in two-phase flows over distances of approximately 1-2 ft. The effects of internals, however, were not considered.

The Westinghouse scaling laws have also been critically reviewed. An independent BilL analysis was carried out to verify the Westinghouse scaling laws. It has been found that the present state-of-the-art on the condensation heat transfer and the mechanism of vapor cavity formation precludes us from deriving any credible scaling criteria. However, it was found that under certain uperating conditions the condensation-induced void collapse could be an oscillatory process. This may partially explain the apparent randomness $i$ the water hammer phenomenon seen in most experimental studies.

The full-scale preheat type-steam generators of both the Westinghouse and the Combustion Engineering design have been reviewed from the viewpoint of condensation-induced water hammer. It is recommended that each plant should be reviewed separately to identify the worst situation(s) for the condensationinduced water hammer, and the appropriate verification test(s) should be performed in plants. In addition, basic research should be sponsored in order to enhance our understanding in this area. 
TABLE OF CONTENTS

Page

ABSTRACT. . . . . . . . . . . . . . . . . . . . . . . . i . . . . .

LIST OF FIGURES . . . . . . . . . . . . . . . . . . . . . . . . vii

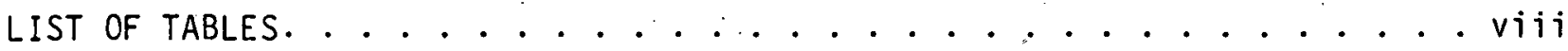

ACKNOWLEDGEMENTS. . . . . . . . . . . . . . . . . . . . . 1

1. INTRODUCTION. . . . . . . . . . . . . . . . . . . . 2

1.1 Background ........................ 2

1.2 Outline of the Report. . . . . . . . . . . . . . . 3

2. ANALYSIS OF WESTINGHOUSE 1/8th SCALE

EXPERIMENTAL RESULTS. . . . . . ................... 5

2.1 Introduction .................... 5

2.2 scope of the Westinghouse Experr ental Program . .........5

2.3 Adequacy of Instrumentation, Data Acquisition

and Playback Systems................... 8

2.4 Analysis of Westinghouse Test Data . . . . . . . . . . . . . 11

2.5 Effect of Noncondensibles. . . . . . . . . . . . . . . . . 24

2.6 Conclusions. . . . . . . . . . . . . . . . . . . . . 26

3. PRESSURE PULSE ATTENUATION IN WESTINGHOUSE PREHEATER

TEST VESSEL UNDER TWO-PHASE CONDITIONS . . . . . . . . . . . . . . . . . . . . . 7

3.1 Introduction . . . . . . . . . . . . . . . . . . . . . . . . . . . . .

3.2 Geometric Attenuation. . . . . . . . . . . . . . . . . . 27

3.3 Irreversible Losses. . . . . . . . . . . . . . . . . 28

3.4 Conclusions. . . . . . . . . . . . . . . . . . . . 28 
4. EVALUATION OF WESTINGHOUSE SCALING LAWS . . . . . . . . . . . . . . . . . . . . .

4.1 TRANFLO Code Approach . . . . . . . . . . . . . . . . . . . . . . . . . .

4.2 Generalized Conservation Laws Approach. . . . . . . . . . . . . 31

4.3 Westinghouse Parametric Study . . . . . . . . . . . . . . 31

4.4 Conclusions . . . . . . . . . . . . . . . . . . . . 42

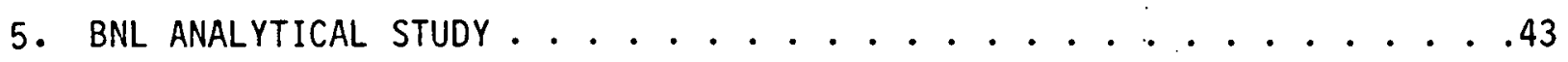

5.1 The Model . ... . . . . . . . . . . . . . . . . . 43

5.2 Nomenclature for BNL Model. . . . . . . . . . . . . . . . . 48

5.3 Results of Calculation . . . . . . . . . . . . . . . . . . . . . . . .

5.4 Conclusions . . . . . . . . . . . . . . . . . . . . . . . . . . . .

6. EVALUATION OF WESTINGHOUSE FULL-SCALE PREHEAT STEAM

GENERATOR . . . . . . . . . . . . . . . . . . . . . . . . . 59

7. EVALUATION OF COMBUSTION ENGINEERING DESIGN . . . . . . . . . . . . . . . . . . .

8. CONCLUSIONS AND RECOMMENDATIONS . . . . . . . . . . . . . . . . . . . . . . . . . . . .

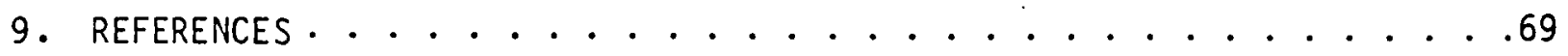

Appendix A: BNL EXPERIMENTS: PRESSURE PULSE ATTENUATION IN

TWO-PHASE VAPOR-LIQUID MEDIA WITH NO INTERNALS . . . . . . 70

A.1 Introduction . . . . . . . . . . . . . . . . . . . . . .

A.2 Experimental Apparatus . . . . . . . . . . . . . . . . . .

A.3 Experimental Procedure . . . . . . . . . . . . . . . . . . . . .

A.4 Experimental Results. . . . . . . . . . . . . . . . . . . .

A.5 Conclusions . . . . . . . . . . . . . . . . . . . . . . . . . . . 


\section{LIST OF FIGURES}

Figure

Page

2.1 Schematic of Westinghouse steam generator with integral preheater ...................... . 6

2.2 Schematic of preheater region . . . . . . . . . . . 6

2.3 Preheater test vessel pressure and temperature measurements locations ................ 7

2.4 Schematic of Westinghouse data acquisition system . . . . . 9

2.5 Pressure pulse magnitudes: Type A fill/drain tests . . . . . 14

2.6 Typical pressure pulses: Type A fill/drain tests . . . . . . 17

2.7 Pressure pulse magntiudes: Type A tests . . . . . . . . 18

2.8 Typical pressure pulses: Type A tests . . . . . . . . . 19

2.9 Pressure pulse magnitudes: Type B tests . . . . . . . . 21

2.10 Typical pressure pulses: Type B tests . . . . . . . . . 22

2.11 Pressure pulse magnitudes: Type $C$ tests . . . . . . . . 23

4.1 Westinghouse mode 1 of entrapped steam cavity . . . . . . . 32

Variation of nondimensionalized pressure with
nondimensionalized time . . . . . . . . . . . . . . . . 34

4.3 Maximum depressurization intensities as a function

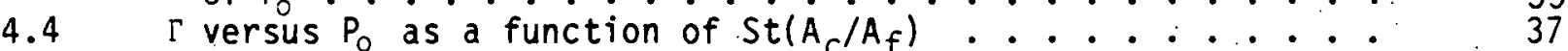

4.5 Maximum depressurization versus $P_{0}$ for various values

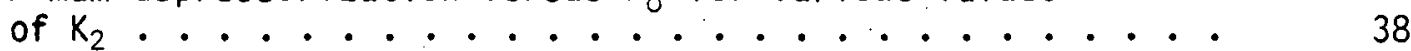

4.6 A comparison of Westinghouse type A test data and Westinghouse parametric study analysis . . . . . . . 39

5.1 BNL model for slug impact water hammer analysis . . . . . . . 44

5.2 Effect of heat transfer coefficient on cavity length . . . . 51

5.3 Effect of heat transfer coefficient on cavity pressure . . . 51

5.4 Effect of heat transfer coefficient on water slug velocity ...................... 51

5.5 Effect of heat transfer coefficient on slug impact pressure ..................... 51

5.6 Effect of initial pressure on cavity length . . . . . . . 53

5.7 Effect of initial pressure on cavity pressure . . . . . . . , 53

5.8 Effect of initial pressure on water slug velocity...... 53

5.9 Effect of initial pressure on slug impact pressure . . . . 53

5.10 Effect of initial relative cavity length on instan-
taneous cavity size . . . . . . . . . . . . . 55

5.11 Effect of initial relative cavity length on cavity

5.12 Effect of initial relative cavity length on water slug

5.13 Effect of initial relative cavity length on slug impact

5.14 Effect of feedwater velocity on cavity length . . . . . . . $\quad 56$

5.15 Effect of feedwater velocity on cavity pressure . . . . . . 56

5.16 Effect of feedwater velocity on water slug velocity..... 56

5.17 tffect of geometric scale.............. 57 
LIST OF FIGURES (Cont'd)

Figure

Page

6.1 Schematic of the McGuire preheat steam generator with the associated feedwater system ............. 60

7.1 CE integral economizer steam generator (axial flow).... 63

7.2 CE main feed system flow diagram . . . . . . . . . . . 64

7.3 CE analytical results. Pressure vs. time - Tihange incident. Variable condensation rate

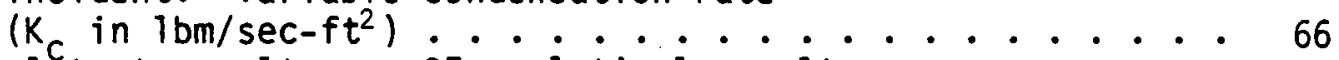

7.4 Doel ${ }^{C}$ test results vs. CE analytical results

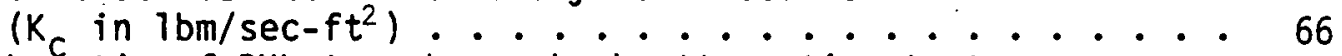

A.1 Schematic of BNL two-phase shock attenuation test section .................... . . 72

A.2 Overall view of shock attenuation apparatus: Test section and instrumentation . ............ . 73

A.3 View of test section: Pressure transducer, focusing cone, tip of shock generator . . . . . . . . . . 73

A.4 Close-up view of test section: two-phase conditions . . . 74

A.5 Calibration pressure traces . . . . . . . . . . . 76

A.6 Pressure transducer calibration data . . . . . . . . 78

A.7 Pressure transducer calibration data . . . . . . . . . 78

A.8 Pressure transducer calibration data . . . . . . . . . 78

A.9 Pressure pulses of waves in single phase air and water : . 79

A.10 Pressure pulses of waves in two-phase bubbly flow . . . . 81

A.11 Pressure pulses of waves in two-phase slug flow ....... 82

LIST OF TABLES

Table

Page

2.1 Westinghouse Test Types . . . . . . . . . . . 12

2.2 Summary of BNL Observations . . . . . . . . . . 15

2.3 Effect of Noncondensibles ............. 25

5.1 Conditions Chosen for BNL Parametrtic Study . . . . . . 50 
ACKNOWLEDGEMENTS

Several people helped the authors in the course of this project, and the authors are thankful to all of them.

In the experimental area, the authors thank Messrs. John Klages and Jim klein for the design and construction of the experimental apparatus used in the pressure pulse attenuation experiments. Special thanks are due to Mr. R. W. Carlson of the Westinghouse Corporation for providing the authors with the piezoelectrtic transducers and the associated electronics used for the BNL experiments.

Ms. L. Schor initiated the BNL. analytical study and the associated computer programs. Later, Dr. E. Cazzoli and H. Makowitz made several improvements to the computer program. Their help is gratefully acknowledged.

The project was sponsored by the Division of Systems Safety of USNRC: The authors are thankful to Mr. Victor Benaroya, Mr. Donald Fischer and Mr. Robert Giardina for their helpful suggestions and comments.

Finally, the fine typing of is. Becky Bishop, Ms. Kathy Becker, Ms. Marisa Canner, and Mrs. Jean Muller is highly appreciated. 


\section{INTRODUCTION}

\section{$1.1 \quad$ Background}

Condensation-induced water hammer in steam generators became of great concern following a significant damage to the main feedwater pipe to the \#22 steam generator of Indian Point \#2 on November 13, 1973 (Cahill, 1974). This and several other less damaging water hammer incidents in feedring type steam generators prompted USNRC to sponsor a study at Creare, Inc. in order to rationalize the sequence of events which could lead to a severe impact on the feedwater piping system (Block, 1977). In the Creare study, it is postulated that when cold water is injected into a partially filled pipe, a water slug may form to trap a steam void. Condensation of this steam void may create a large pressure difference across the water slug so that the latter will move rapidly into the void and collapse it completely. The resultant pressure wave, if severe enough, can damage the feedwater piping system.

It should be kept in mind that in the feedring type steam generators, cold auxiliary feedwater is injected into the feedring if the water level in the secondary side drops below the feedring. This can happen during a number of abnormal operating situations such as loss of feedwater pump or loss of off-site power. Although such occurrences are infrequent, their consequences must be considered for safe operation of nuclear power plants.

Several hardware "fixes" were recommended by the PWR vendors as well as Creare, Inc. based on small-scale tests. These include top discharge of feedwater from the feedring and the shortest possible horizontal length of piping outside the steam generator. It was found in the Creare study (B1ock, 1977) that these two fixes separately could not reduce the potential for damaging water hammer significantly, but when employed together, they seemed to be successful in reducing the severity of water hammer. Although, a complete understanding of this behavior is not available yet, a number of PWR steam generators have been retrofit to comply with this recommendation. Verification tests in these full scale steam generators suggest that the fixes work. However, to be sure, NRC requires that all new plants with feedring design undergo confirmatory testing.

Recently, Westinghouse Electric Corporation and Combustion Engineering, Inc., have introduced new designs of steam generators. In these steam generators, feedwater is introduced at a lower section called the "preheater" or the "economizer" section. In the Westinghouse design, the feedwater may impinge on a vertical diffuser plate and spl it into two parts (in the split flow design), or it may flow downwards through an annular downcomer and then move upwards in the tube-bundle region (in the counterflow design). The Combustion Engineering design is similar to the Westinghouse counterflow design and, in addition, has a downcomer nozzle at the mid-section of the steam generator. This downcomer nozzle is designed primarily to introduce the auxiliary feedwater and the main feedwater at low operating power $(<15 \%)$. Some of the Westinghouse preheat steam generators al so have a downcomer nozzle. 
The USNRC became concerned at the introduction of these new designs. It was not known a priori whether cold water could be injected into the preheater region by design or inadvertantly. Therefore, questions regarding the possibility of having a damaging water hammer in the preheater region were raised. In response, Westinghouse conducted a high pressure water hammer test program in a $1 / 8$ th scale model of their split flow preheat steam generator (Carlson, 1978a). They have also advanced scaling laws to extrapolate the results of the $1 / 8$ th scale test to the full-scale steam generators. From these studies, Westinghouse concluded that "the occurrence of water hammer during normal and abnormal plant operating conditions is very unlikely". Combustion Engineering also expressed a similar position strictly from the design features of their preheat steam generators.

Brookhaven National. Laboratory (BNL) was requested by the Division of Systems Safety of NRC to evaluate the possibility of having a condensation induced water hammer in the preheat steam generators of both the Westinghouse and the Combustion Engineering designs. The task includes: (a) evaluation of the Westinghouse 1/8th scale test and their scaling criteria; (b) suggestions for additional testing and analytical studies; (c) evaluation of both the Westinghouse and the Combusiton Engineering full-scale steam generators; (d) suggestions for any design changes; and (e) recommendation regarding any need for confirmatory testing in full-scale steam generators.

The purpose of this report is to present the results of BNL evaluation of the work done at Westinghouse and Combustion Engineering, independent experiments and analytical studies done at BNL and to make recommendations regarding the full-scale preheat steam generators. No design change has been recommended. However, need for confirmatory testing in full-scale steam generators has been stressed

\subsection{Outline of the Report}

In Section 2 of the report, a detailed evaluation of the Westinghouse 1/8th scale test is presented. Several questions regarding the interpretation of the test data were raised. Subsequently, additional tests were done at Westinghouse and BNL. The BNL study on the pressure pulse attenuation in two-phase flow has been described in Appendix $A$ and summarized in Section 3.

In Section 4 , the Westinghouse analytical work and the scaling criteria have been reviewed critically. Additional independent studies, done at BNL, have been desc -ibed in Seçtion 5. It is concluded that the present state-of-the-art precludes us from deriving. any credible scaling laws for condensation induced water hammer.

In Section 6, a Westinghouse plant, namely the McGuire plant, with preheat steam generator has been scrutinized to see under what circumstances cold water might be introduced into the preheater section. Finally, a confirmatory test for the plant has been suggested.

In Section 7, attention is shifted to the Combustion Engineering design. Since Combustion Engineering did not conduct any experiment or transient 
analysis in the preheater region, their arguments were mainly based on the design features and intuition. Therefore, the evaluation of the Combustion Engineering design is more qualitative in nature.

Finally, in Section 8, we summarize the results of our evaluation and independent studies done at BNL. It is emphasized that because of the lack of predictive tools, each power plant should be scrutinized separately to find under what situation(s) cold or significantly subcooled water might be injected into the preheater region with steam voids. Confirmatory testing for these situations are recommended. Further basic research is needed to enhance our understanding of the condensation-induced water hammer and to develop predictive tools. 


\section{ANALYSIS OF WESTINGHOUSE $1 / 8$ th SCALE EXPERIMENTAL RESULTS}

\subsection{Introduction}

Westinghouse designed an experiment to investigate the potential for generation of damaging pressure forces resulting from steam void collapse during cold water injection into steam generators containing integral preheaters. The apparatus was a 1/8th scale model of the preheater section of the steam generator. The flow facility, test vessel, instrumentation, experimental procedures and test results are described in detail by Carlson (1978a). The objectives of the analysis presented here is to provide BNL's interpretation of the Westinghouse experiments. A brief description of the scope of the Westinghouse tests is presented in Section 2.2. Section 2.3 discusses the adequacy of the instrumentation, data recording and playback procedures used in the experiments, judged primarily from the point of view of detection of pressure pulses arising out of steam void collapse events. Section 2.4 provides BNL's interpretation of the test data. Section 2.5 discusses the effect of noncondensibles on the results. Finally, Section 2.6 presents conclusions based upon BNL's analysi.s of the Westinghouse tests.

\subsection{Scope of the Westinghouse Experimental Program}

If a steam bubble is surrounded by cold water injected into the steam generator, then condensation-induced steam void collapse could occur. If the event occurs rapidly, then liquid-liquid impact could lead to generation of a pressure pulse which would propagate through the system and interact with structural members. This steam void collapse "water hammer" has been observed in operating steam generators and has been the subject of recent experimental investigations (Block, 1977).

The basic objective of the Westinghouse experiments was to observe the appearance of pressure pulses within the model preheater under conditions covering a selected range of temperature, flow rate, initial preheater pressure, power level,.liquid level and feedwater injection mode (downcomer or feedwater pipe). In addition, the tests were interpreted to attempt to determine the influence of non-condensable gas content on the magnitude of recorded pressure events.

Figure 2.1 is a schematic diagram of a Westinghouse steam generator containing an integral preheater: Feedwater is normally introduced into the preheater. Under abnormal conditions, cold feedwater may be introduced either through the auxiliary feedwater nozzle located above the normal level or through the feedwater nozzle. Figure 2.2 shows a schematic diagram of the preheater region. Under normal flow conditions, water entering the preheater splits, and a fraction flows upwards and the remainder flows down, mixes with downcomer flow and. passes up through the not leg.

A schematic diagram of the test vessel is shown in Figures 2.3 (a) and (b) with pressure and temperature instrumentation locations indicated. All pressure 
or

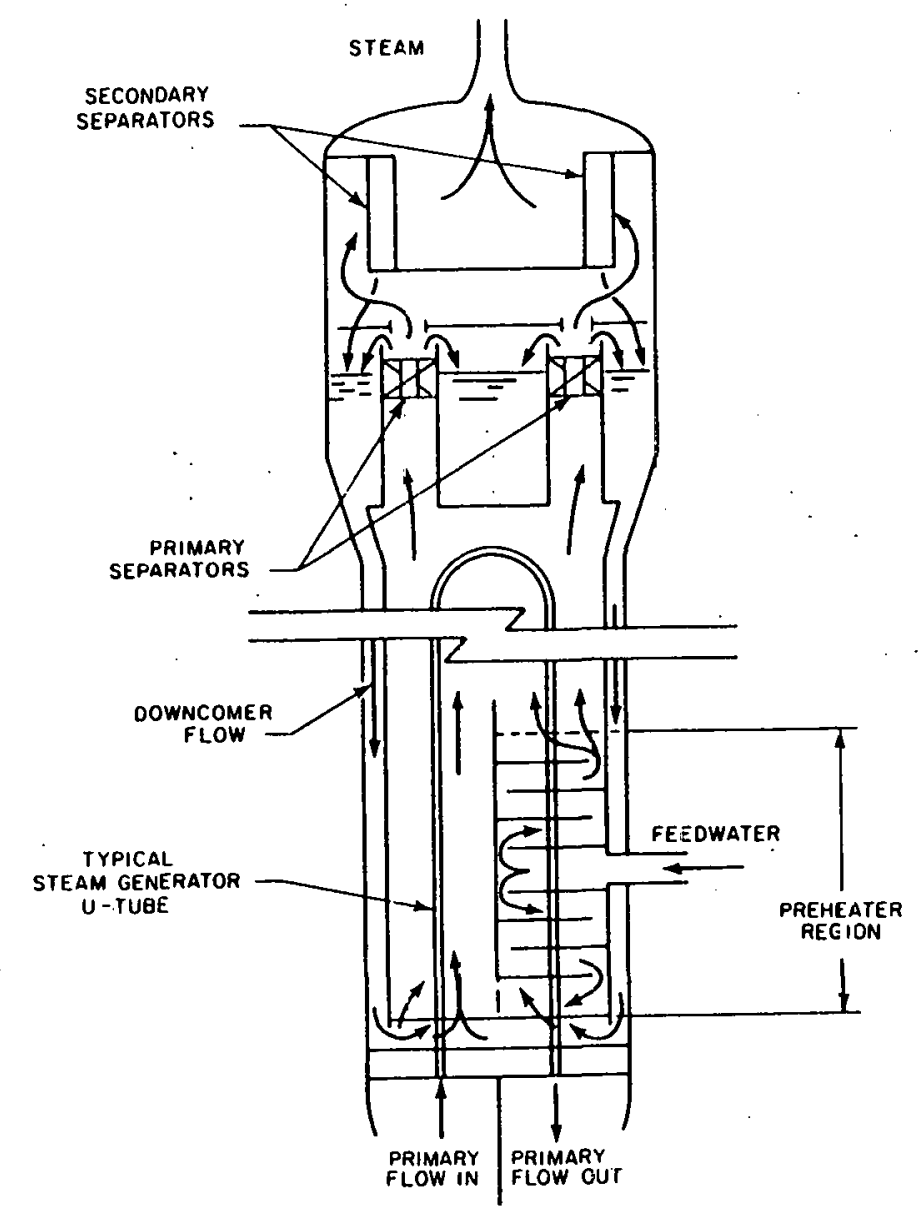

Figure 2.1 Schematic of Westinghouse steam geneiator with integral preheater.' (BNL-21136-80)

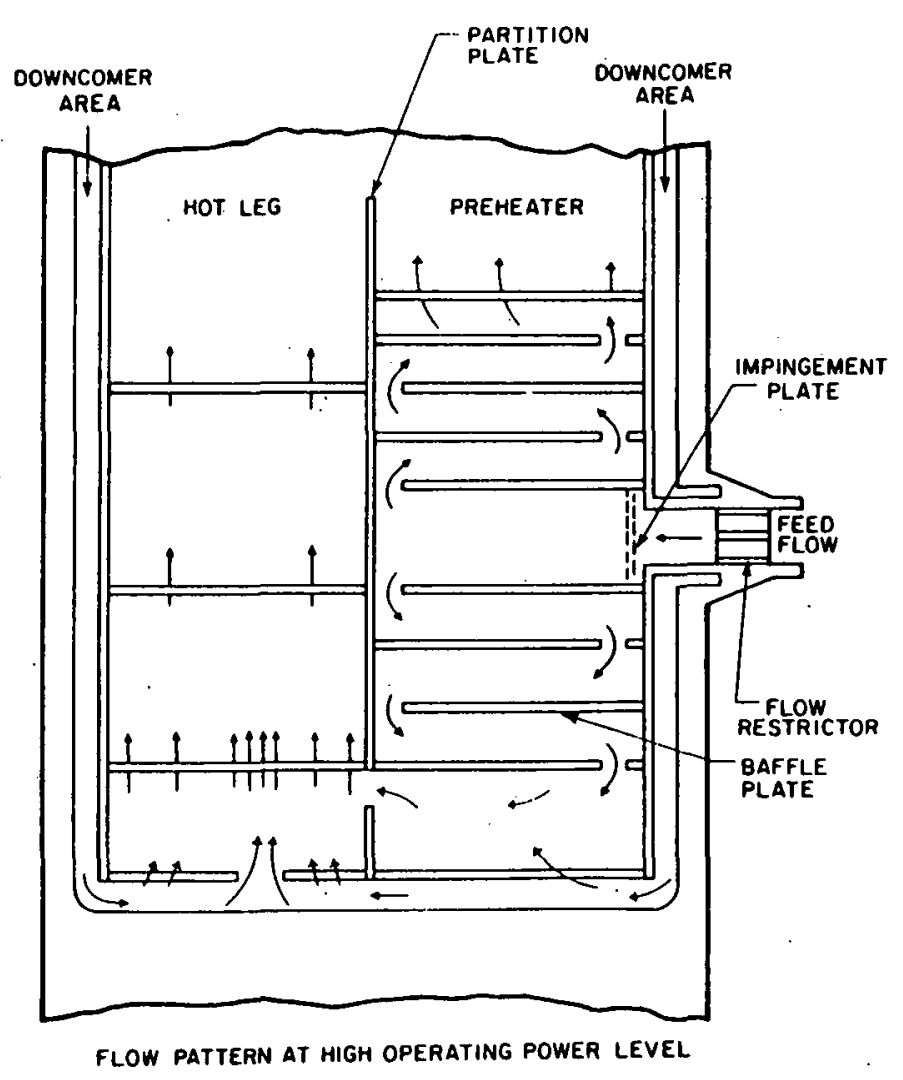

Figure 2.2 Schematic of preheater region. (BNL-2-1135-80) 
Pressure

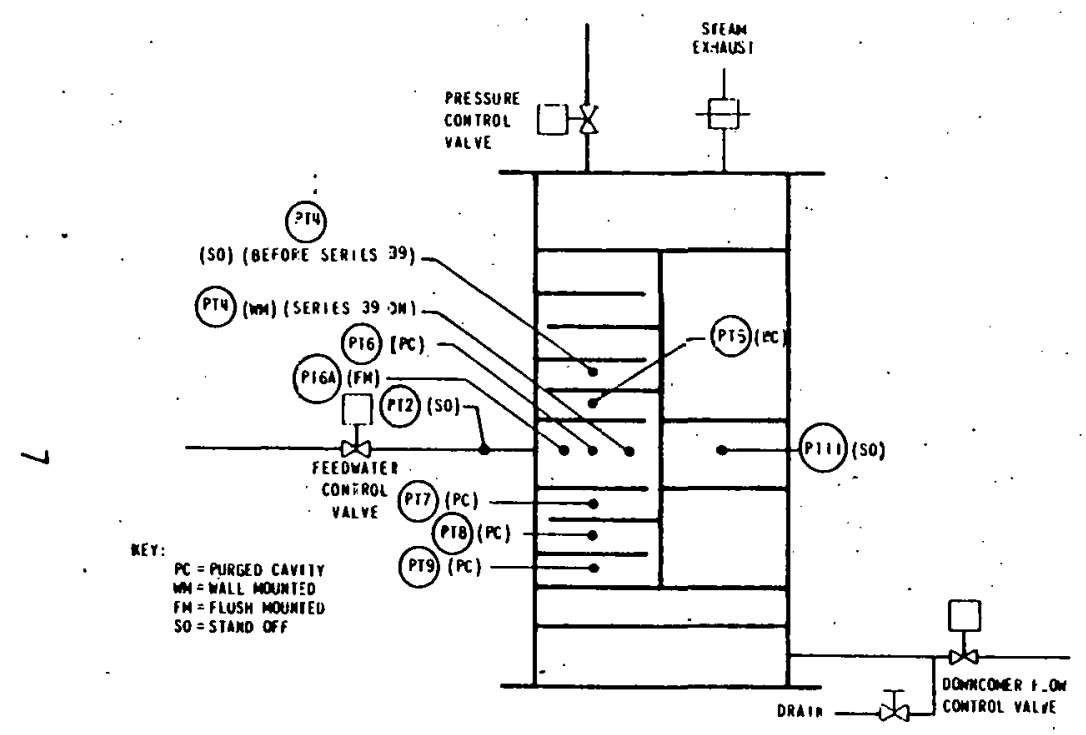

(a)
Temperature

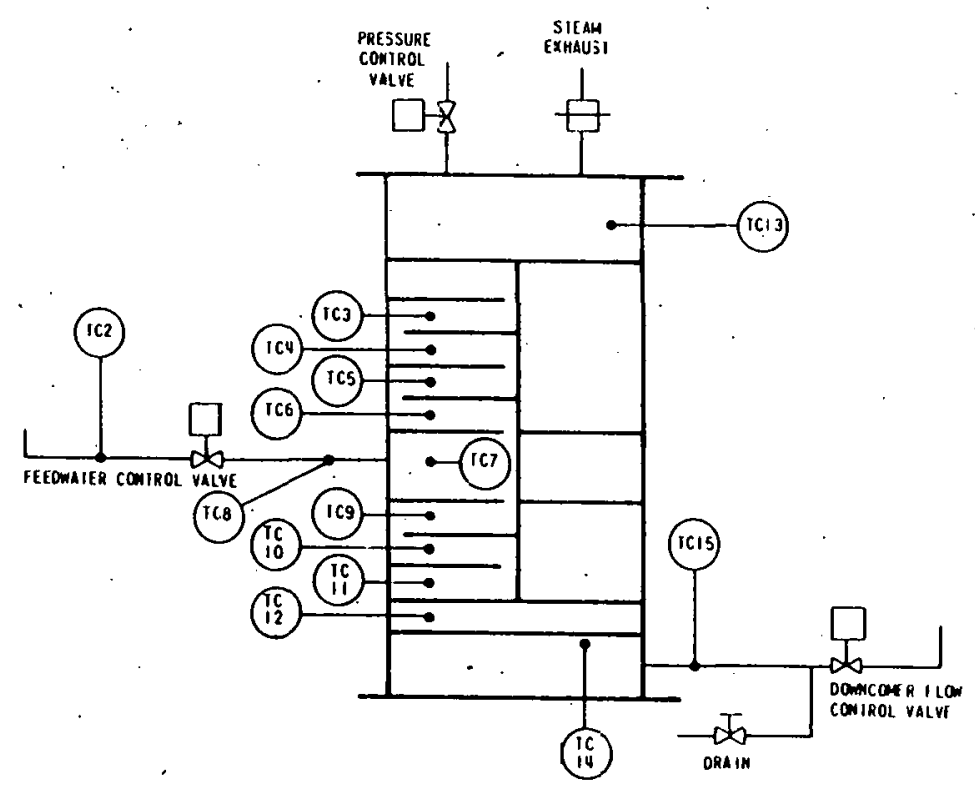

(b)

Figure 2.3 Preheater test vessel pressure and temperature measurement locations. (BNL-2-179-80) 
transducers are mounted on the walls of the test vessel. Cold feedwater flow can be introduced through either the feedwater nozzle, or through a simulated, external downcomer line. The Westinghouse tests addressed cold water flow into the preheater under two distinct sets of conditions:

(i) The test vessel is steam-filled, simulating abnormal operating conditions during which the water level is below the feedwater nozzle.

(ii) The test vessel is filled with two-phase fluid, simulating the "normal" operational condition of the preheater.

The potential for generation of damaging void collapse water hammer was investigated under the above conditions. Section 2.4 contains a more detailed description of test conditions.

\subsection{Adequacy of Instrumentation, Data Acquisition and Playback Systems}

Pressure and temperature were measured at various locations around the periphery of the test vessel, as shown in Figure 2.3. Also recorded were initial vessel pressure and temperature, cold feedwater flow rate and liquid level. A prerequisite for interpretation of test results is the demonstration that pressure pulses generated within the test vessel were measured accurately and unambiguousiy. In the BNL review, therefore, emphasis was placed on determination of the adequacy of the pressure measurement system, including the transducers, transducer mounting techniques, and recording and playback equipment.

Pressure pulse events were monitored with transducers mounted along the periphery of the test vessel. It is conceivable that a pressure pulse which originates within the steam generator would be attenuated by interaction with the two-phase fluid before it is detected by the pressure transducer. This effect, not evaluated by Westinghouse, was investigated by BNL in a series of separate effects tests. These experiments are described in Appendix $A$ and summarized in Section 3 .

\subsubsection{Instrumentation and Data Acquisition}

Figure 2.4 schematically represents the data acquisition system. of particular concern are the dynamic pressure measurements, made with PCB piezoelectric pressure transducers. These transducers have a specified range of $0-5000$ psi, and were used with a manufacturer's supplied calibration over this range of pressure. Linearity of $1-2 \%$ of full-scale was specified by the manufacturer. The rise time was specified as [ ] .* The observed pressure pulse widths were roughly [ ]. The time response characteristics of the transducer was, therefore, adequate, based upon manufacturer specifications.

The charge output of the transducer was amplified and converted to a DC output using Unholtz-Dickie Corporation Model 022 signal conditioning amplifiers. The instrument bandwidth was [ ]. The output of the charge amplifier was further conditioned by passage through a Dynamics d.c. amplifier.

\footnotetext{
*.Information in [ ] is proprietary to Westinghouse Electric Corporation.
} 


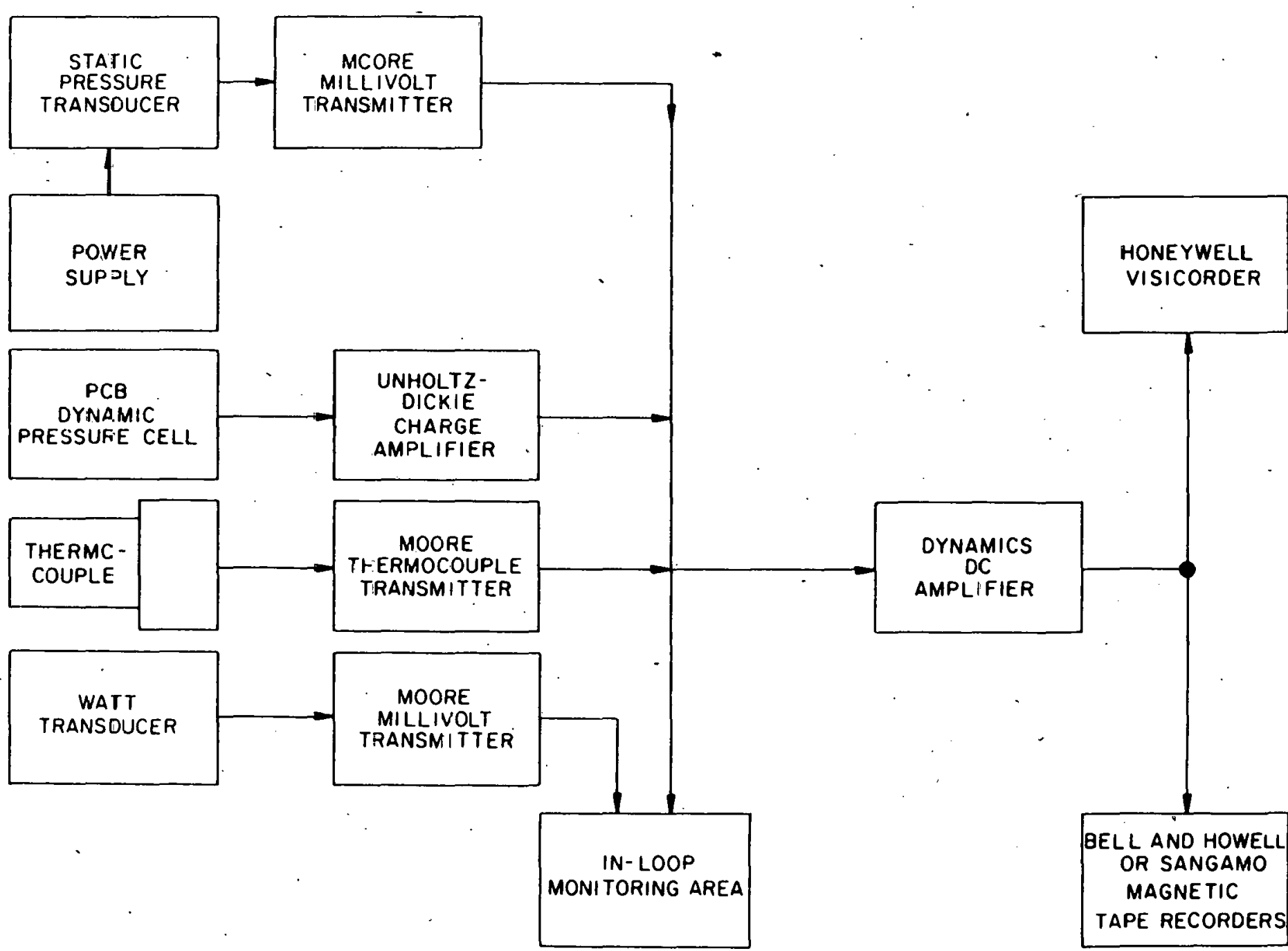

=igure 2.4 Schematic of Westinghouse data acquisition system. (BNL-2-1137-80) 
This amplifier, with a [ ], was usually operated with a gain of unity. The dc signal was recorded on a Sangamo FM tape recorder at $30 \mathrm{in} / \mathrm{s}$, with a bandwidth of $10 \mathrm{kHz}$. The tape recorder saturation voltage was 1.5 volts RMS ( 2.1 volts peak-to-peak).

The sensitivity of the charge amplifier was adjusted, during most of the Westinghouse experiments, to generate an output signal of 1 volt per 100 psi, for transmittal to the tape recorder. This implies that dynamic pressures in excess of 200 psi would exceed the saturation voltage of the tape recorders.

At the request of BNL, separate "Water Hammer Data Acquisition System Response Tests" were conducted by Westinghouse (Carlson, 1978b) to evaluate the range of pressure pulse magnitudes that would have been recorded during the water hammer tests. The test results showed the positive amplitude pressure pulses were "clipped" at 400 psi and negative pulses were "clipped" at -200 psi, due to saturation of the FM tape recorder. It was concluded that during the water hammer tests, the maximum positive pressure pulse amplitude that could be recorded was 400 psi. Similarly, a limit of -200 psi was found to apply to negative pressure pulses.

It is concluded that the pressure measurement and recording system was capable of measuring positive pressure pulses with amplitudes up to 400 psi in magnitude, and negative pulses up to $-200 \mathrm{psi}$, with an accuracy of not less than + 50-100 psi. The system bandwidth was adequate for recording approximately I msec width pulses. It should be noted that the maximum amplitude positive pressure pulse recorded in any of the Westinghouse tests was [ ]. Thus, the saturation voltage (positive amplitude) of the tape recorder was probabiy not exceeded in any of the tests.

\subsubsection{Playback Techniques}

The data was originally recorded on FM tape at $30 \mathrm{in} / \mathrm{sec}$. The tape was played back at $17 / 8 \mathrm{in} / \mathrm{sec}$ and digitally sampled at $900 \mathrm{samples} / \mathrm{sec}$. The factor limiting the bandwidth of the resulting output is due to Nyquist aliasing. Using the Nyquist frequency criterion, the sampling rate of 900 samples/sec implies a bandwidth of the digitized data of $450 \mathrm{~Hz}$. With a tape speed turndown ratio of 30:1 7/8, the corresponding effective bandwidth of the recorded data is $7.2 \mathrm{kHz}$. This is judged adequate for the water hammer ex- . periments, in which minimum pulse widths were approximately [ ]. 


\subsubsection{Interpretation of Pressure Pulses}

Interpretation of the observed pressure pulses is ambiguous. Westinghouse has identified three experimental "artifacts" which may lead to observed pressure pulses:

(i) Thermal effects - Cold water contacting a hot transducer can generate a signal which looks like a pressure pulse, but is actually due to contraction of the transducer case and resultant stress on the crystal. Signals of up to [ ] amplitude and [ ] in pulse width were observed in bench tests.

(ii) Cavity water hammers - Some transducers were mounted within cavities or within standoffs. Westinghouse suggests that cold water entering the cavities could lead to collapse of the void within the cavity or standoff, leading to a "localized water hammer." No test program was identified to evaluate this phenomenon.

(iii) Transducer ringing - This was characterized by an oscillatory signal which was superposed on presumed water hammer events. In many cases the true shape of the pressure signal caused by some event within the test vessel was obscured by the oscillatory behavior.

Westinghouse feels that introduction of purged-cavity mounted transducers eliminated problems (i) and ( $i$ i). Some of the early tests (Type A) are difficult to interpret because of the possible artifacts discussed above. This oscillatory behavior was characteristic of all the tests, and was eliminated by the purged-cavity mounting technique. It is felt, in agreement with Westinghouse, that the purged-cavity procedure leads to the most reliable data. These, however, were introduced in the later stages of the test program.

The basic source of the ambiguity in identification of "true" water hammers is the lack of a "signature," or characteristic pulse shape associated with a well-defined vapor collapse pressure pulse which originates in the steam generator or in the feedwater pipe. It is not possible, therefore, to directly distinguish a void collapse pulse from other experimental artifacts.

\subsection{Analysis of Westinghouse Test Data}

The Westinghouse test results were analyzed by BNL in order to make an independent evaluation of the appearance of void collapse pressure pulses, and to thereby evaluate the validity of the conclusions drawn by Westinghouse from their own analysis.

Table 2.1 briefly describes the test types which were executed by Westinghouse. They are, basically, of two categories:

(i) The Type A series of tests simulate conditions where the water level in the steam generator falls below the feedwater nozzle. Refill with cold water is initiated. 


\section{Table 2.1 Westinghouse Test Types}

Test Description

A - Feedline

A - Fill/Drain

A - Downcomer

B - No Downcomer

B - With Downcomer

C - With Downcomer

\section{Test Type}

Steam-filled vessel. Refill from feedline.

Steam-filled. Rapid on-off flow.

Steam-filled. Refill from downcomer.

Two-phase. Cold water injected from feedline.

Two-phase. Cold water injected from feedline:

Two-phase. Split flow ramp. 
(ii) Types B \& C simulate conditions which could occur during twophase operation (shell-side) of the steam generator during which the liquid level is near normal. Cold water is injected into the preheater under various operating conditions:

The Westinghouse analysis of the test data focused on the magnitude of depressurization events. In the BNL analysis, it was assumed that a depressurization event was an indication of the condensation heat transfer resulting from cold water injection. The actual water hammer event would be detected by a positive pressure pulse event resulting from either liquid-liquid, or liquid-solid impact.

\subsubsection{Type A Tests: Steam-Filled Conditions}

A. Type A Fill/Drain Tests

These tests were run in order to examine the potential for a water hammer in the feedwater line. The test vessel was steam-filled. The flow in the feedline was quickly ramped up to fill the pipe, then immediately ramped down. It was thought that steam bubbles would be trapped in the feedline and, surrounded by cold water, would collapse and induce a water hammer event. The BNL effort focused on an attempt to isolate water hammer events in the feedwater line. The response of pressure transducer PT2, which was mounted on a standoff tube on the feedwater line, was examined.

Figure 2.5 shows the magnitude of both positive and negative pressure pulse events recorded from PT2, obtained and plotted from Table I-32 of Carlson (1978a). Positive pulse magnitudes of up to [ ] (above system pressure $P_{0}$ ) were recorded. The pulse magnitude appears to be a random variable. There appears to be no system pressure threshuld fur the appearance of pressure events in the range of pressure up to $1000 \mathrm{psi}$. Table 2.2 summarizes these observations.

The pressure events recorded by PT2 are, as discussed in Section 2.3.3, difficult to interpret. Figure $2.6(a)$ shows a trace characterized by a long depressurization [ ] followed by a series of oscillations with a peak of approximately [ ] above initial system pressure. The signal appears clipped at $-150 \mathrm{psi}$. While the trace definitely indicates that a pressure event occurred, the physics of the event is obscured due to the unexplained oscillatory behavior. It is not clear whether the oscillation is due to mechanical vibration of the transducer, or due to pressure pulse propagation within the PT2 stand off tube, or due to an electrical mode of oscillation. The actual width of the water hammer pressure pulse is ambiguous as well. Is it less than [

], as delernined by the width of the individual pulses, or is it several milliseconds with the signal modulated by the higher frequency oscillation? Further ambiguity is shown by comparison w1th Figure $2.6(\mathrm{D})$, a trace from PT8, from the same experimental series. PT8 was located in the third pass below the feedwater nozzle [see Figure 2.3(a)]. This trace is similar in magnitude and shape to the event in Figure $2.6(a)$. However, the Fill/Drain test series was conducted with the vessel filled with steam only. The flow was ramped up, then 
Westinghouse Proprietary Class 2

NO. TESTS

$\begin{array}{llllll}7 & 10 & 8 & 7 & 3 & 1\end{array}$

$31 \div 23 \quad 1 \quad 1 \quad 2$
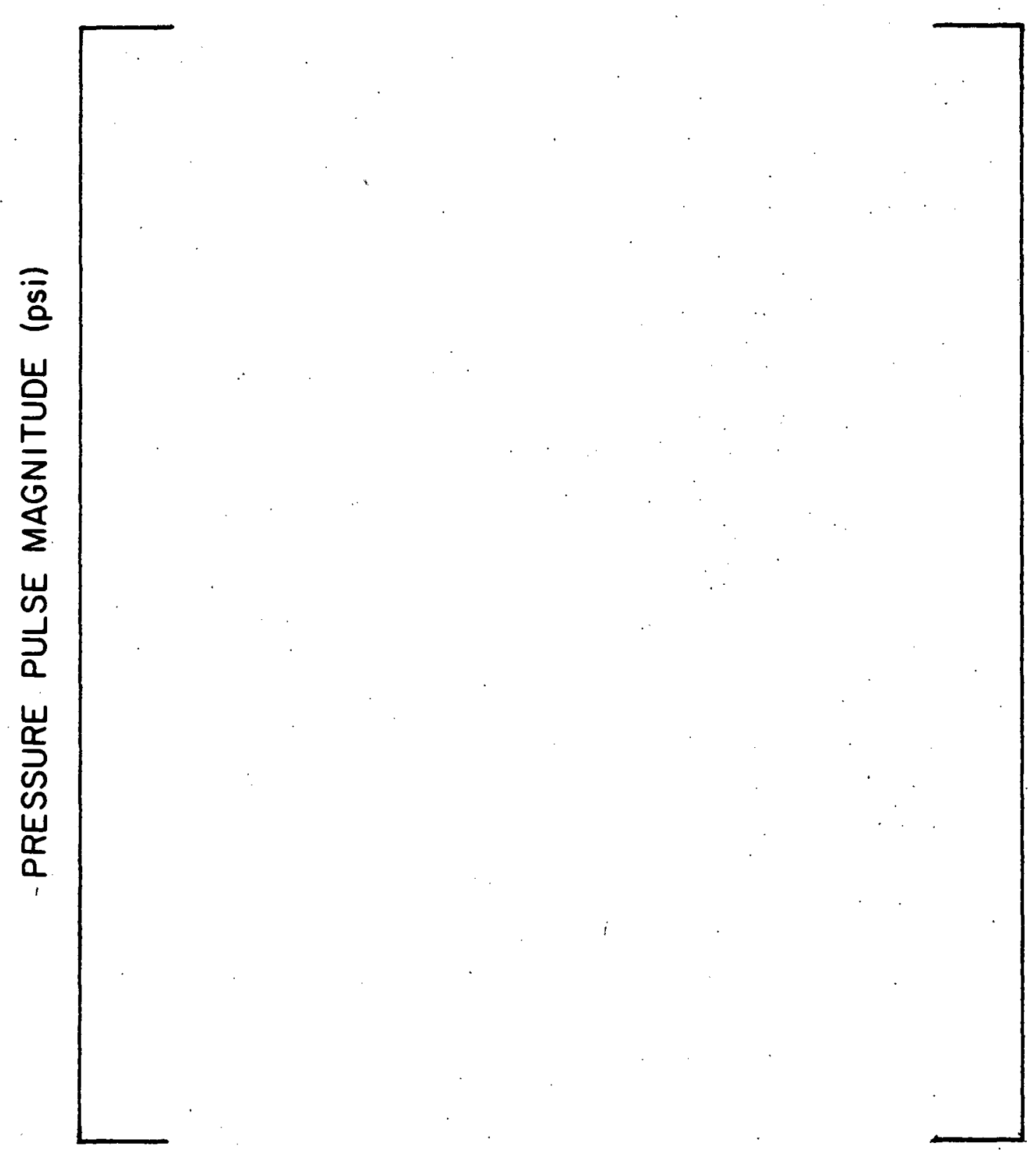

INITIAL SYSTEM PRESSURE, $P_{O}$ (psia)

Figure 2.5 Pressure pulse magnitudes: Type A fill/drain tests. 
Westinghouse Proprietary Class 2.

Table 2.2 SIJMMARY OF BNL OBSERVATIONS

\begin{tabular}{|c|c|c|c|c|c|c|c|}
\hline \multirow{2}{*}{ TEST TYPE } & \multicolumn{2}{|c|}{$\Delta P^{+}(P S I G)$} & \multicolumn{2}{|c|}{$\Delta P^{-}(P S I G)$} & \multirow{2}{*}{$\tau_{+}(\mathrm{MSEC})$} & \multirow{2}{*}{$\tau_{-}$(MSEC) } & \multirow{2}{*}{$\begin{array}{l}\text { PRESSURE } \\
\text { THRESHOLD }\end{array}$} \\
\hline & F.W. & S.G. & F.W. & S.G. & & & \\
\hline A/FILL-DRAIN & F & & & & & & \\
\hline \multicolumn{8}{|l|}{$\begin{array}{l}\text { A/FEEDL INE } \\
\text { INJECTION }\end{array}$} \\
\hline \multicolumn{8}{|l|}{$\begin{array}{l}\text { A/DOWNCOMER } \\
\text { INJECTION }\end{array}$} \\
\hline \multicolumn{8}{|l|}{$B$} \\
\hline C & 1. & & & & & & \\
\hline
\end{tabular}


immediately down to zero. Under these conditions it is difficult to imagine how a steam bubble would be trapped by cold liquid in the third pass below the feedwater nozzle. Most likely the event of Figure 2.6(b) is an artifact of the experiment, and does not represent a true water hammer pulse within the steam generator. Comparison of Figures 2.6(a) and (b) demonstrate that some degree of subjectivity is involved in interpretation of the pressure traces.

Figure $2.6(c)$ is another trace from PT2 showing the occurrence of some pressure event. The event, however, is obscured by the oscillatory behavior whose origin is unknown.

It appears to us that water hammer events did occur in the Type A - Fill/ Drain tests. These events probably originated in the feedwater line due to steam bubble entrapment and collapse in the cold feedwater. The events probably occurred during a partially-filled configuration of the feedwater pipe. The maximum positive pressure pulse magnitude was [ ]. Observed (multiple) pulse-widths were approximately [ ]. It is noted, however, that considerable ambiguity exists in identification of the physical source of the measured pressure traces.

\section{B. Type A - Feedline Injection}

This series of tests were designed to examine the potential for water hammers during refill of a voided preheater. The vessel water level was initially well below the feedwater pipe and full of saturated steam when cold feedwater flow was initiated. Flow of cold feedwater was continued until the water level rose to the top of the preheater.

Table 2.2 summarizes the observations of the maximum magnitudes of positive and negative pressure events which were recorded for both the feedwater pipe (transducer PT2) and the inlet pass of the preheater (transducers PT4, PT6, and PT6A). Figure 2.7 indicates that observation of pressure events in the preheater was 1 imited to initial vessel pressures of less than [ ]. Figures $2.8(a)$ and (b) show the traces from two of the higher magnitude pressure events ( [ ], respectively) observed from the preheater transducers. The physical origin of these events is highly ambiguous. The interpretation of the signals is even more difficult in the light of Figure $2.8(c)$ which shows a trace from PT8. A pulse of nearly [ ] magnitude is observed, well below the inlet pass. The origin of their pulse, whether it be an instrument artifact, or real vapor collapse impact pressure, is not clear from the trace.

It appears to us that water hammer pressure pulses occurred in the feedwater line, with positive pulse magnitudes up to [ ] (as summarized in Table 2.2). Pressure pulses were al so observed in the pre-heater, with magnitudes up to [

] in the preheater inlet pass. Pulse magnitudes to [ ] were observed in the lower passes. These (lower pass) pulses are thought to be artifacts of the experiment, and do not represent void collapse water hammers initiating in the test vessel. 
Westinghouse Proprietary Class 2

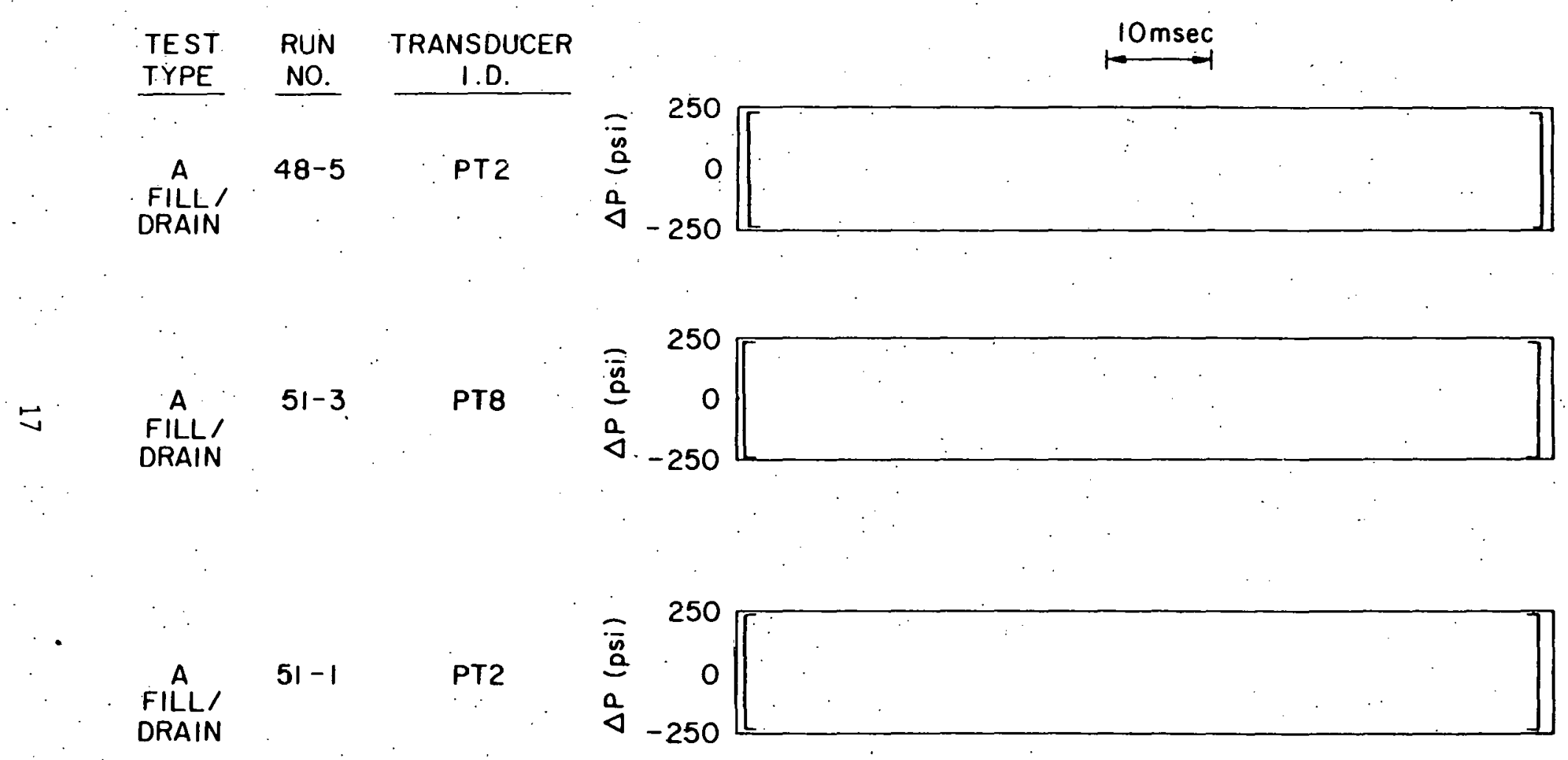

Figure 2.6 Typical fressure pulses: Type A fill/drain tests. 
Westinghouse Proprietary Class 2

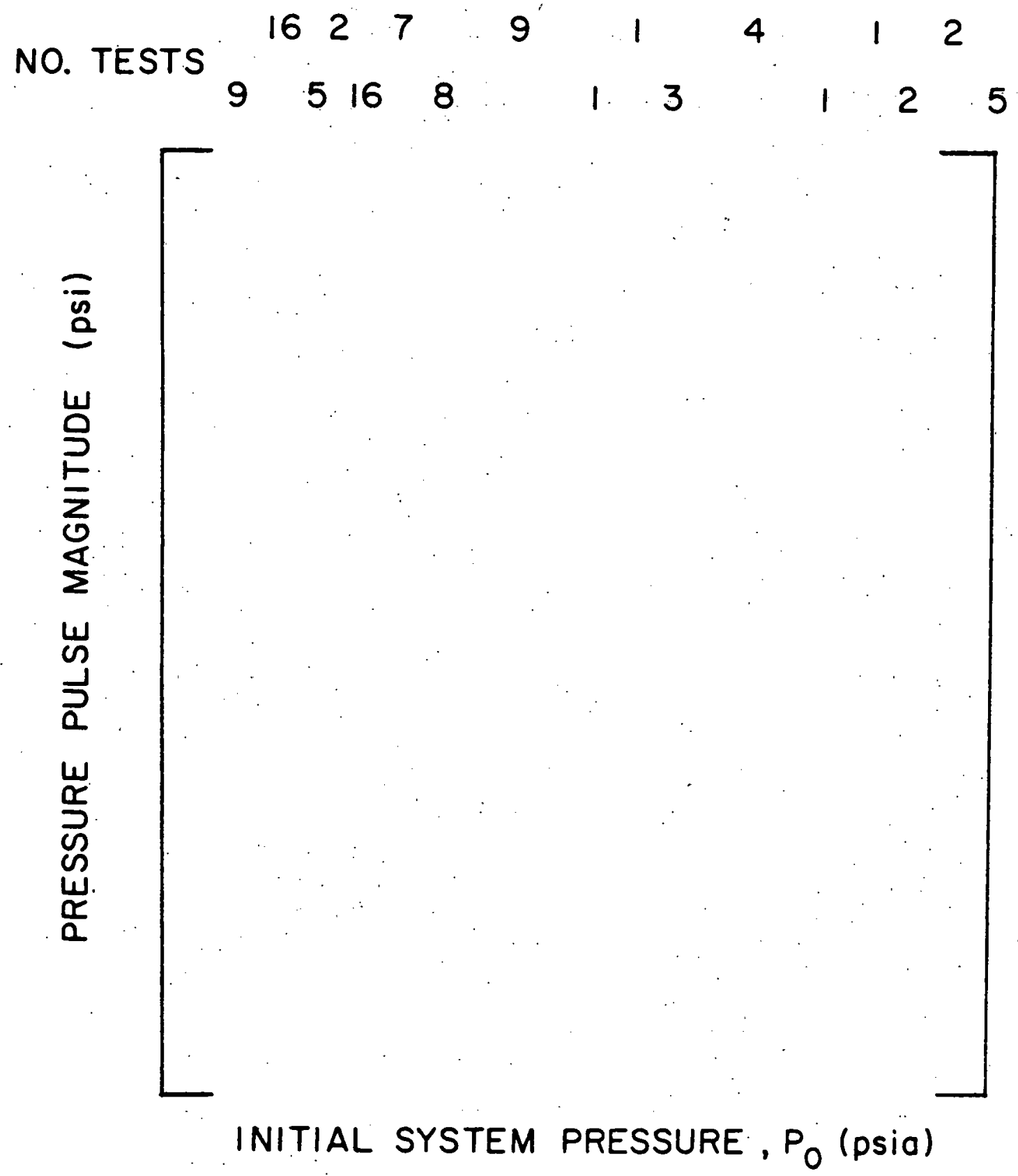

Figure 2.7 Pressure pulse magnitudes: Type A tests. 
Westinghouse Proprietary Class 2

$\begin{array}{lcc}\begin{array}{l}\text { TEST } \\ \text { TYPE }\end{array} & \begin{array}{l}\text { RUN } \\ \text { NO. }\end{array} & \begin{array}{c}\text { TRANSDUCER } \\ \text { I.D. }\end{array} \\ & & \\ \text { A } & 51-5 & \text { PT6 }\end{array}$

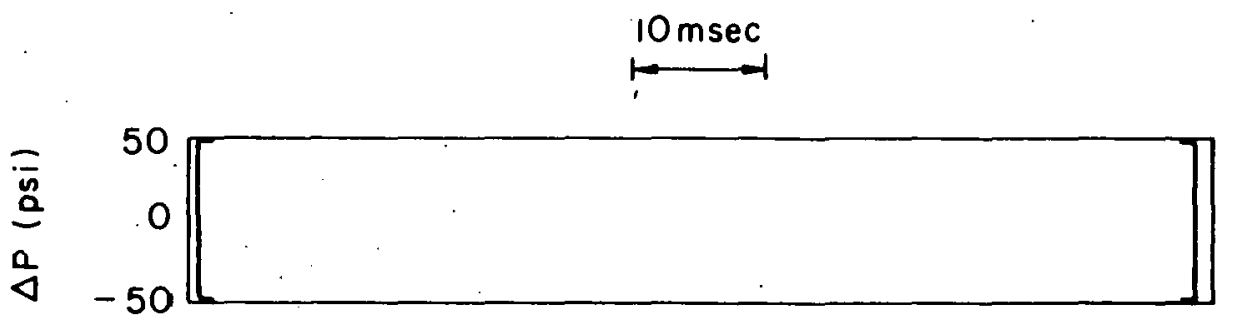



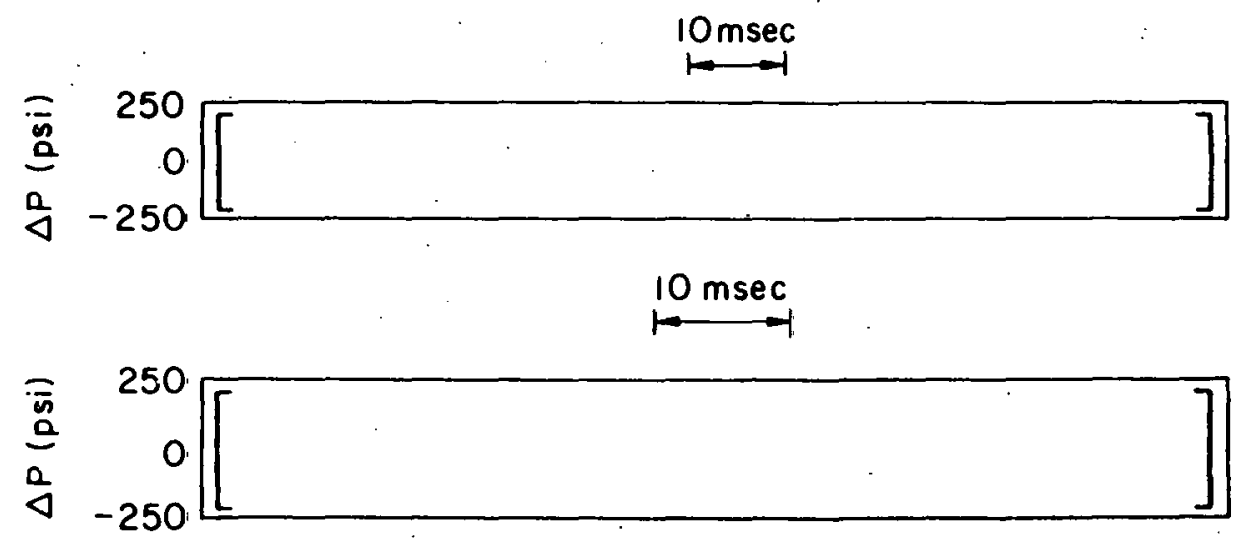

Figure 2.8 Typical pressure pulses: Type A tests. 


\section{Type A - Downcomer Injection}

In this series of tests, feedwater was introduced into the test vessel through an external pipe which fed the bottom of the steam-filled vessel. The inlet nozzle at the bottom of the vessel was covered with water at the onset of the experiment. No pressure events were recorded using this mode of refill.

Since the feedwater nozzle was not used, feedline water hammers were not possible in this series of experiments. Furthermore, the refill mode ensured quiescent rise of the liquid level. Hence, steam vapor entrapment was unlikely. It is reasonable, therefore, that no collapse events were recorded.

\subsubsection{Two-Phase Conditions: Types B and C Tests}

\section{A. Type B Tests (With \& Without Downcomer Flow)}

These tests were run to simulate conditions wherein the steam generator water level is somewhat below normal, but yet well above the preheater. Power was supplied to the heater rods to generate two-phase operating conditions. cold feedwater flow was injected through the feedwater nozzle. Flow was continued until boiling was completely suppressed. The object of these tests was to observe void collapse pressure pulses in the steam generator model.

A portion of the test results for positive pressure pulse amplitudes in the feedwater pipe is presented in Figure 2.9. The results indicate significant activity below [ ] system pressure, and little activity above. The largest amplitude pulse in the entire water hammer series of tests was recorded. This pulse, [ J in amplitude, is shown in Figure 2.10(a). The trace actually shows a series of pulses of [ ] in amplitude, and approximately [

I in pulse width. The signals are apparently clipped at approximately -100 psi. The reasons for the multiple pulses are unknown.

Very little positive pressure pulse activity was observed within the test vessel. Out of all the runs for which data is shown in Figure 2.9 , only 9 runs showed some positive pressure pulse activity. of these, only 2 pulses were above [ ] in amplitude. The largest positive amplitude pulse observed was [

], the trace of which is shown in Figure 2.10(b). This trace does show some indication of activity, but the nature of the event is not clear. It is assumed that the pulse was driven by void collapse within the test vessel.

The results for the Type $B$ experiments are summarized in Table 2.2. It appears that water hammers occurred within the feedwater pipe. Peak positive pulse amplitude was [ ]. Within the preheater itself, however, very little pressure pulse activity was observed. Those few pulses that were observed were of very low magnitude. It is concluded, therefore, that cold water injection into the test vessel at simulated two-phase operating conditions did not lead to significant water hammer activity, as observed by transducers located on the wall is of the test vessel. Either void collapse water hammers are untikely events under these two-phase operating conditions, or pressure pulse events that did-occur were attenuated in magnitude by the two-phase medium and the internals between the collapsing void and the pressure transducer. 
Westinghouse Proprietary Class 2

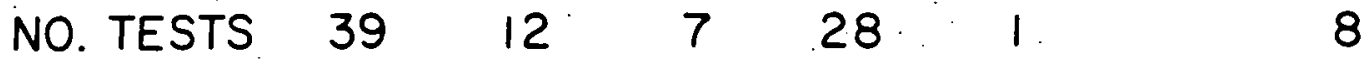

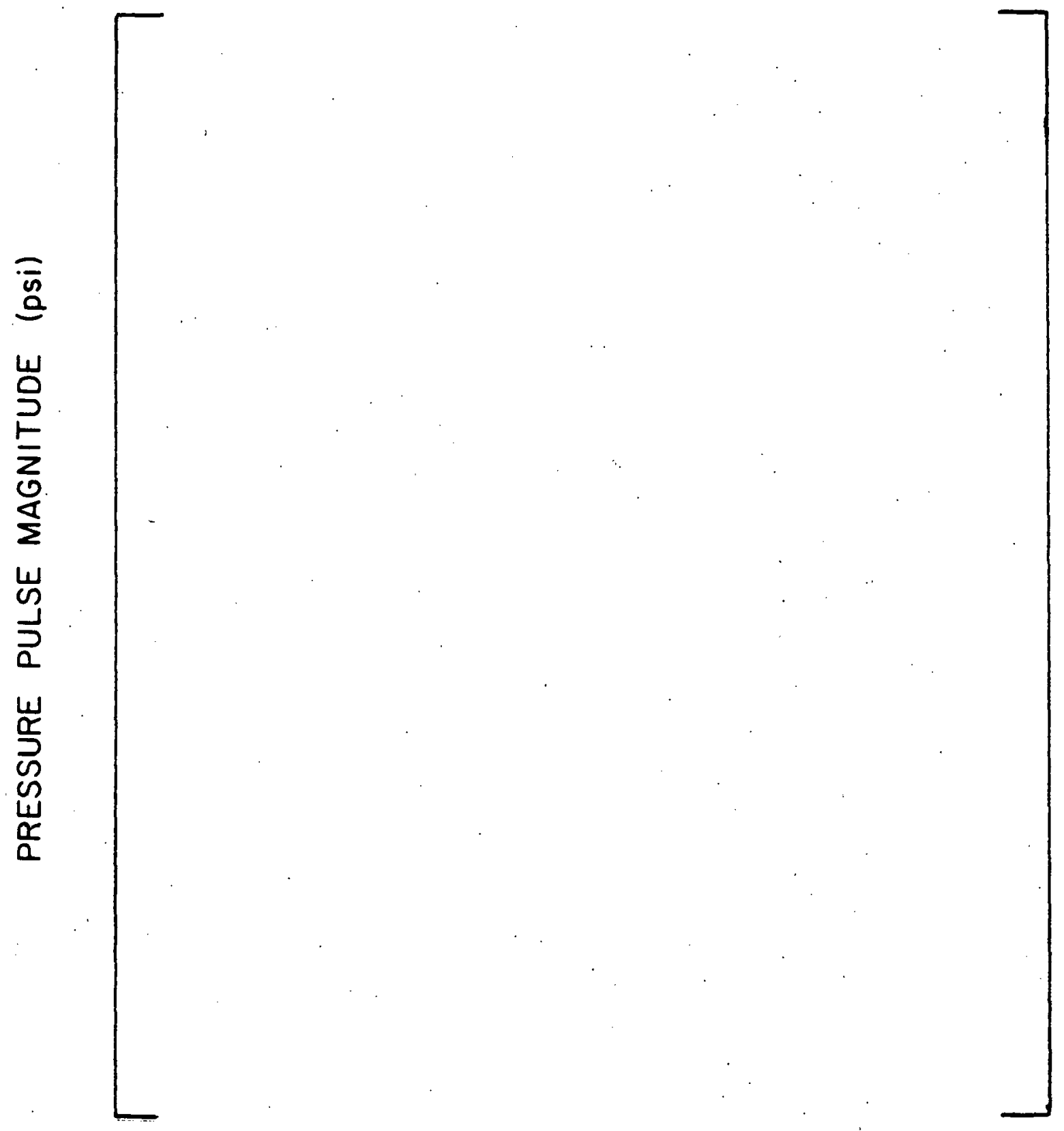

INITIAL SYSTEM PRESSURE, $P_{0}$ (psia)

Figure 2.9 Pressure pulse magnitudes: Type B tests 
Westinghouse Proprietary Class 2
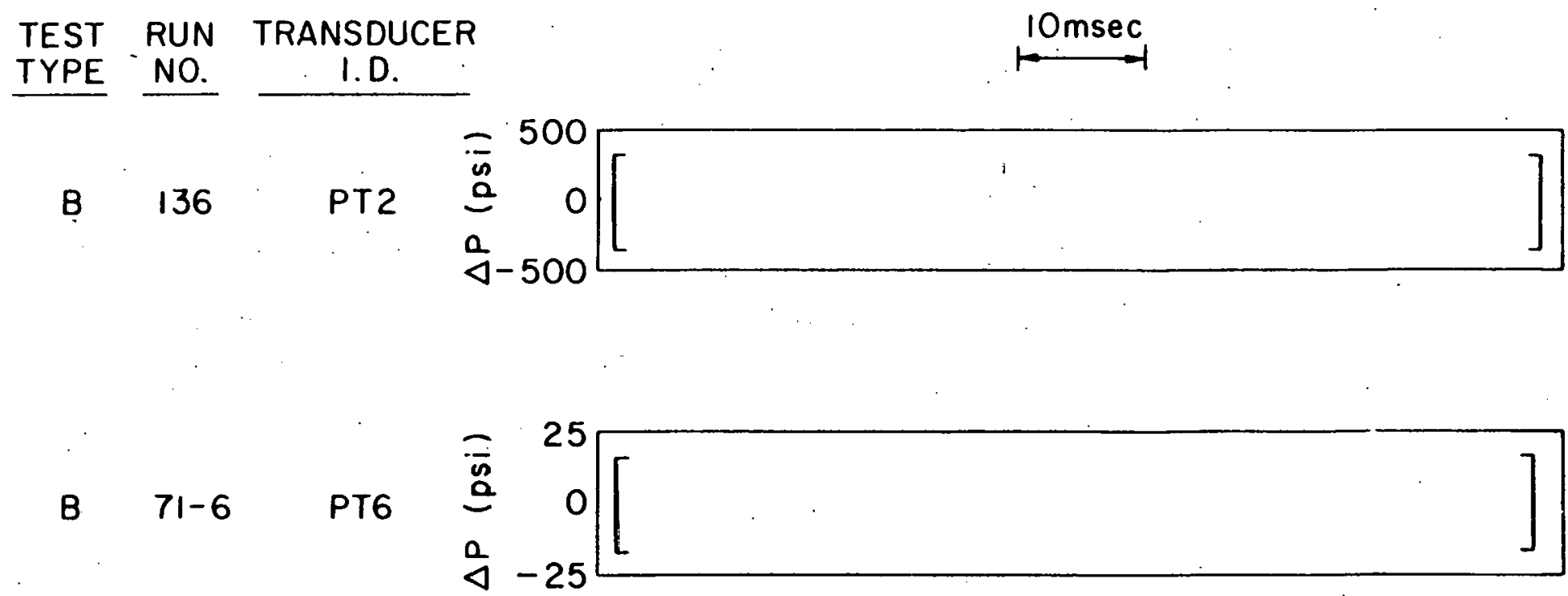

Figure 2.10 Typical pressure pulses: Type B tests. 


\section{Westinghouse Proprietary $\mathrm{Class} 2$}

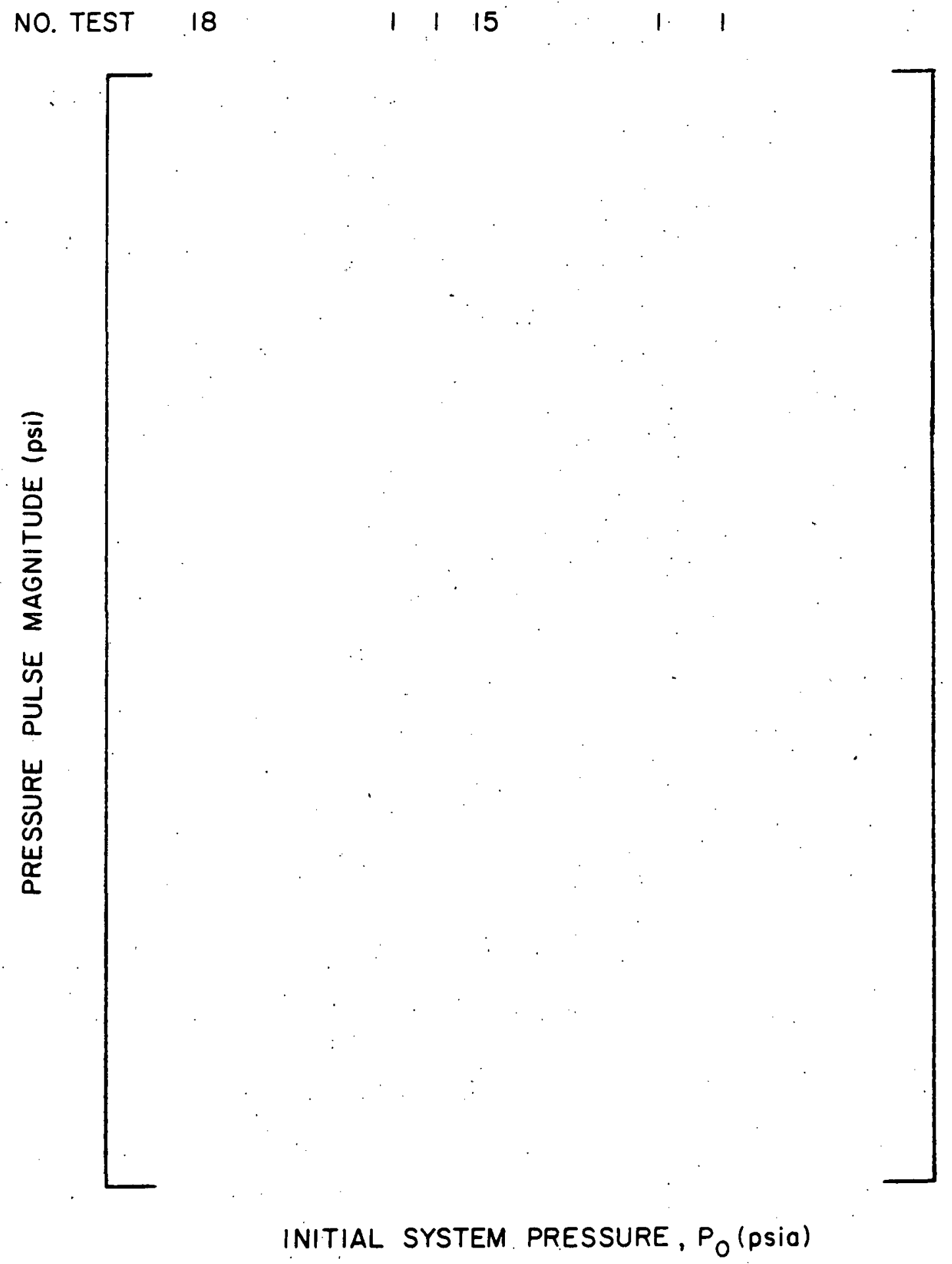

Figure 2.11 Pressure pulse magnitudes: Type $C$ tests. 


\section{B. Type C Tests}

These tests were conducted to investigate the potential for void collapse water hammers in the situation during which the feedwater flow increases from "low" to "high" flow rate. Flow through the preheater is initially upwards during low flow operation. As the feedwater flow rate increases, the feedwater flow splits in the inlet pass, such that part flows up and the remainder flows down. The Type $C$ tests were conducted to evaluate the potential for void collapse water hammers in the lower passes of the preheater, as cold water begins to flow downward into the two-phase fluid in the lower passes. It was expected that at the instant of flow splitting, stagnation conditions would exist in the lower region of the preheater. It was speculated that this could be a time period favorable to void collapse water hammer development.

Positive pressure pulses were observed, as shown in Figure 2.11, in the feedwater line, with magnitudes up to [ ]. These pulses occurred during flow acceleration or deceleration, when the feedwater pipe may have been partially voided. Within the preheater, however, the maximum positive pressure pulse observed was [ ].

The evidence suggests that void collapse water hammers occurred in the feedwater pipe during partially-full operation. No significant activity was recorded by the pressure transducers mounted at the wall of the preheater. A mechanistic understanding of the lack of water hammer activity under the Type $C$ test condition is not available.

\subsection{Effect of Noncondensibles}

Steam bubble condensation rates and, hence, collapse velocities, can be influenced by the presence of noncondensibles. Operating plant main steam lines contain noncondensible gas mass fractions of [ $]$. Steam sampled from the Westinghouse test facility showed noncondensible fractions of between [ and ] [Carlson, et al (1978a)]. The experiments, therefore, were characterized by larger gas contents than operating plants. In principle, therefore, the potential for damaging water hammers would be greater in operating plants than in the Westinghouse experiments.

Westinghouse sought to show from their test data that the effects of noncondensibles are negligible below mass concentrations of [ ]. The data, they claimed, for which this condition was satisfied would be directly applicable to operating plant conditions. The Westinghouse contention is based upon the data shown in their Table 3-7 [Carlson (1978a)], reproduced here as Table 2.3.

Our analysis of the data of Table 2.3 leads to the conclusion that the results do not support the contention that the effects of noncondensibles are negligible (in terms of magnitude of depressurization) below gas fractions of [ ]. It is felt that the data are too meager to base any quantitative conclusion. There is a lack of sufficient data to judge the effects of noncondensibles on the magnitude of observed water hammer events which occurred during the Westinghouse tests. 
TABLE 2.3 - EFFECT OF NONCONDENSIBLES*

Westinghouse Proprietary Class 2

WESTINGHOUSE TABLE $3-7$

STANDARD TYPE A TESTS: MAXIMUM DEPRESSURIZATIONS

\begin{tabular}{|c|c|c|c|}
\hline $\begin{array}{c}\text { Test } \\
\text { Series/Run }\end{array}$ & $\begin{array}{l}\text { Noncondensible Gas Mass } \\
\text { Fraction in Vapor }\end{array}$ & $\begin{array}{c}\text { Feedwater Flow Rate } \\
\text { (gpm) }\end{array}$ & $\begin{array}{c}\text { Depressurization } \\
\text { on PT6 } \\
\text { (psi) }\end{array}$ \\
\hline \multicolumn{4}{|c|}{100 Psig Nominal Test Pressure } \\
\hline $\begin{array}{l}65 / 5 \\
44 / 1 \\
44 / 2\end{array}$ & $\Gamma$ & $\Gamma 7$ & $\Gamma]$ \\
\hline \multicolumn{4}{|c|}{200 Psig Nominal Test Pressure } \\
\hline $\begin{array}{l}54 / 4 \\
54 / 2 \\
54 / 3 \\
54 / 1 \\
54 / 5\end{array}$ & 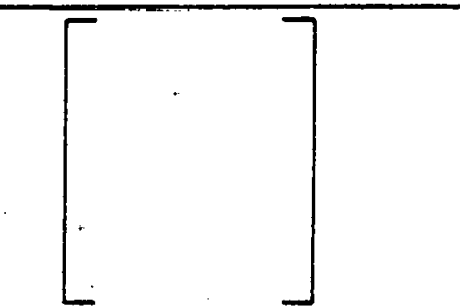 & $\Gamma 7$ & $\Gamma$ \\
\hline
\end{tabular}

*Table reproduced from Carlson (1978a) 
Thus, the effect of noncondensibles is one of the major uncertainties of the experiment. This uncertainty also precludes a clear extrapolation of the data to operating plant conditions.

\subsection{Conclusions}

The major objective of this BNL analysis of the Westinghouse $1 / 8$ th scale test data was to determine whether or not water hammer events occurred during the test series. The analysis led to the following observations:

(i) A water hammer event is expected to be preceded by a depressurization event, which is indicative of the condensation process. The water hammer event, however, is indicated by a positive pressure pulse arising out of a liquid-liquid or liquid-solid impact.

(ii) Interpretation of this observed pressure pulse is ambiguous. The basic source of the ambiguity is that it is not possible to directly distinguish a void collapse pressure pulse from other experimental "artifacts."

Table 2.2 summarizes our observations of maximum pressurization and depressurization magnitudes which were recorded in the Westinghouse tests. The following conclusions were drawn from our analysis of the Westinghouse test data:

(i) Feedwater line water hammers probably occurred during the tests throughout the entire range of initial pressures and for all of the test series except Type A with downcomer injection. These events probably occurred during a partially-filled configuration of the feedwater pipe.

(ii) In-vessel pressure pulse activity was recorded during the Type A series of experiments. The origins of the pulses are, however, ambiguous. It is felt that, because of the turbulent flow conditions characteristic of the inlet pass, that observed pulses in this region may be indicative of true water hammer activity. The pulses recorded in the lower passes, on the other hand, are felt to more likely be "artifacts" of the experiment.

(iij) In-vessel pressure pulse activity was al so recorded during two-phase conditions within the steam generator under Type $B$ and Type $C$ tests. However, the observed pressure pulses were relatively few in number and small in magnitude. The origin of the signals, which were recorded at the periphery of the test vessel, is uncertain. Their source, however, may have been water hammer events.

(iv) The effects of noncondensibles on the magnitude of observed pressure pulses are uncertain.

(v) The effect of pressure pulse attenuation (see Section 3 and Appendix A) on the magnitude of pressure pulses recorded at the boundary of the test vessel is also uncertain. 
3. PRESSURE PULSE ATTENUATION IN WESTINGHOUSE PREHEATER TEST VESSEL UNDER TWO-PHASE CONDITIONS

\subsection{Introduction}

The concern was raised in the previous section that a pressure event which occurred within the Westinghouse test vessel could be attenuated by the time it reached the boundaries of the test vessel on which the pressure transducers were mounted. Two basic mechanisms can be identified which would lead to attenuation of a pressure wave generated within the test vessel:

(i) A pressure wave generated by a sudden deposition of a finite amount of energy at a given point will be attenuated geometrically as it spreads out as a spherical wave front. For the case of Westinghouse test vessel, this mechanism is complicated by the presence of internal structures, making analysis of the effect difficult.

(ii) Irreversible losses in the two-phase medium, which may contain internal structures, may lead to attenuation of the strength of the pressure waves.

\subsection{Geometric Attenuation}

A pressure pulse generated near the center-line of the Westinghouse test vessel would have had to travel up to approximately 8 inches before it would be sensed by a transducer (half the diameter of the Westinghouse test vessel).

If

(i) the disturbance occurred at a point in the flow field,

(ii) there were no internals,

then a pressure pulse which would have originated at a distance of 8 inches from a transducer would have been attenuated by a factor of 64 greater than an equivalent pulse originating at a distance of 1 inch from the transducer simply on the basis of geometric attenuation. The presence of a dense array of internals (heater rods) could modify the attenuation characteristics significantly. It is possible, however, that geometric attenuation alone may have significantly reduced recorded pressure pulse magnitudes. This effect was not examined in greater detail in BNL work.

Positive magnitude pressure pulses were observed within the test vessel under Type A conditions and under the two-phase conditions of Test Series $B$ and C. The physical origins of the events which triggered these signals are not known. It is not possible, therefore, to estimate the extent of geometric attenuation suffered by pressure pulses enroute to the transducer. This represents one of the uncertainties of the experiment. 


\subsection{Irreversible Losses}

Attenuation due to irreversible processes within the preheater may have occurred as a result of two mechanisms:

First, the two-phase medium could attenuate the pressure pulse and, second, the presence of the preheater internals (tubes, baffle plates, support structure) could.also influence the attenuation.

In order to obtain an order-of-magnitude estimate regarding the potential for significant attenuation of the strength of shock waves in two-phase mixtures, a two-phase shock stube experiment was devised and undertaken at BNL for both bubbly and slug flow conditions. One-dimensional propagation of plane waves in a cylindrical pipe is not subject to geometrical attenuation and the attenuation by irreversible processes may be singled out. A one-dimensional experiment, performed using a circular pipe as a shock tube, was therefore chosen for the study.

The BNL experiment is described in Appendix A. The results and conclusions are summarized below.

On the basis of the two-phase experiments described in Appendix $A$, and within the experimental error in pressure measurement, it is judged that pressure pulse attenuation in two-phase flow (in a tube with no internal structures) is negligible over distances of approximately 1-2 feet. Certainly, order of magnitude attenuation is not to be expected on the basis of the experimental results. This conclusion is meant to apply to flows with void fractions up to approximately 0.30 , and to the bubbly-and-slug-flow regimes. It applies to low pressure (near atmospheric) conditions.

The above conclusion is difficult to extrapolate to the conditions existing within the Westinghouse preheater vessel. The major uncertainty is judged to be the effect of the internal structures (tubes, baffles, supports) on the attenuation characteristics. While the results of the BNL experiment suggest that pressure pulse attenuation in two-phase flow is small over distances on the order of 1-2 feet, the possible effects of internal structures cannot be discounted. Further experimental investigation is required in order to determine the effects of internal structures on pressure pulse attenuation in two-phase media.

\subsection{Conclusions}

The influence of pressure wave attenuation on the magnitude of recorded pressure pulses in the Westinghouse water hammer tests is one of the unresolved uncertainties of the experimental test program. The following conclusions are drawn from BNL analysis and experiments:

(i) BNL experiments, on the one hand, indicate that attenuation due to irreversible losses in the absence of internal structures is small. 
(ii) On the other hand, the effect of internals on attenuation by irreversible losses is not known.

(iii) Geometrical attenuation is potentially significant. However, the presence of the internal structures and a lack of knowledge of the origin of the event which triggers the observed pressure pulse, precludes quantitative evaluation of this mode of attenuation. 


\section{EVALUATION OF WESTINGHOUSE SCALING LAWS}

In order to extrapolate the results obtained from the Westinghouse $1 / 8$ th scale test to the full-scale situations, Westinghouse supported three different. analytical studies to derive scaling laws for condensation-induced water hammers in steam generators. These are:
(a) Simulation of transients using the TRANFLO code,
(b) Derivation of scaling laws from the conservation equations,
(c) Parametric study of a vapor cavity collapse.

The Westinghouse conclusions from these studies are the following:

(a) The magnitude scale factor is 1 . That is to say that the water hammer pulses have the same magnitude in a geometrically-scaled test model and a full-size steam generator when operating under identical conditions of pressure, temperature and the like.

(b) The time scale factor is 8 . That is to say that the time duration of the pressure pulses is eight times longer for a fullsize steam generator than for a 1/8th scale test model under equivalent operating conditions.

The Westinghouse studies will now be evaluated to check the above conclusions. For the sake of brevity, only the essential features will be focused on.

\subsection{TRANFLO Code Approach}

The TRANFLO code is a transient thermal hydraulic analysis computer program which has been used to study postulated accidents and flow transients in the 1/8th scale test apparatus and the full-scale steam generators. The program divides the steam generator primary and secondary sides into a number of control volumes or nodes. Equations for conservation of mass and energy are written for each of these nodes. The momentum equation is used between the node centers to calculate flows between the nodes. The inherent assumptions in the equations used in the TRANFLO code are: (i) the flow is homogeneous in each node, i.e., there is no relative velocity between the liquid and the vapor, and ( $i i)$ the phases are in thermal equilibrium in each node, i.e., the liquid and the vapor are at saturation temperature. Although the assumption of homogeneous flow may be accepted as a first approximation, the assumption of thermal equilibrium is clearly in error for the case of cold water injection into a steam generator or the $1 / 8$ th scale test model.

Westinghouse has argued that the assumption of thermal equilibrium is expected to produce an overprediction of pressure pulses resulting from vapor condensation. This notion is correct since in an actual or nonequilibrium situation, the rate of condensation is finite, whereas in the equilibrium model a complete mixing (or condensation) is assumed to occur instantaneously. This implies an infinite rate of heat and mass transfer in the equilibrium model and 
an associated rapid drop in pressure. It is interesting to note that Westinghouse has not reported any comparison between the water hammer test data obtained from the 1/8th scale test and the predictions obtained from the TRANFLO code. Instead, they have shown code calculations for an excess feedwater transient for both the 1/8th scale model and a full-size steam generation. This transient does not have any relevance to the question of condensation-induced water hammer that might occur in the preheater type steam generator during emergency cold water injection. Therefore, the calculations of the TRANFLO code cannot be accepted as a verification of the Westinghouse scaling laws. And, as mentioned earlier, the code does not contain the essential element of nonequilibrium phase change rate to be suitable for analyzing condensation-induced water hammers.

\subsection{Generalized Conservation Laws Approach}

The use of conservation equations for deducing scaling laws is, in general, a valid approach. However, in the Westinghouse study, the conservation equations are written at a given point without any time- or volume-averaging. As such, the equations resemble the Tocal instant formulation (Ishii, 1975) for each phase. However, because of the lack of time- or volume-averaging, the equations do not contain any term representing the mass, heat or momentum transfer at the vapor-liquid interface.

It has been noted earlier that the condensation rate of vapor at the vaporliquid interface is a governing parameter in determining the decrease in pressure in the vapor pocket. This decrease in pressure is the driving force which may accelerate a liquid slug rapidly and finally result in a damaging water hammer. Thus, the derivation of a scaling criterion for condensation-induced water hammer must start from the governing equations containing interfacial heat and mass transfer. As the Westinghouse conservation equations do not contain interfacial transfer terms, they are not the proper governing equations for studying the phenomenon of condensation-induced water hammer. Therefore, the scaling laws derived from them cannot be accepted as the scaling laws for the situation of interest, i.e., the condensation induced water hammer in preheat steam generators.

\subsection{Westinghouse Parametric Study}

The Westinghouse parametric study assumes that a steam volume or cavity is somehow trapped in the preheater region and is condensed by the incoming subcooled water. The presence of the primary tubes and the perforations in the baffle plates are neglected to keep the model simple. It is also assumed that a slug of water with a constant mass, $M$, is accelerated towards the vapor cavity as the cavity collapses due to condensation (as shown in Fig. 4.1). The pressure at the other side of the water slug is kept constant at the initial pressure, $p_{0}$. The momentum equation for the liquid slug and the energy equation for the vapor cavity are written. It is shown that the thermodynamic process within the vapor volume may be approximated by an isentropic expansion or depressurization. A. nonequilibrium condensation rate was postulated, and finally, the set of governing equations were nondimensionalized. The nondimensionalized 
Westinghouse Proprietary Class 2

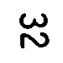

Figure 41 Westinghouse model of entrapped steam cavity. 
pressure in the vapor cavity, $\mathrm{p} / \mathrm{p}_{0}$, is shown to depend on a single parameter, $B$, which is a function of initial pressure, $p_{0}$, initial steam volume, $V_{0}$, mass of water slug, $M$, the effective area over which the pressure difference acts on the slug, $A_{A}$, the effective area for condensation, $A_{C}$, and the condensation rate. It is shown in Fig. 4.2 that as the value of $B$ is increased, or the value of condensation rate is decreased, the maximum depressurization of the steam volume started to decrease. This agrees with our physical intuition.

The parameter $\beta$ is then re-written as a function of initial pressure, feedwater temperature and a parameter, $k$, such that

where

$$
[
$$

$$
]
$$

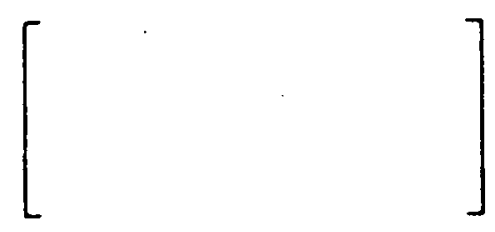

In the above expressions, $h$ is the condensation heat transfer coefficient, $V_{0} / M$ is the ratio of initial. steam volume to the water slug mass, $A_{A} / A_{C}$ is the area ratio, $\Delta T$ is the subcooling of the feedwater, $p_{0}$ is the initial system pressure, $v_{0}$ is the initial specific volume of steam and $h_{\mathrm{fg}}$ is the latent heat of condensation. For a given feedwater temperature and a given value of $k$, the maximum depressurization in the vapor cavity were calculated as a finction of initial pressure. Such calculations were also performed for various values of $K$, and the results are shown in Fig. 4.3. The nature of the curves ( $\Delta p_{\max }$ vs. $P_{0}$ ) did not change with $K$. However, for any value of $K$, the value of the maximum depressurization, $\Delta p_{\text {max }}$, reaches the thermodynamic maximum of $p_{0}$ up to a certain value of initial pressure, $p_{0}$. Beyond that, the value of $\Delta p_{\max }$ starts to decline with an increase in the initial pressure and eventualily reaches a positive non-zero asymptotic value. This is in contrast to the experimental observations in the 1/8th scale model where, as per Westinghouse, a threshold pressure existed beyond which no depressurization was observed.

To reflect this experimental observation of a threshold pressure in their theory, Westinghouse argued that if the volumetric rate of feedwater addition is greater than or equal to the volumetric rate at which the vapor is removed, then there will not be any depressurization. This led to the following criterion for no depressurization:

$$
[
$$

$$
j
$$

The criterion depends on the feedwater Stanton number, system pressure, feedwater temperature and an area ratio, $A_{c} / A_{f}$, where $A_{c}$ is the effective area 
WESTINGHOUSE PROPRIETARY CLASS 2

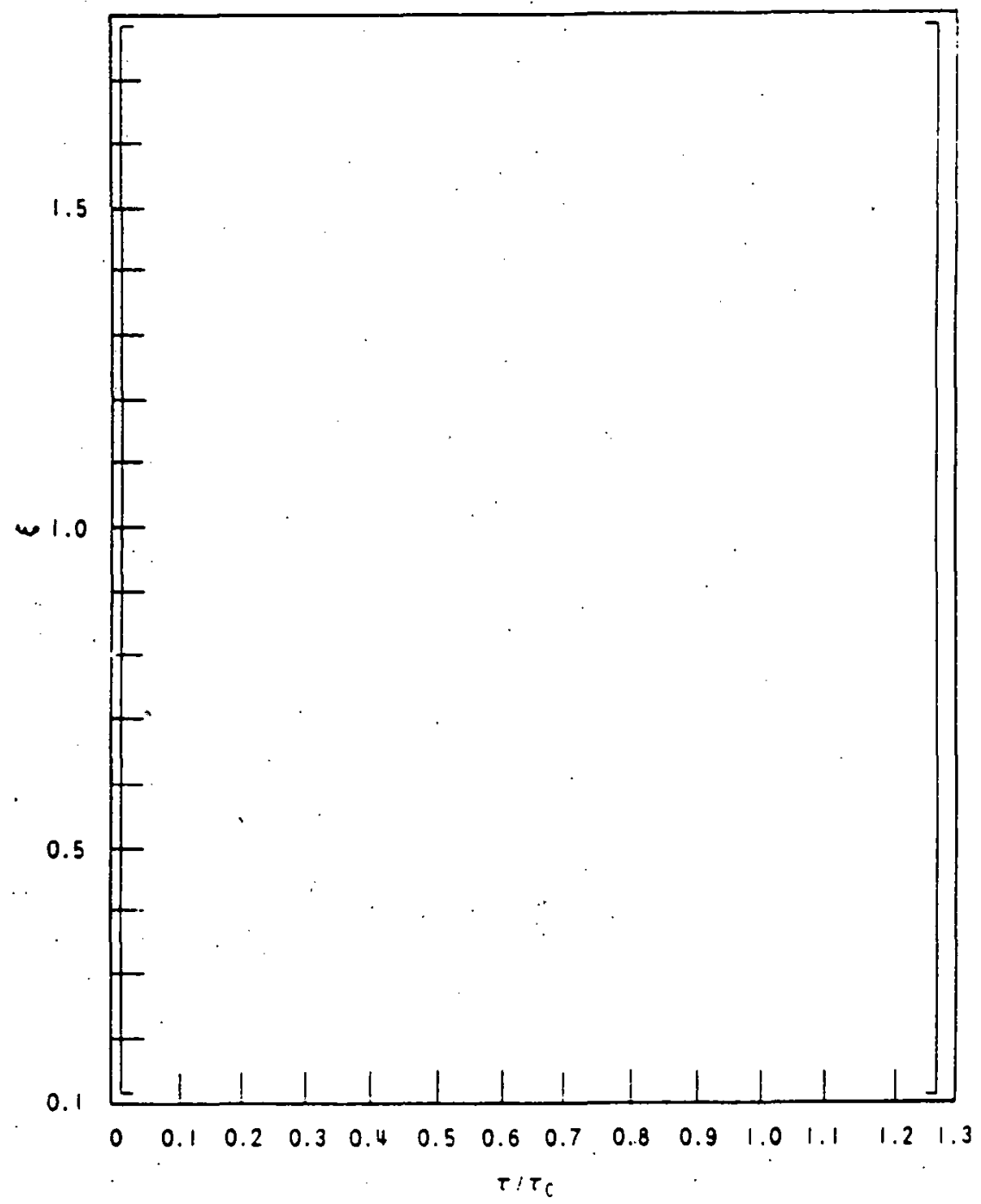

Figure 4.2 Variation of nondimensionalized pressure with nondimensionalized time. 


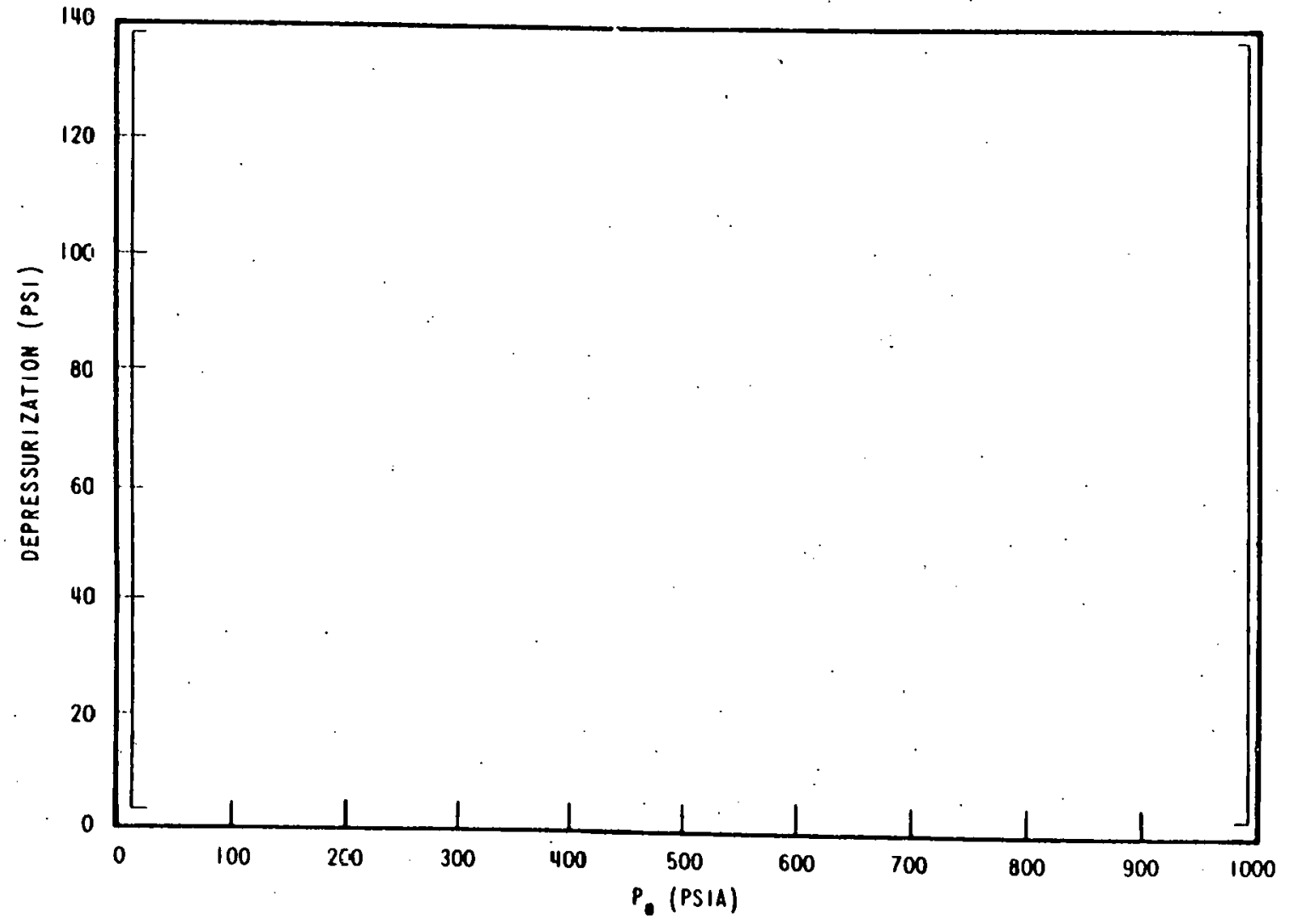

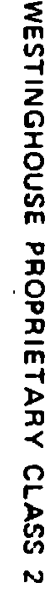

Figure 4.3 Maximum depressurization intensities as a function of $P_{0}$. 
for condensation and $A_{f}$ is the feedflow cross-sectional area. By choosing the feedwater Stanton number as 0.0105 , which is valid for free turbulent shear 1 ayer (Eckert and Drake, 1972), and an empirical value of [ ] for $A_{c} / A_{f}$, Westinghouse showed that this theory could predict a threshold pressure in agreement with their experiment. However, one should keep in mind that the results of the experiment were used in choosing the value for $A_{c} / A_{f}$. Therefore, the good agreement between the theory and the experimental results is of no surprise. It was found later at BNL, and is shown in Fig. 4.4 , that the Westinghouse pressure threshold criterion is very sensitive to the product of the Stanton number and the area ratio. This means that if there is a small error in either the Stanton number or the area ratio, the predicted threshold pressure could be affected significantly. We shall discuss more about the Stanton number and the area ratio later in this section.

Anyway, the original $\beta$-theory, discussed at the beginning of this section, was then modified to include the effects of feedwater flow rate. This combined theory resulted in a set of nondimensionalized equations with two parameters, namely $\Gamma^{\prime}$ and $\beta^{\prime}$. The parameter $\Gamma^{\circ}$, similar to $\Gamma$, controls the threshold and it is comprised of a feedwater Stanton number equal to 0.0105 and an empirical value of $\left[\right.$ ] for $A_{c} / A_{f}$ chosen from the experimental results, as discussed earlier. The parameter $\beta^{-}$is similar to the earlier parameter $\beta$, and is written as a product of the initial system pressure, $p_{0}$, and a parameter $K_{2}$. The parameter $\mathrm{K}_{2}$ is defined as:

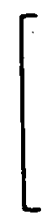

$$
]
$$

where $u_{f}$ is the feedwater velocity at the feedflow cross-sectional area of $A_{f}$. It is seen that $K_{2}$ is composed of the variables which are difficult, if not impossible, to predict individualiy. A parametric study with various values of $K_{2}$ showed that the parameter $K_{2}$ does not affect the threshold pressure at a11, but it has some effect in determining the maximum depressurization if the operating pressure is below the threshold pressure (see Fig. 4.5). It was also found that a suitable value [ ] of $K_{2}$ can indeed bound the most of the depressurization data obtained from the Westinghouse 1/8th scale model type $A$ tests, as shown in Fig. 4.6 .

In summary, according to the Westinghouse parametric study, the maximum depressurization during the collapse of a steam volume depends on three unknown or "unpredictable" parameters. These are: (i) the feedwater Stanton number; ( $i i)$ the area ratio, $A_{C} / A_{f}$; and $(i i i)$ the parameter $K_{2}$ which contains another area ratio $A_{A} / A_{f}$, the initial vapor volume to water slug mass, $V_{0} / M$, and the feedwater velocity at feedflow cross-sectional area $A_{f}$. Westinghouse argues that the Stanton number is either a constant or a weak function of feedwater velocity, and in two geometrically similar apparatus (i.e., in the 1/8thscale model and in the full size steam generator) the area ratios $A_{c} / A_{f}$, and the ratio $V_{0} / M$ will be the same. Therefore, if the feedwater velocity is kept scale-independent, the depressurization magnitude will be the same in both the scale model and the full-size steam generator. This is the basis of the Westinghouse scaling laws. 
Westinghouse Proprietary Class 2

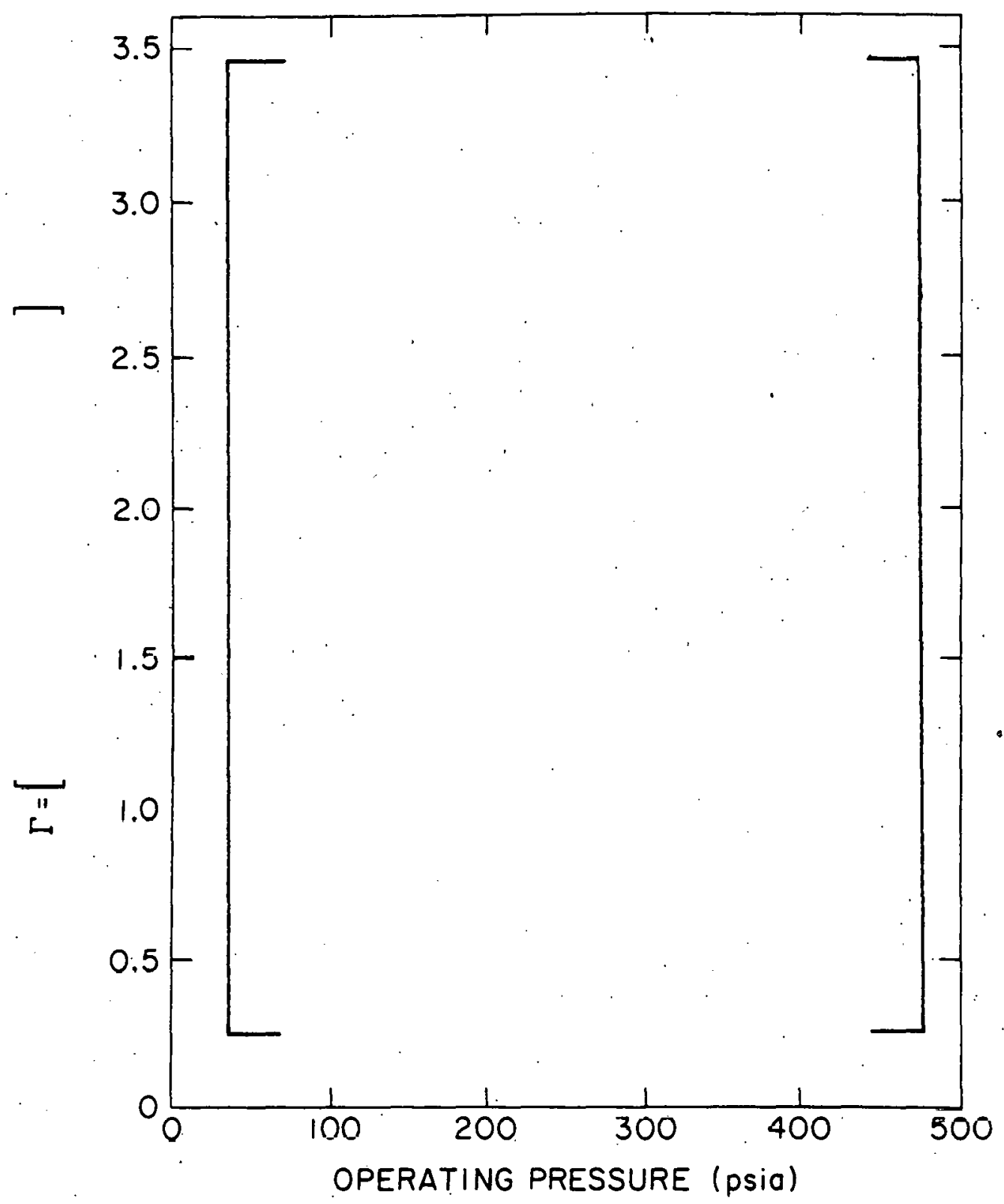

Figure 4.4 . I versus $P_{0}$ as a function of $5 t\left(A_{C} / A_{f}\right)$.

37. 
WESTINGHOUSE PROPRIETARY CLASS 2

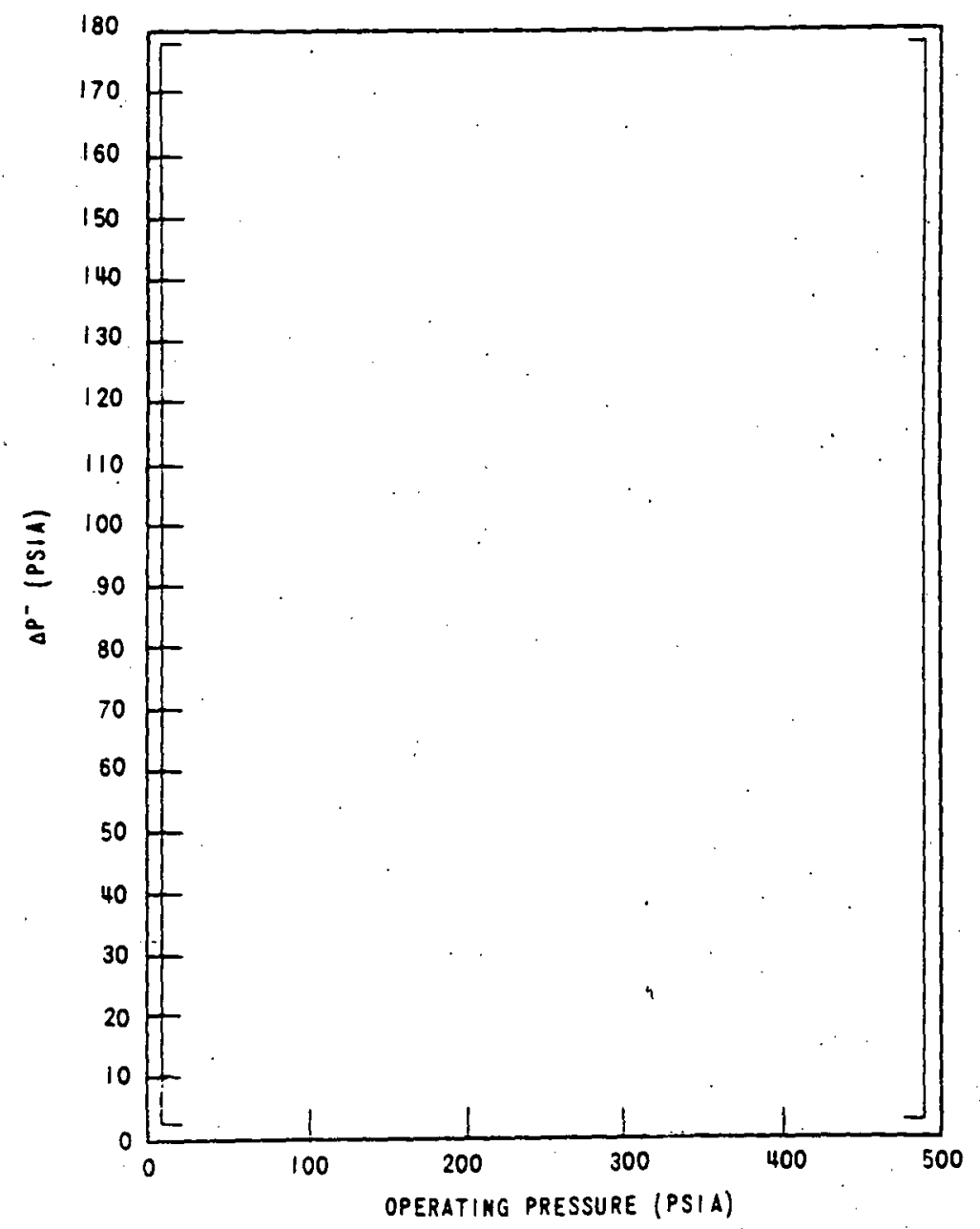

Figure 4.5 Maximum depressurization versus $P_{0}$ for various values of $K_{2}$. 
WESTINGHOUSE PROPRIETARY CLASS 2

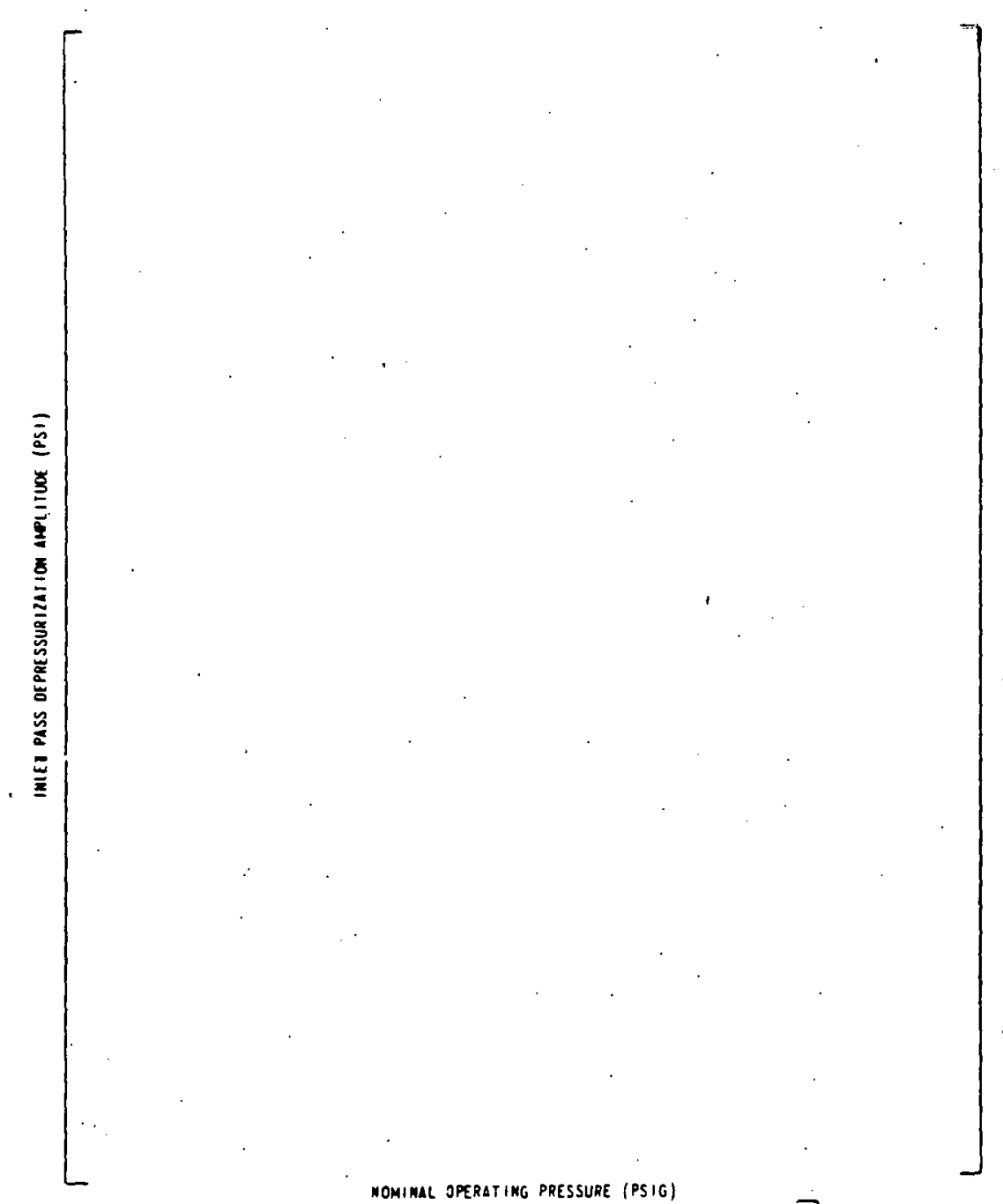

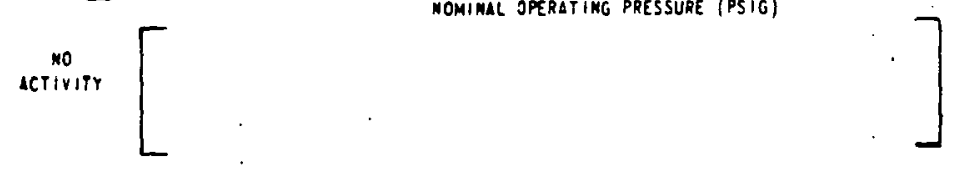

Figure 4.6 A comparison of Westinghouse type A test data and Westinghouse parametric study analysis.

39 
Considering the complexity of the problem, the above Westinghouse study is a reasonable first approach. In contrast to the TRANFLO code or the conservation 1 aw approach, this parametric study includes the effects of nonequilibrium condensation which is an essential ingredient for determining the pressure inside the vapor cavity. Unfortunately, the study restricts itself to the depressurization aspect only, and does not extend itself to the slug impact or the overpressurization stage of the transient which is really the major issue. However, it is true that a depressurization is needed to cause a complete collapse and subsequent overpressurization. This is probably the reason why the study was limited to the depressurization stage only.

Apart from a number of simplifying assumptions (e.g., constant mass for the accelerating water slug, a constant condensation rate, etc.) which were employed to keep the model tractable, the following criticism and comments are in order:

(a) The value of 0.0105 for the feedwater Stanton number may not be applicable for condensation of steam entrapped by a water mass because it was obtained for the case of a free turbulent shear layer downstream of a step, and the two situations are completely different. Not much information is available in the literature regarding the condensation heat transfer coefficient for vapor pockets. Of the limited experimental results avaliable, there are large differences in the heat transfer coefficients. For example, in the study of Brucker and Sparrow (1977) the condensation heat transfer coefficient on the order of $10^{4} \mathrm{~W} / \mathrm{m}^{2}$ - ${ }^{\circ} \mathrm{C}$ has been reported. On the other hand, Bank off and Mason (1962) has reported condensation heat transfer coefficients as high as $1.8 \times 10^{6} \mathrm{~W} / \mathrm{m}^{2}-{ }^{\circ} \mathrm{C}$ for steam bubble collapse in highly subcooled water. Cumo, et al (1978) has also reported very high (on the order of $3 \times 10^{6} \mathrm{~W} / \mathrm{m}^{2}-{ }^{\circ} \mathrm{C}$ ) condensation heat transfer cofficients for condensation of steam jets in subcooled water pool.

The question of whether the feedwater Stanton number is scaleindependent is even more difficult to resolve. By definition, Stanton number is $h / \rho_{f} c_{p}$, fuf where $u_{f}$ is the liquid velocity at or near the vapor-liquid, interface. Since vapor pockets may form anywhere in the preheater box or in the feedpipe it is virtually impossible to assign a value of $u_{f}$ from the feedwater floir rate. Even if the feedwater mass-flux is kept constant in the scale model and in the prototype, there is no guarantee that uf in the two systems will be the same. Thus, even at the same operating conditions of pressure and temperature, the heat transfer coefficient, which usually depends on the water velocity, might change and so could the Stanton number.

(b) An empirical value of [ $]$ for the area ratio $A_{c} / A_{f}$ where, $A_{c}$ is the effective area for condensation and $A_{f}$ is the feedflow crosssectional area corresponding to the velocity $u_{f}$ is chosen from the experimental information of a threshold pressure in Type $A$ tests in the $1 / 8$ th scale model. Westinghouse argues that they expect to have the same value for $A_{c} / A_{f}$ in both the small-scale model and the fullsize steam generator. This is hard to justify. First of all, the value of $A_{c} / A_{f}$ chosen by Westinghouse does not have any physical reasoning and it depends on the choice of the stanton number value 
which has been criticized in the previous paragraph. Secondly, the mechanism of vapor pocket formation is not well understood even in a simple geometry like circular pipe or rectangular channel, and we are not aware of any quantitative study of vapor pocket formation in the complex preheater region of a steam generator. Therefore, one has to stretch one's imagination too far without any theoretical and/or experimental evidence to suggest that the ratio $A_{c} / A_{f}$ is scaleindependent.

(c) The Westinghouse study suggests that there is a threshold system pressure above which no depressurization can occur. Under the same operating conditions of initial system pressure and feedwater temperature, this threshold pressure depends on the product of the feedwater Stanton number and the area ratio, $A_{c} / A_{f}$. As mentioned earlier, Westinghouse expects both of these parameters to be scale-independent. Thus, Westinghouse expects the same threshold pressure for the $1 / 8$ th scale test model and the full-scale steam generator.

Simple calculations at BNL showed that the criterion for the threshold pressure suggested by Westinghouse is very sensitive to the value of $\operatorname{St}\left(A_{c} / A_{f}\right)$. Thus even a small change in the values of $S t$ and $A_{c} / A_{f}$ can make an appreciable difference in the value of threshold pressure. It is also found that the higher the value of $\operatorname{st}\left(A_{C} / A_{f}\right)$, the higher is the threshold pressure. This suggests that the water hammer phenomenon may not be restricted to the low system pressure if the value of $S t\left(A_{c} / A_{f}\right)$ increases with size. The reverse is true if $\operatorname{st}\left(A_{C} / A_{f}\right)$ decreases with an increase in size.

(d) Below the threshold pressure, the maximum depressurization is controlled by a parameter $K_{2}$ which is a function of the area ratio $A_{A} / A_{f}$, the initial vapor volume to the accelerating water slug mass, $V_{0} / M$, and the feedwater velocity at or near the condensing interface, $u_{f}$. Westinghouse has chosen a suitable value for $K_{2}$ from the depressurization data obtained from Type A tests in the 1/8th scale model and expects it to be the same in the full-scale steam gcncrator. It should be mentioned that the lower the value of $K_{7}$, the higher is the value of maximum depressurization. Let us now examine the terms in the parameter $K_{2}$ and judge if it is scaleindependent.

Like the problem of vapor pocket formation, the problem of determining the mass of the accelerating water slug is a difficult one. This is particularly true in the preheater box region, and we are not aware of any experimental or theoretical study which has tried to quantify the mass of water slug that will be accelerated should a vapor pocket form in the preheater region or even in the feedpipe. Thus, there is no justification in assuming that the ratio $V_{0} / M$ is scale-independent. So is the case for the area ratio $\left(A_{A} / A_{f}\right)$ and the feedwater velocity at or near the condensing surface, $u_{f}$. Therefore, there is no guarantee that the parameter $K_{2}$ is scale-independent. 
In view of the above discussion, it is concluded at BNL that although the Westinghouse parametric study was a reasonable and useful first attempt to analytically study the behavior of a collapsing vapor pocket in a preheat steam generator, it is not sufficient for establishing the scaling laws suggested by Westinghouse. This is not due to any deficiency of the analysis, but primarily due to the lack of knowledge and understanding regarding several phenomena associated with the condensation-induced water.hammer. These are: (a) condensation heat transfer coefficient and it.s dependence on system variables, (b) mechanism of formation of vapor pockets, and their shapes and sizes, (c) mass of the accelerating water slug, (d) interfacial area for condensation and its relationship with the area over which the pressure difference acts on the water slug. Unt il one has better knowledge regarding these items and how they vary with the size of the equipment, no credible scaling laws can be derived.

In the following section, the analytical work independently done at BNL to verify the parametric study of Westinghouse will be described in detail.

\subsection{Conctusions}

Although the Westinghouse parametric study was a reasonable and useful attempt to analytically study the behavior of a collapsing vapor pocket in a preheat steam generator, no credible scaling laws can be derived until one has better knowledge regarding the effect of equipment size on the governing physical parameters. 
5. B̀NL ANALYTICAL STUDY

\subsection{The Model}

In order to verify the results of the Westinghouse parametric study described in the previous section, an independent analytical study was conducted at BNL.

The geometry of concern is shown in Figure 5.1 where it is assumed that a cylindrical water slug of length ND has been formed at rest in a pipe of diameter $D$. Initial watér temperature is generally taken to be at room temperature and the instantaneous steam temperature is taken as the saturation value for the given pressure. Condensation is assumed to occur at the steam-water interfaces located at $z_{1}$ and $z_{2}$ only. Compressibility of the liquid is ignored, and the pipe wall is assumed to be adiabatic.

Water Slug

The conservation equations of mass, momentum, and energy are

mass: $\quad \frac{\partial \rho_{\ell}}{\partial t}+\frac{\partial G}{\partial z}=0$

momentum: $\frac{\partial G}{\partial t}+\frac{\partial}{\partial z}\left(\frac{G^{2}}{\rho_{\ell}}\right)=-\frac{\partial p}{\partial z}-\frac{f|G| G}{2 D \rho_{\ell}}$

entery: $\quad \frac{\partial i_{\ell}}{\partial t}+\frac{G}{\rho_{\ell}} \frac{\partial i_{\ell}}{\partial z}=-\frac{1}{\rho_{\ell}} \frac{d \dot{q}^{\prime \prime}}{d z}-\frac{\partial p}{\partial t}$

where the notations are explained in Section 5.2 .

Since the wall is adiabatic, the axial heat flux term has been retained in (5.3). The constant liquid density assumption allows Equation (5.1) to be integrated to give

$$
\langle\rangle_{1}=G_{0+}=G_{1-}
$$

where $\langle>$ symbols represent volume averaged quantities. 


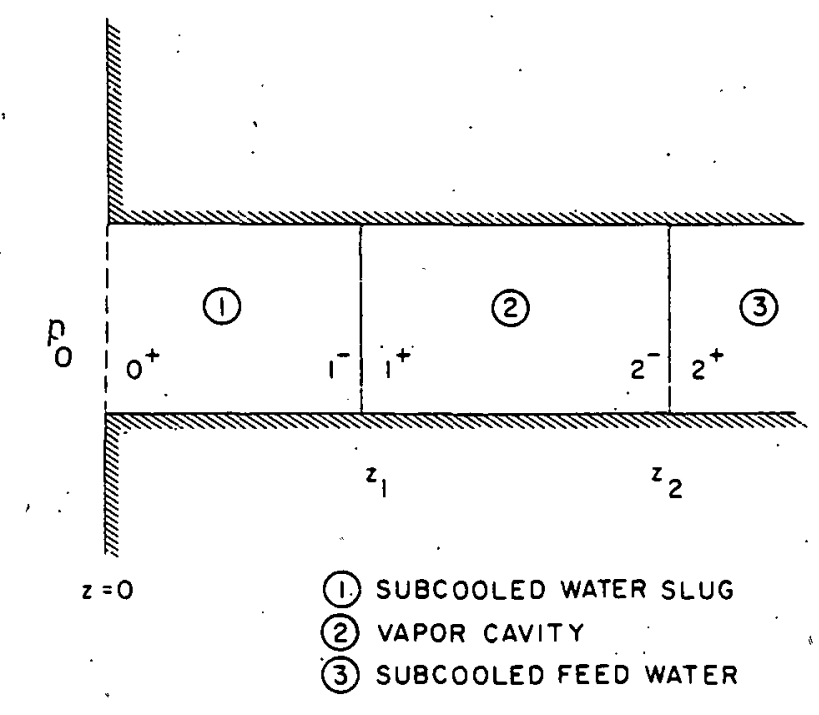

Figure 5.1 BNL model for slug inpact water hammer analysis. (BNL-11-800-79) 
Integration of the momentum equation spatially, including application of Leibnitz rule results in

$$
\frac{d<G\rangle_{1}}{d t}=-\frac{\left\langle p_{2}\right\rangle-p_{0}}{z_{1}}-\frac{f\left|\langle G\rangle_{1}\right|\langle G\rangle_{1}}{\left.2 D<p_{\ell}\right\rangle_{1}} .
$$

Similarly, the energy equation is integrated. with the assumption of uniform temperature in the liquid, $\left(i_{1-}=\langle i\rangle_{1}\right)$, so that

$$
\frac{d<i\rangle_{1}}{d t}=\frac{\langle G\rangle_{1}}{\rho_{\ell} z_{1}}\left(i_{0}+-\langle i\rangle_{1}\right)-\frac{\dot{q}_{1}^{\prime \prime}}{\rho_{\ell} z_{1}}
$$

where the heat flux is given as

$$
\left.\dot{q}_{1-}^{\prime \prime}=h_{\ell 1}\left[\langle T\rangle_{1}-T_{s}(<p\rangle_{2}\right)\right] \text {. }
$$

Equations of state are used to calculate the density and temperature of the liquid slug from the liquid enthalpy and the average slug pressure.

\section{Vapor Cavity}

The pressure and enthalpy in the vapor cavity are assumed to be uniform. This implies uniform density distribution inside the cavity. Should two-phase mixture form in the vapor cavity, the liquid (or droplets) are assumed to be in thermal equilibrium with the vapor. The momentum equation for the vapor cavity is not required because the inertia and the friction terms are neglected, resulting in a uniform pressure distribution inside the vapor cavity. Therefore, the conservation equations for the vapor cavity are:

mass: $\quad \frac{\partial \rho_{m}}{\partial t}+\frac{\partial G}{\partial z}=0$

energy. $\frac{\partial\left(\rho_{m} i_{m}-p\right)}{\partial t}+\frac{\partial\left(i_{m l} G_{m l}\right)}{\partial z}=-\frac{\partial \dot{u} "}{\partial z}$.

Integration of (5.8) for the vapor cavity yields

$$
\left(z_{2}-z_{1}\right) \frac{d<p_{m} 2}{d t}+G_{2-}-G_{1+}=0
$$

while the energy equation integrated over the steam cavity volume using Leibnitz rule results in 
$\left(z_{2}-z_{1}\right) \frac{d}{d t}\left[\left\langle\rho_{m} 2^{<i_{m}{ }^{2}}-\langle p\rangle_{2}\right]+\left(G_{m} i_{m}\right)_{2-}-\left(G_{m} i_{m}\right)_{1+}=-\dot{q}_{1^{\prime}}^{\prime \prime}-\dot{q}_{2^{-}}^{\prime \prime} \cdot\right.$

Now the assumption of uniform enthalpy in the vapor cavity results in $i_{\mathrm{m} 2^{-}}=$ $i_{\mathrm{ml}+}=\left\langle i_{\mathrm{m}}\right\rangle_{2}$. Also, the net heat flux out of the vapor cavity is expressed as

$$
\sum \dot{q}_{\text {out }}^{\prime \prime} \equiv \dot{q}_{2-}^{\prime \prime}-\dot{q}_{1}^{\prime \prime}=\left(h_{v 2}+h_{v 1}\right)\left[\langle T\rangle_{2}-T_{s}\left(\langle p\rangle_{2}\right)\right] \text {. }
$$

The equation of state for the mixture density in terms of enthalpy and pressure yields

$$
\frac{d<\rho_{m}>2}{d t}=\left(\frac{\partial \rho_{m}}{\partial i_{m}}\right)_{<p>2} \frac{d<i_{m} 2}{d t}+\left(\frac{\partial \rho_{m}}{\partial p}\right)_{<i_{m}>2} \frac{d<p>2}{d t} .
$$

Linear combination of Equations (5.10), (5.11), and (5.13) gives two coupled ordinary differential equations in terms of pressure and enthalpy given by

$$
\left(z_{2}-z_{1}\right) \frac{d<p\rangle_{2}}{d t}=\frac{\left(G_{2}-G_{1}+<\rho_{m}\right\rangle_{2}\left(\frac{\partial i_{m}}{\partial \rho_{m}}\right)_{<p\rangle_{2}}-\sum \dot{q}_{\text {out }}^{\prime \prime}}{\left.\left[<\rho_{m}\right\rangle_{2}\left(\frac{\partial i_{m}}{\partial p}\right)_{\left.<\rho_{m}\right\rangle_{2}}-1\right]}
$$

and

$$
\left(z_{2}-z_{1}\right) \frac{d<i_{m}>2}{d t}=\frac{\left(z_{2}-z_{1}\right)}{\left\langle\rho_{m}\right\rangle_{2}} \frac{d<p\rangle_{2}}{d t}-\frac{1}{\left\langle\rho_{m}\right\rangle} \sum \dot{q}_{\text {out }}^{\prime \prime} .
$$

\section{Interface Equations}

For compatibility between the water siug and the vapor cavity, the following interface jump equations are used:

mixture mass jump: $\left(G-\rho_{m} \dot{z}_{1}\right)_{1-}=\left(G-\rho_{m} \dot{z}_{1}\right)_{1}+$ 
vapor mass jump: $\left[c\left(G-\rho_{m} \dot{z}_{1}\right)\right]_{1+}=\left[c\left(G-\rho_{m} \dot{z}_{1}\right)\right]_{1}+\Gamma_{i 1}$.

where $c$ is the vapor mass concentration or static quality.

Now $c_{1-}=0$, and $c_{1+}=\langle c\rangle_{2}$, while $z_{1+}=z_{1^{-}}=z_{1}$ so that these two relations yield

and

$$
\frac{d z_{1}}{d t}=\dot{z}_{1}=\frac{\langle G\rangle}{\rho_{1}-}-\frac{\Gamma_{i 1}}{\left\langle C{ }_{2}{ }^{\rho_{1}}-\right.}
$$

where

$$
G_{1^{+}}=\frac{\left\langle\rho_{m}\right\rangle^{2}}{\rho_{1-}}\langle G\rangle_{1}+\left(\frac{A_{i}}{A}\right)_{1} \frac{\left(\dot{q}_{l i}^{\prime \prime}+\dot{q}_{v i}^{\prime \prime}\right)_{1}}{\langle c\rangle^{\Delta} \dot{i}_{f g}} \frac{\left(\rho_{1}-\left\langle\rho_{m}\right\rangle_{2}\right)}{\rho_{1-}}
$$

$$
\Gamma_{i 1}=\left(\frac{A_{i}}{A}\right)_{1} \frac{\left(\dot{q}_{l i}^{\prime \prime}+\dot{q}_{v i}^{\prime \prime}\right)_{1}}{\Delta \dot{i}_{f g}}
$$

Equation (5.18) shows that the interfacial motion is due to the slug velocity its $f$ plus the added effects of evaporation or condensation mass transfer between the vapor cavity and the slug. Similar relations for the feedwater-vapor interface include

and

$$
\begin{gathered}
\frac{d z_{2}}{d t}=\dot{z}_{2}=\frac{G_{f w}}{\rho_{f w}}+\frac{\Gamma_{12}}{\langle c\rangle_{2} \rho_{2^{+}}} \\
G_{2^{-}}=\frac{\left\langle\rho_{m}\right\rangle}{\rho_{f w}} G_{f w}-\left(\frac{A_{i}}{A}\right)_{2} \frac{\left(\dot{q}_{v i}^{\prime \prime}+\dot{q}_{\ell j}^{\prime \prime}\right)_{2}}{\left\langle c{ }^{\Delta 1} f g\right.} \frac{\left(\rho_{f w}-\left\langle\rho_{m}{ }^{\Delta} 2\right.\right.}{\rho_{f w}}
\end{gathered}
$$

where

$$
\Gamma_{i 2}=\left(\frac{A_{i}}{A}\right)_{2} \frac{\left(\dot{q}_{v i}^{\prime \prime}+\dot{q}_{\ell j}^{\prime \prime}\right)_{2}}{\Delta i_{f g}}
$$

Note that condensation acts to affect the interface velocity in opposite manners on the two interfaces. The interface heat fluxes are expressed as: 


$$
\dot{q}_{\ell j}^{\prime \prime}=h_{\ell}\left(T_{\ell}-T_{s}\right)
$$

and

$$
\dot{q}_{v i}^{\prime \prime}=h_{v}\left(T_{v}-T_{s}\right)
$$

Notice that the heat transfer is predominantly from the interface to the cold liquid, $i: e .$, negative of $\dot{q}_{l i}^{\prime \prime}$. The heat transfer from vapor cavity to the interface, $\dot{q}_{v i}^{\prime \prime}$, is zero unless the vapor is superheated.

Solution Method

The model of vapor cavity collapse with water slug motion is now formulated by Equations $(5.5)-(5.7),(5.14),(5.15),(5.18)-(5.23)$. For the present calculation, the temperature rise in the water slug is ignored so that Equation (5.6) is replaced by

$$
<i\rangle_{1}=\text { constant. }
$$

This is done for the sake of simplicity. The temperature of the incoming feedwater is also held constant, and the feedwater velocity is specified to effect closure. At the other end, i.e., behind the water slug, the pressure is held at the initial value of $p_{0}$. The entire system starts at rest.

The system of five ordinary differential equations, namely Equations (5.5), $(5.14),(5.15),(5.18)$ and $(5.21)$, are solved by using the Hamming's modified predictor-corrector method. These equations provide the five major variables, namely the mass-velocity of the water slug, $\langle G\rangle_{1}$, the pressure and enthalpy in the vapor cavity, $\langle p\rangle_{2}$ and $\left\langle i_{m}\right\rangle_{2}$, and the positions of the interfaces, $z_{1}$ and $z_{2}$. The rest of the algebraic equations including the constitutive equations (e.g., 5.24) are then solved in a straight-forward manner.

\subsection{Nomenclature for BNL Model}

English

$\begin{array}{ll}\text { A } & \text { Cross sectional pipe area } \\ a & \text { Sonic velocity } \\ \text { C } & \text { Vapor mass concentration } \\ D & \text { Diameter } \\ f & \text { Friction coefficient } \\ G & \text { Mass flux } \\ h & \text { Heat transfer coefficient } \\ i & \text { Specific enthalpy } \\ \Delta i & \text { Latent heat of vaporization } \\ p & \text { Pressure } \\ Q & \text { Total heat input rate } \\ \dot{q}^{\prime \prime} & \text { Heat flux } \\ T & \text { Temperature } \\ t & \text { Time } \\ v & \text { Velocity } \\ z & \text { Axial location }\end{array}$


Greek

$\Gamma \quad$ Areal vapor generation rate

p Fluid density

Subscripts

$\begin{array}{ll}0 & \text { Interface "o" or initial value } \\ 1 & \text { Interface "I" } \\ 2 & \text { Interface " } 2 \text { " } \\ f g & \text { Liquid-to-vapor difference } \\ f w & \text { Feedwater } \\ i & \text { Interface or impact } \\ \text { in } & \text { Into the section considered } \\ \ell & \text { Liquid } \\ m & \text { Mixture } \\ \text { out } & \text { Out of section considered } \\ \text { s } & \text { Saturation } \\ v & \text { Vapor } \\ - & \text { L.H.S. of an interface } \\ + & \text { R.H.S. of an interface }\end{array}$

\subsection{Results of Calculation}

For parametric evaluation, the conditions shown in Table 5.1 were investigated. The effects of water side heat transfer coefficient, $h_{l}$, initial pressure, $p_{0}$, relative lengths of vapor cavity and water slug, $\left(z_{2}-z_{1}\right)_{0} / z_{10}$, and feedwater mass-fiux, $G_{f w}$, were thus determined over a range of conditions. The feedwater temperature was kept at $27^{\circ} \mathrm{C}$ for all cases. The vapor side heat transfer coefficient, $h_{v}$, which was not a dominant factor, was kept at $1 \mathrm{kw} / \mathrm{m}^{2}$ $-{ }^{\circ} \mathrm{C}$. The interfacial area, $A_{j}$, at both $z_{1}$ and $z_{2}$ was assumed to be equal to the pipe cross-sectional area, A. The chosen pipe diameter was close to the feedwater pipe diameter in the Westinghouse 1/8th scale model. Furthermore, a Blasius-type friction factor was used in Equation (5.5).

\section{Effect of Condensation Heat Transfer Coefficient}

The liquid side heat transfer coefficient was varied over a range of 20 with a maximum of $2 \mathrm{MW} / \mathrm{m}^{2}-{ }^{\circ} \mathrm{C}$. The corresponding case numbers in Table 5.1 are 1 through 5. This type of high heat transfer coefficients has been reported in a number of experimental studies (e.g., Bankoff and Mason, 1962). The results are. shown in Figures 5.2 through 5.5. It is seen from Figures 5.2 and 5.3 that the higher the value of the heat transfer coefficient, the faster is the rate of cavity depressurization and the cavity collapse. Ihis is to be expected. Moreover, at very high heat transfer coefficients, the process of vapor condensation and the water slug motion is bastcally inertia controlled; and the steam volume collapse is monotonic. This is similar to inertia controlled collapse of a spherical bubble (Florshuetz and Chao, 1965). However, as the heat transfer coefficient is lowered, the cavity pressure, cavity length and the water slug velocity (Figure 5.4) start to oscillate. This is due to the coupling of the inertia of the water slug and the thermal limitation for condensation. In 
Table 5.1: Conditions Chosen for BNL Parametric Study ( $P$ ipe diameter, $D=4.3 \mathrm{~cm}$, Water temperature $=27^{\circ} \mathrm{C}$ )

\begin{tabular}{|c|c|c|c|c|c|}
\hline $\begin{array}{l}\text { CASE } \\
\text { NO. }\end{array}$ & $\begin{array}{l}\text { INITIAL WATER } \\
\text { SLUG LENGTH }\end{array}$ & $\begin{array}{l}\text { INITIAL VAPOR } \\
\text { CAVITY LENGTH }\end{array}$ & $\begin{array}{c}\text { INITIAL PRESSURE } \\
\text { (bar) }\end{array}$ & $\frac{h_{l}}{M W / m^{2}-{ }^{\circ} \mathrm{C}}$ & $\begin{array}{l}V_{f w} \\
m / s e c\end{array}$ \\
\hline 1 & 40 & 20 & 21.7 & 2.0 & 0.9125 \\
\hline $2^{\star}$ & 40 & 20 & 21.7 & 1.0 & 0.9125 \\
\hline 3 & 40 & $2 D$ & 21.7 & 0.5 & 0.9125 \\
\hline 4 & 40 & 20 & 21.7 & 0.2 & 0.9125 \\
\hline 5 & 40 & 20 & 21.7 & 0.1 & 0.9125 \\
\hline 11 & 40 & $2 D$ & 4.48 & 1.0 & 0.9125 \\
\hline 12 & 40 & 20 & 7.93 & 1.0 & 0.9125 \\
\hline 13 & 40 & 20 & 42.4 & 1.0 & 0.9125 \\
\hline 14 & 40 & 20 & 70.0 & 1.0 & 0.9125 \\
\hline 21 & 5.50 & 0.50 & 21.7 & 1.0 & 0.9125 \\
\hline 22 & 50 & 10 & 21.7 & 1.0 & 0.9125 \\
\hline 23 & $3 D$ & 30 & 21.7 & 1.0 & 0.9125 \\
\hline 24 & 20 & 40 & 21.7 & 1.0 & 0.9125 \\
\hline & & & & & \\
\hline 31 & 40 & 20 & 21.7 & 1.0 & 0.0912 \\
\hline 32 & 40 & 20 & 21.7 & 1.0 & 9.125 \\
\hline
\end{tabular}

*Reference run 


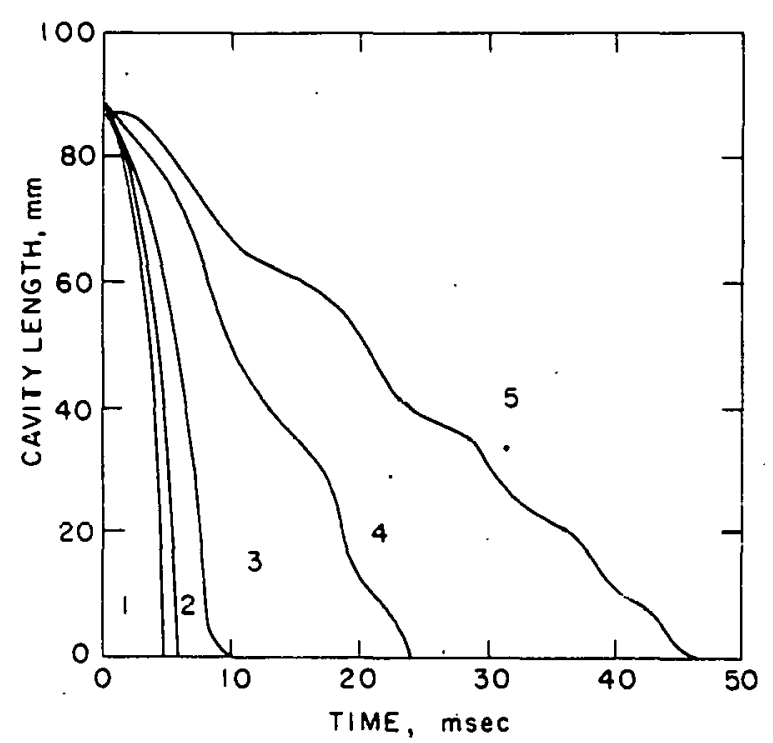

Figure 5.2 Effect of heat transfer coefficient on cavity length. (BNL11-801-79)

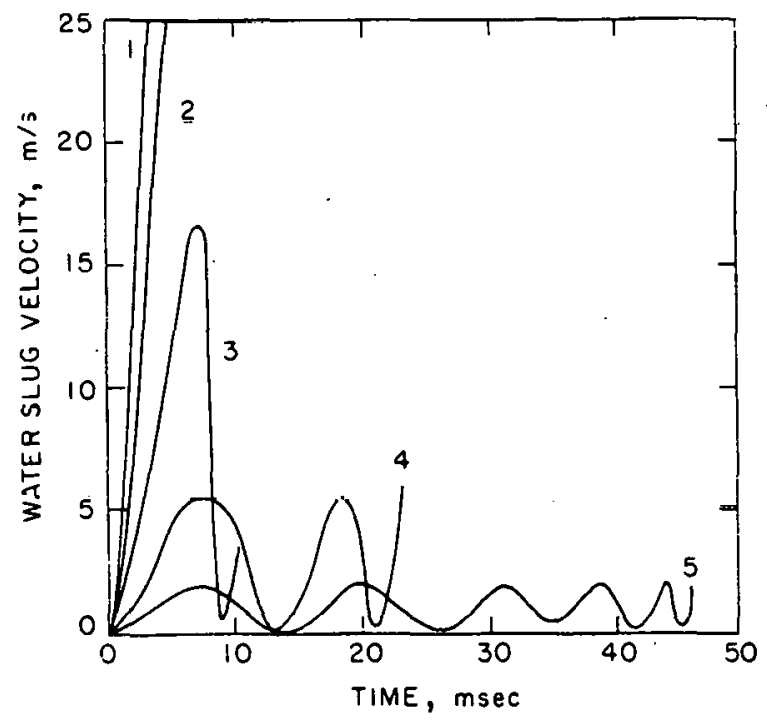

Figure 5.4 Effect of heat transfer coefficient on water slug velocity. (BNL-11-798-79)

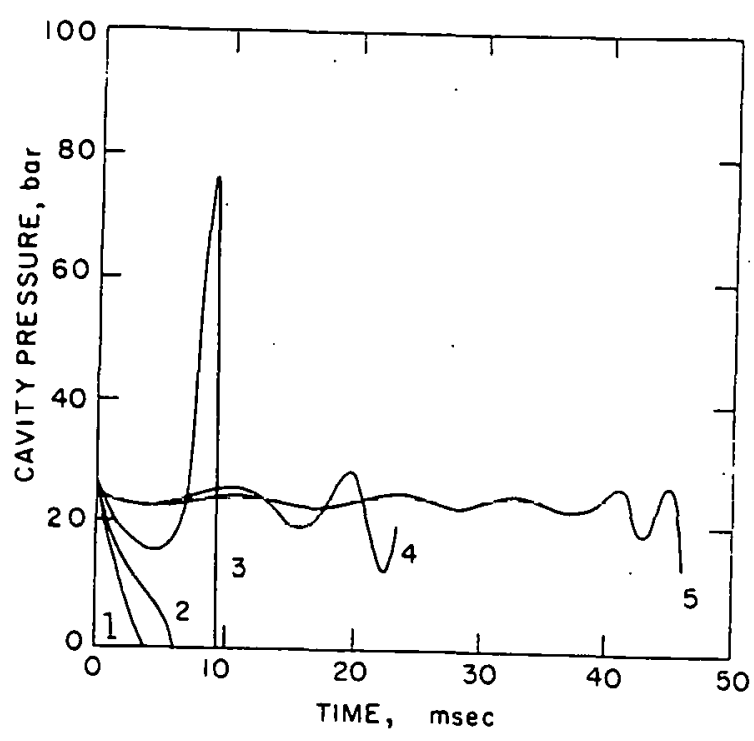

Figure 5.3 Effect of heat transfer coefficient on cavity pressure. (BNL-11-799-79)

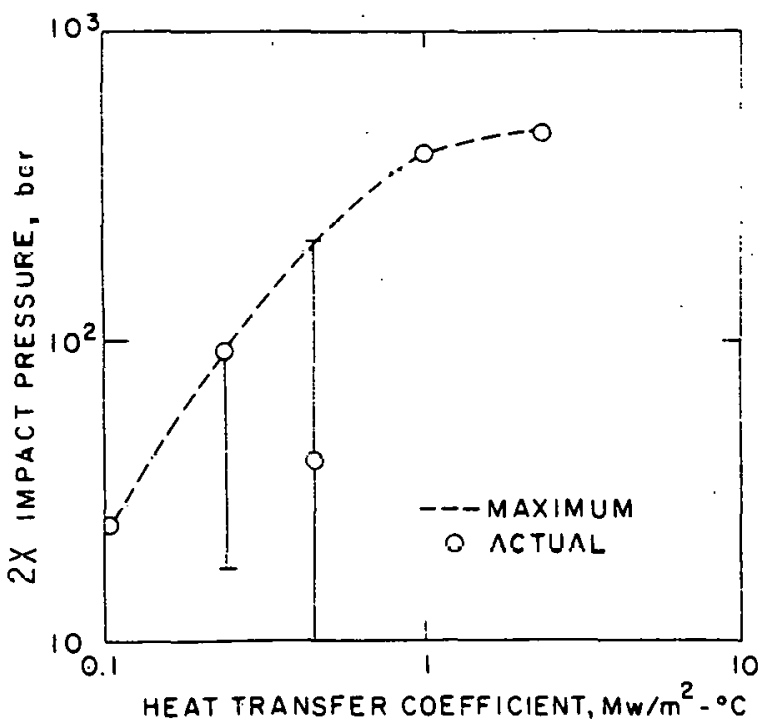

Figure 5.5 Effect of heat transfer coefficient on slug impact pressure. (BNL-11-805-79) 
other words, condensation heat transfer is not high enough to compensate for the inertia of the accelerating water slug. This causes pressure in the vapor cavity to go up which increases the condensation (due to an increase in saturation temperature) and the subsequent drop in pressure. If sufficient time is available before a complete collapse of the vapor cavity, the process repeats itself with an ever decreasing time period due to the increasing stiffness associated with the decreasing steam volume. Similar behavior has also been seen for collapse of a spherical bubble by Florschuetz and Chao (1965).

The over-pressure due to liquid-liquid-impact at complete cavity collapse is calculated as (Block, 1977)

$$
p_{i}=a(\rho v) / 2=a\langle G\rangle_{1} / 2
$$

where $a$ is the sonic velocity in liquid and $\langle G\rangle_{1}$ is the mass velocity of the water slug at the moment of impact. Figure 5.5 shows the maximum impact pressures by a dashed line calculated from the slug velocity envelope. Notice that for lower values of condensation heat transfer coefficients, where the process of cavity collapse is oscillatory, the actual value of impact pressure is lower than the maximum because of the lower instantaneous slug velocity at impact. However, since no two slugs will form and behave exactly the same way even in the same operating conditions, there will always be an inherent randomness in the magnitude of impact pressure when the void-collapse process is oscillatory. This may be one of the reasons why the water hammer phenomenon is so random and non-reproducible in the Westinghouse and Creare experimental studies.

\section{Effect of Initial Pressure}

The initial system pressure was varied from 4.48 bar ( 50 psig) to 70 bar (1000 psig) keeping other variables constant. The corresponding case numbers in Table 5.1 are 2 and 11 through 14. As the system pressure is increased, the driving potential for condensation, $T_{\text {sat }}-T_{l}$, is also increased for the same feedwater temperature. Also, the latent heat of condensation decreases with increasing pressure. Both of these effects cause a faster collapse of vapor cavity at the beginning for higher initial pressures. This is in agreement with Equations (5.18) and (5.21), and is seen more clearly in Figure 5.6. However, this faster collapse rate results in a faster acceleration of the water slug, which causes an overpressurization of the vapor cavity. This triggers an oscillatory void collapse process (at higher initial pressures) as seen in figures 5.7 and 5.8. The impact pressures at complete void collapse are shown in Figure 5.9 which indicates that at higher pressures the magnitude of maximum impact pressure starts to decrease. Also, the water hammer phenomenon could become random at higher pressures. This may explain why water hammer phenomenon is relatively scarce at high pressures in the Westinghouse and Creare studies.

\section{Effect of Relative Initial Vapor Cavity Length}

The initial length of the vapor cavity, $\left(z_{2}-z_{1}\right)_{0}$, and the initial length of the water slug, $z_{10}$, are the two most uncertain initial conditions. Therefore, the relative initial vapor cavity length, i.e., the ratio of the initial cavity length and the initial water slug length, was varied from 0.091 to 2 . 


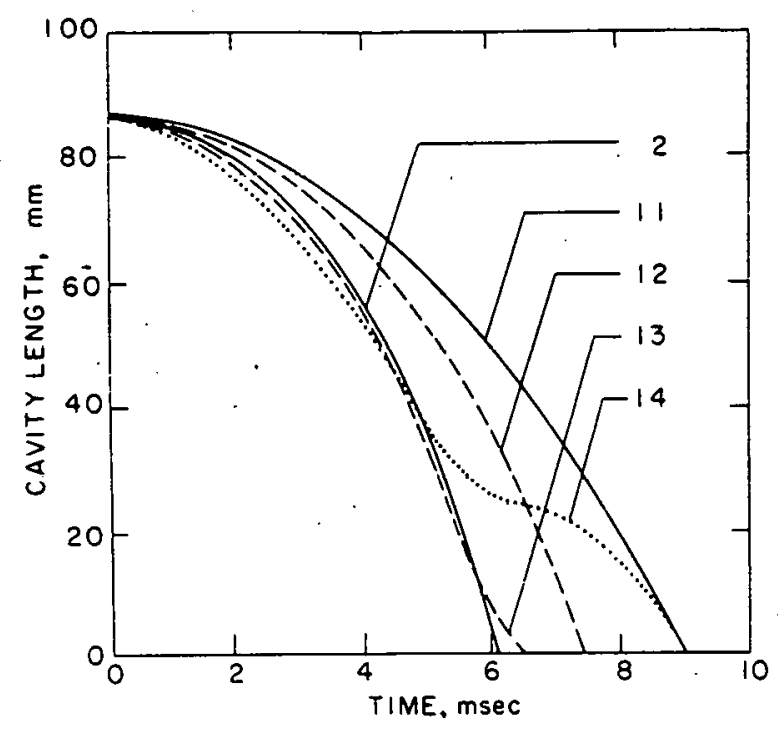

Figure 5.6 Effect of initial pressure on cavity length. (BNL-11-80379)

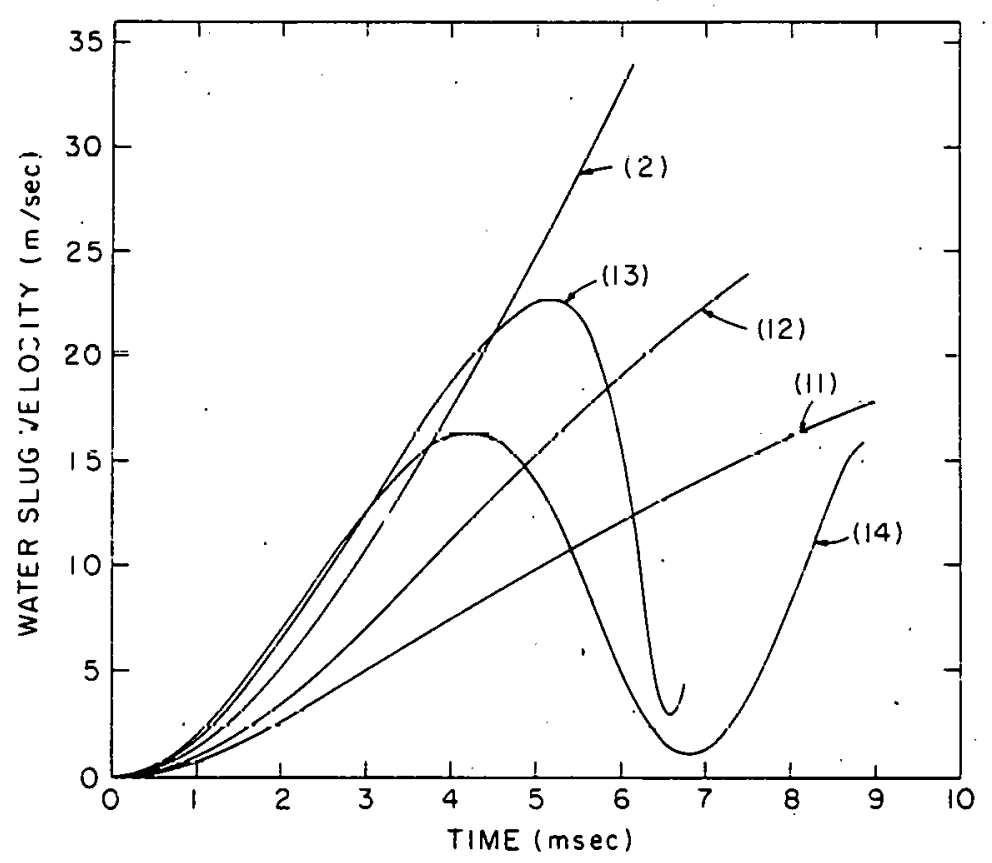

Fiçure 5.8 Effect of initial pressure on water slug velocity. (BNL$3-163-80$ )

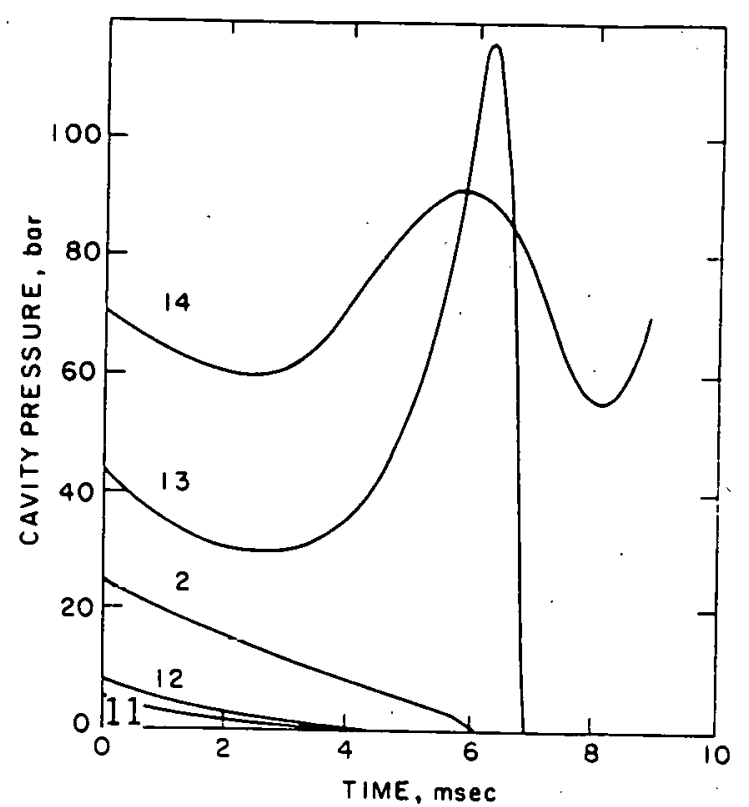

Figure 5.7 Effect of initial pressure on cavity pressure. (BNL-11802-79)

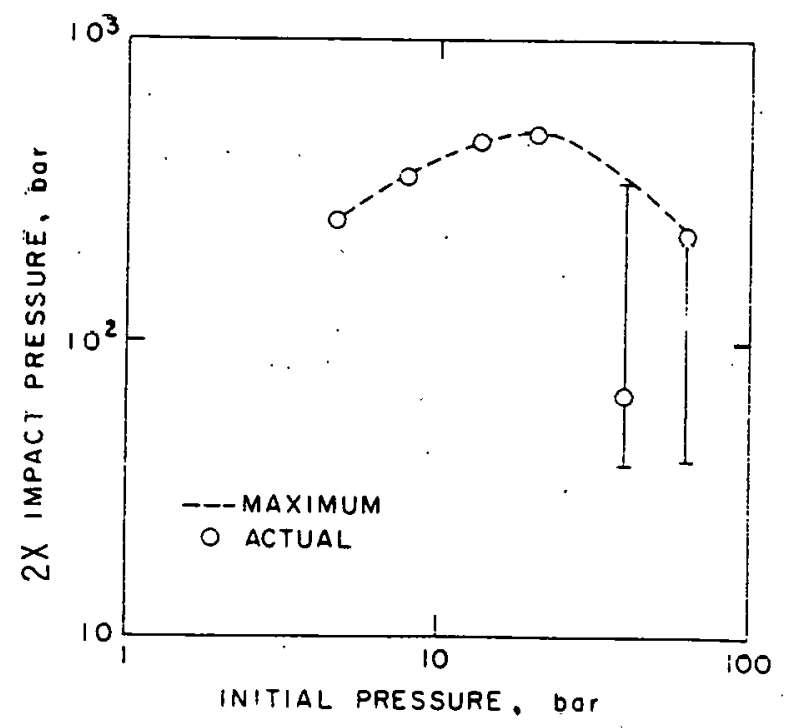

Figure 5.9 Effect of initial pressure on slug impact pressure. (BNL11-804-79) 
The corresponding case numbers in Table 5.1 are 2 and 21 through 24. Notice that the total initial length of the vapor cavity and the water slug was kept constant. The results for the above case are shown in Figures 5.10 through 5.13. As the relative vapor cavity length was decreased, the mass of vapor to be condensed was also reduced. This led to a faster depressurization of the vapor cavity and a faster acceleration of the water slug as shown in Figure 5.11 and 5.12, respectively: However, because the time for complete collapse is reduced with the reduction in the relative initial cavity length, the impact pressure decreases in spite of faster water slug acceleration. On the other hand, as the relative vapor cavity length is increased, the rate of depressurization decreases (because of the larger vapor mass to be condensed). Still, a shorter initial water siug length can cause an over-acceleration of the water slug and a resultant overpressurization of the vapor cavity as seen in Figure 5.12 and 5.11 , respectively. Therefore, there could be an optimum relative initial cavity length which would produce the maximum slug impact pressure, as seen in Figure 5.13 .

\section{Effect of Feedwater Velocity}

The feedwater velocity was varied by two orders of magnitude in case numbers 31,2 and 32 of Table 5.1. The results are shown in Figure 5.14 through 5.16. It can be seen that the effect of increasing the feedwater velocity is the same as collapsing the vapor cavity at a faster rate by force. This is implied through Equation (5.21). However, the feedwater velocity must be very high or, at least comparable to the water slug velocity to have any appreciable effect on the cavity pressure and the water slug velocity. Such high feedwater velocity may not be realistic in practical applications. Moreover, if the relative velocity at impact is used instead of the water slug velocity for the calculation of impact pressure, the feedwater velocity seems to have only a small effect on the impact pressure.

\section{Effect of Geometric Scale}

In order to verify the Westinghouse's scaling laws, calculations were done for a pipe diameter ten times that of the reference run (i.e., Case 2 ). The initial slug length and the vapor cavity length were also increased by ten times: However, the initial system pressure, feedwater temperature, feedwater velocity and the condensation heat transfer coefficient are kept constant. This is the same as keeping a constant Stanton number and a constant relative initial vapor cavity volume. Note that in the BNL model, there is no ambiguity regarding the area ratios.

The computed result confirmed the notion that if the heat transfer coefficient and the initial ratio of vapor cavity volume to water slug volume (or mass) are scale-independent, the depressurization magnitude in the full-scale is the same as in the small-scale model. It is also true that the time duration of depressurization is increased proportionally in the large scale. Therefore, if the cavity pressures for the two runs are plotted along a reduced time, i.e., $t^{*}=t / N$ where $N$. is the linear scale factor, no distinction can be made between the two curves (see Fig. 5.17). The water slug velocities at the time of impact are also virtually identical (e.g., $33.84 \mathrm{~m} / \mathrm{sec}$ for the $1 / 10$ th scale and $34.0 \mathrm{~m} / \mathrm{sec}$ for the full-scale). This leads to almost the same impact pressure. 


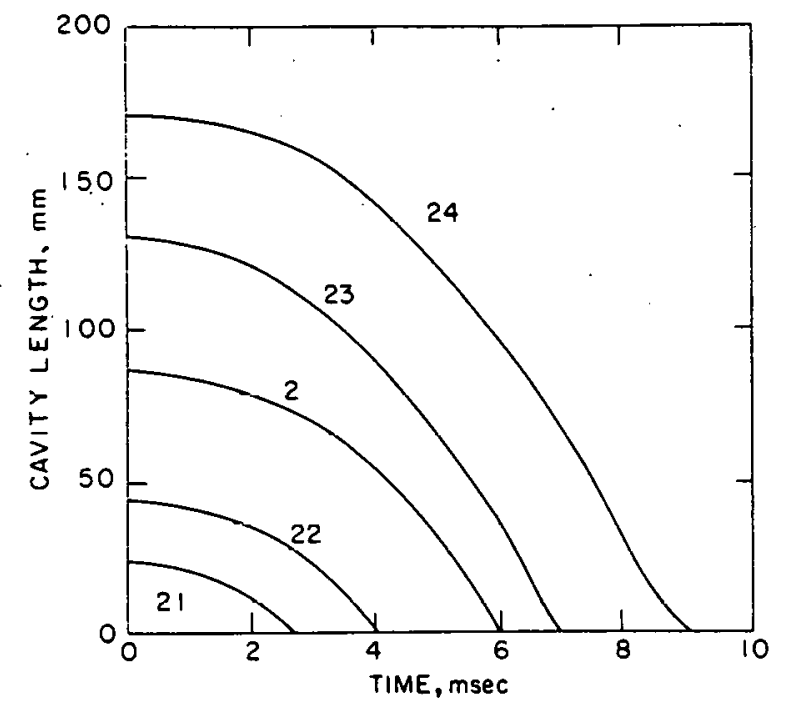

Figure 5.10 Effect of initial relative cavity length on instantaneous cavity size. (BNL-11-809-79)

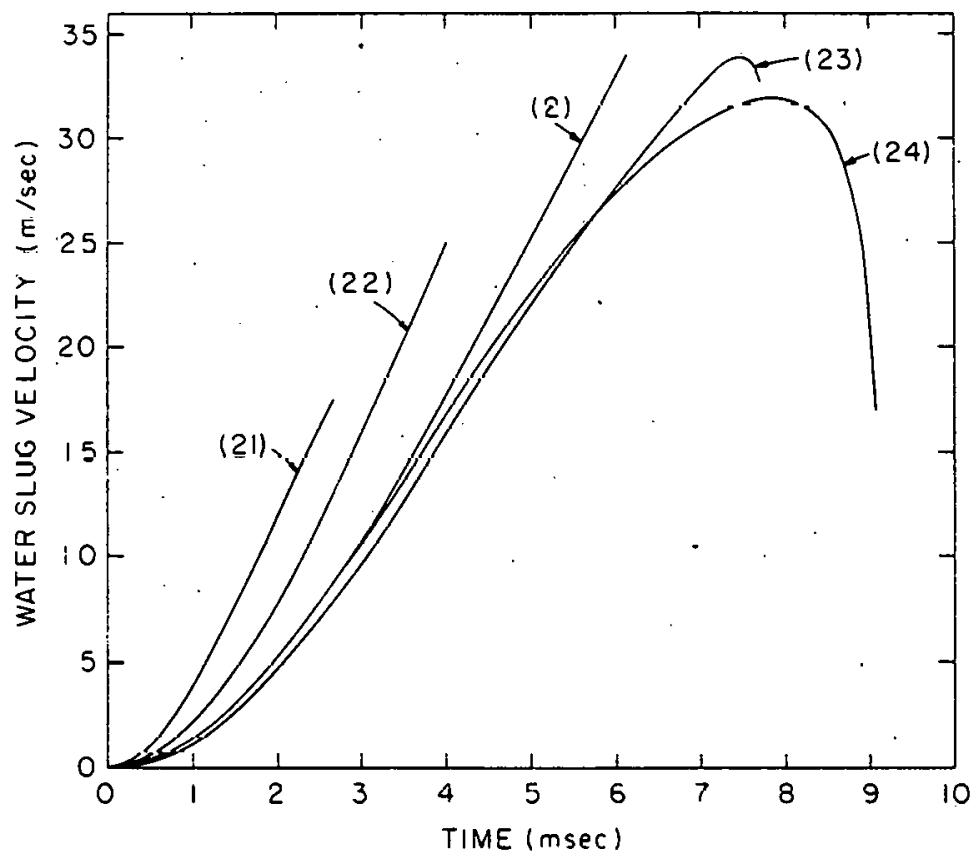

Figure 5.12 Effect of initial relative ravity length on water slug velocity. (BNL-3-162-80)

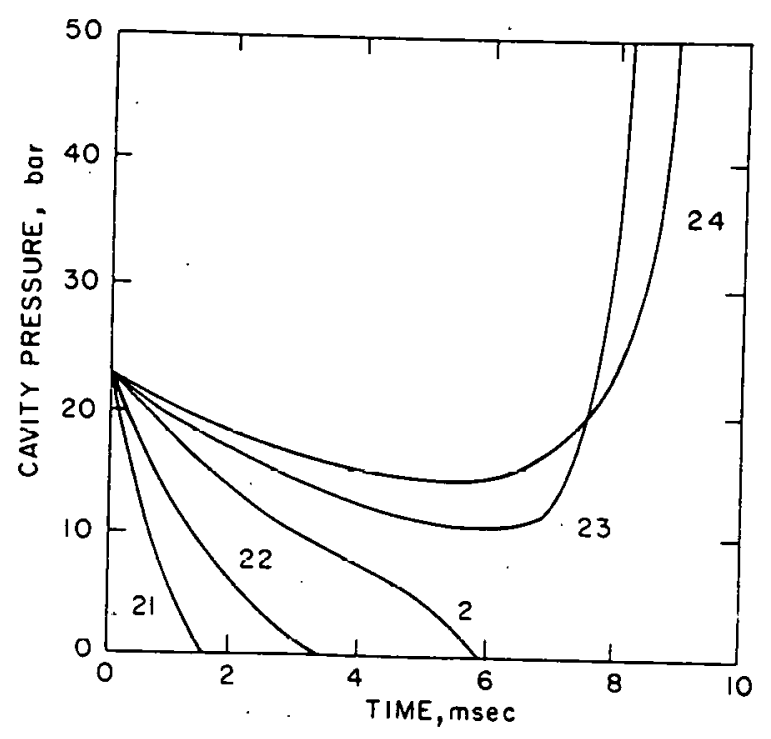

Figure 5.11 Effect of initial relative cavity length on cavity pressure. (BNL11-808-79)

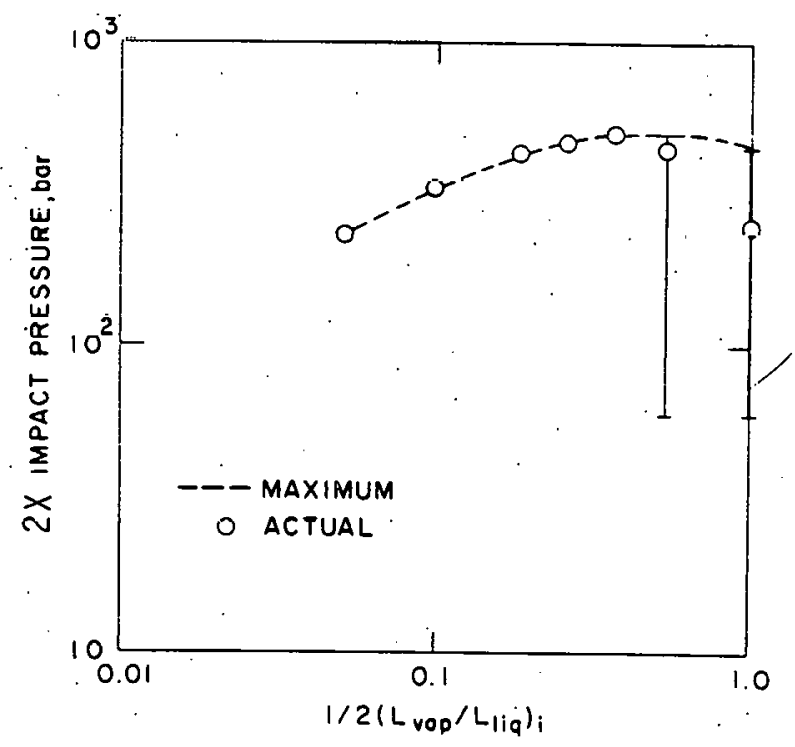

Figure 5.13 Effect of initial relative cavity length on slug pressure. (BNL=11-800-79) 


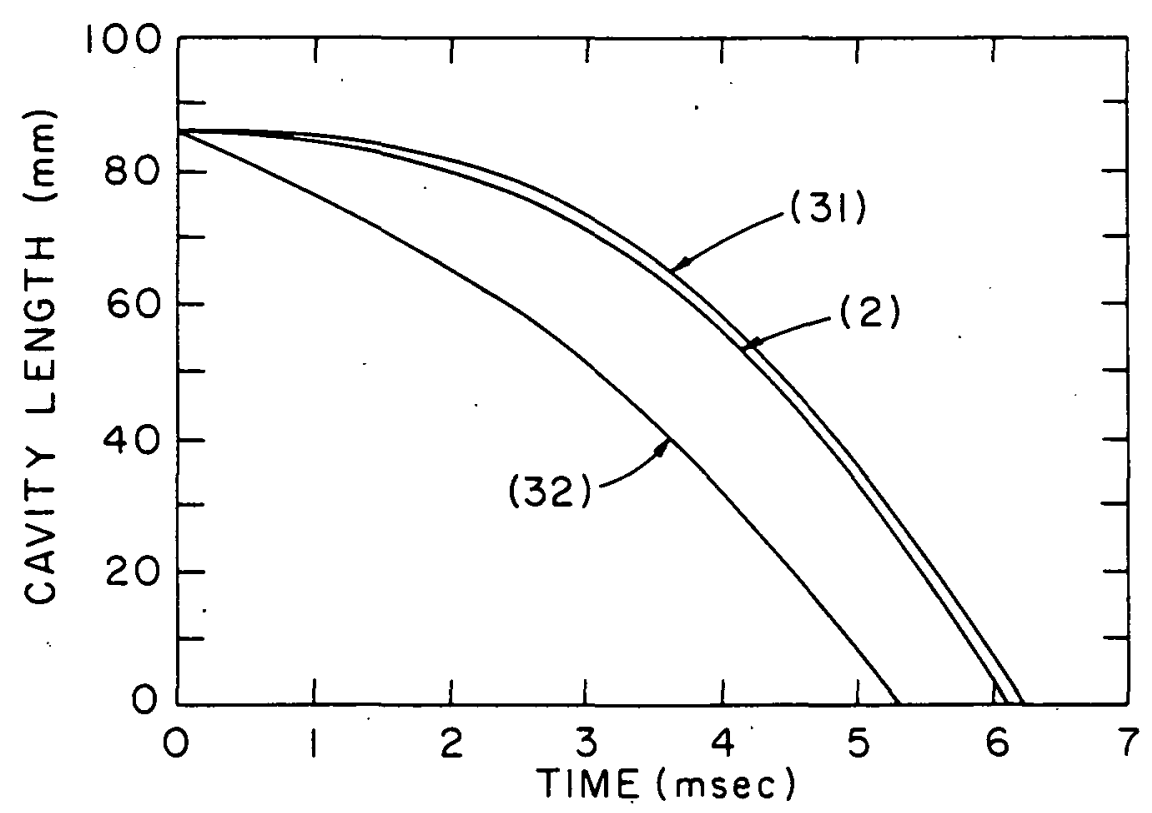

Figure 5.14 Effect of feedwater velocity on cavity length. (BNL-3-166-80)

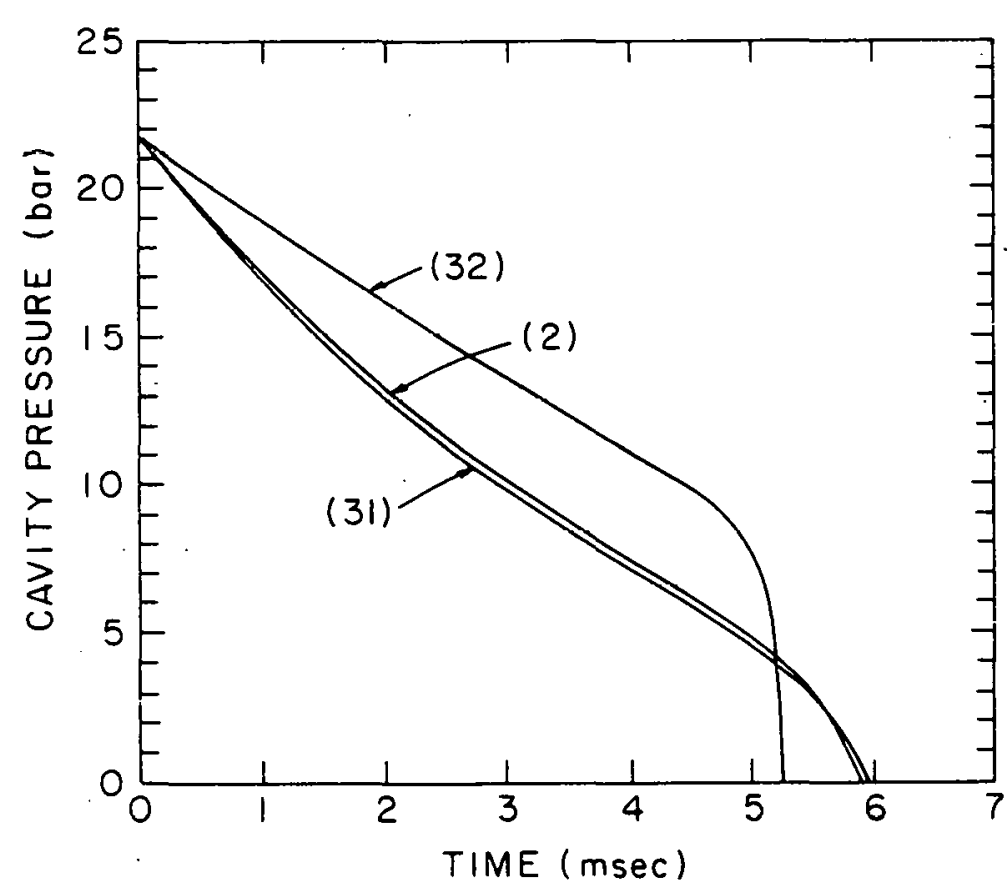

Figure 5.15 Effect of feedwater velocity on cavity pressure. (BNL-3-167-80)

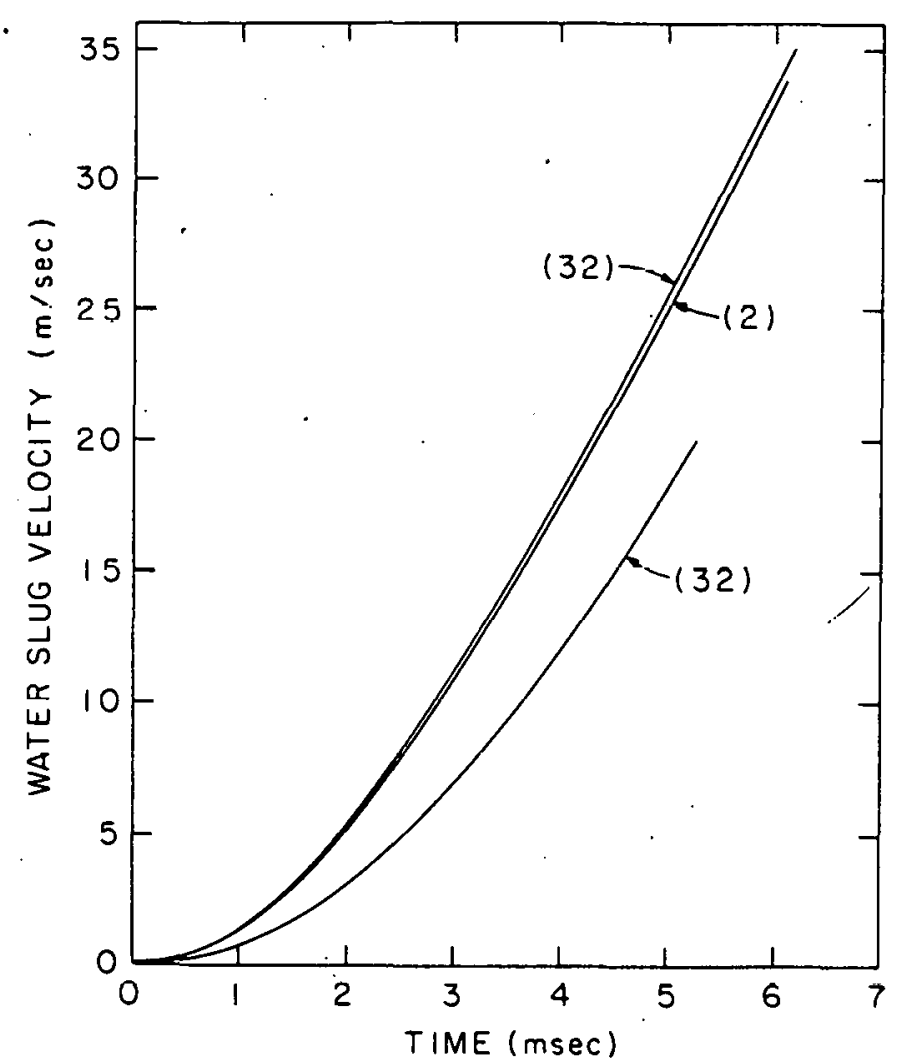

Figure 5.16 Effect of feedwater velocity ón water slug velocity. (BNL-3-165-80) 


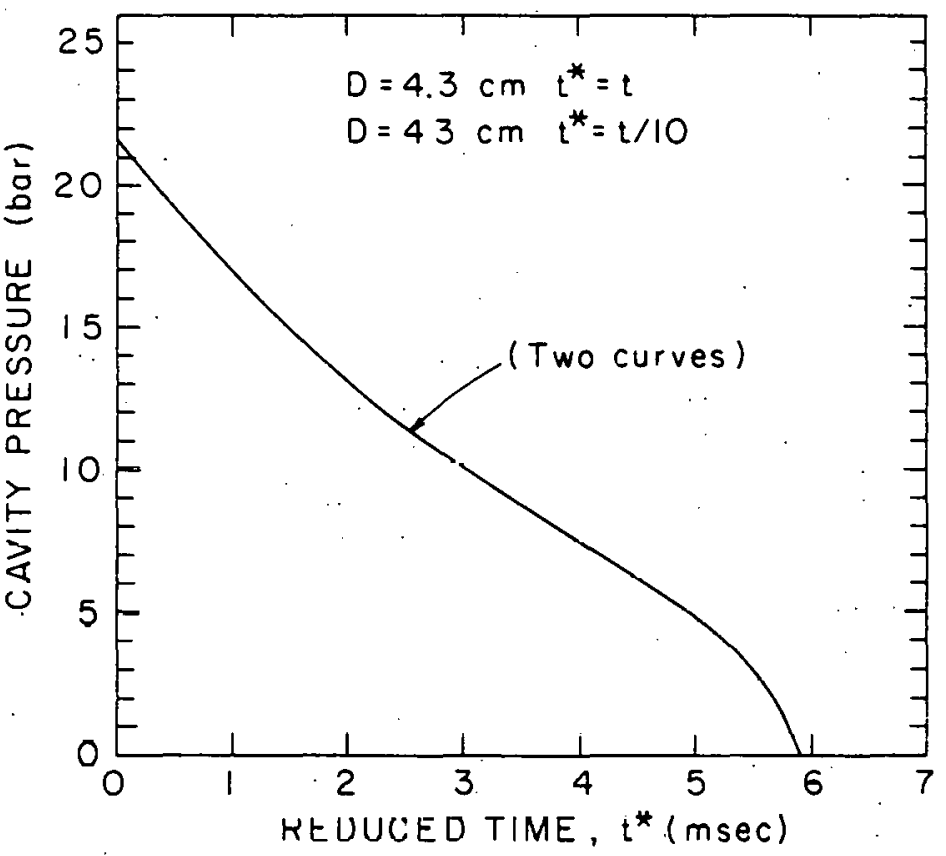

Figure $5.17^{\circ}$ Effect of geometric scale. (BNL-3= 164-80) 
However, it must be kept in mind that no analytical or experimental evidence exists as to the question of scale-independence of the condensation heat transfer coefficient and the initial ratio of the vapor cavity and the water slug volume. This is the major unresolved issue even in a simple geometric configuration assumed in the BNL model:

\subsection{Conclusions}

The following conclusions can be drawn from the BNL analytical studies:

(a) The condensation heat transfer coefficient, the initial system pressure and the initial relative volumes of the vapor cavity and the water slug are all important parameters in determining the course of the cavity collapse and the resultant impact pressure. The feedwater velocity, on the other hand, does not seem to be that important for following the void-collapse transient. However, it might be important in determining the initial volumes of the vapor cavity and the water slug, and the value of the condensation heat transfer coefficient. This aspect of the problem has not been studied at BNL.

(b) In certain operating conditions and circumstances, the process of vapor cavity collapse can be an oscillatory one. This could introduce a large degree of randomness in the water slug velocity at the time of impact, and thus, in the impact pressure. This might explain the randomness and the non-reproducibility of water hammer tests conducted at Westinghouse and Creare, Inc.

(c) Westinghouse scaling laws are correct, at least for the simple geometric configuration assumed in the BNL model, if the heat tra sfer coefficient and the initial ratio of vapor cavity length to the water slug are scale-independent. However, this is still an open item because of the lack of theoretical or experimental evidence. 


\section{EVALUATION OF WEST-INGHOUSE FULL-SCALE PREHEAT STEAM GENERATOR}

In view of the inconclusive nature of the Westinghouse $1 / 8$ th scale tests and the scaling laws, the Westinghouse steam generator for McGuire plant was reviewed in a NRC-BNL-Westinghouse-Duke Power meeting on October 31, 1978. The purpose of the meeting was to critically review the feedwater piping and control systems of the McGuire plant to determine the worst possible condition (from the viewpoint of condensation induced water hammer) for this particular plant.

It was found that the McGuire plant employs Westinghouse split flow preheat steam generators (Model D2/D3) with Westinghouse-suggested modifications. These modifications require that the cold (room temperature) auxiliary feedwater be injected through the top-feed nozzle located at the upper section of the steam generator and not through the main feedwater nozzle located at the preheater section. The Westinghouse personnel stated that the suggestion for modification was related to economics, and not to the question of safety of the nonmodified design. Based on the small-scale water hammer tests, Westinghouse felt that there could be commercial damage, i.e., loss of effectiveness of the preheater, outage or even baffle deformation due to small amplitude pressure pulses if the cold auxiliary water is injected through the preheater box area. However, there could be plants, other than McGuire, which may not implement the Westinghouse suggested modifications. Anyway, the following major aspects of the McGuire preheat steam generator/feedwater system were observed from the discussion at the above meeting.

(a) Because the Westinghouse-suggested modifications have been implemented, the cold (room temperature) auxiliary feedwater is injected through the top-feed nozzle. A failure of the check valve in the pipe connecting the auxiliary feed pipe and the main feedwater pipe can cause injection of cold auxiliary feedwater through the main feed nozzle (see Fig. 6.1). Even in that case, an alarm system will be expected to alert the plant operators.

(b) Westinghouse personnel stated that uncovery of the main feedwater nozzle, due to boil-off of the secondary side of the steam generator, can occur only due to feedwater pipe break, steam line break, or during a loss of off-site power, a combined failure of an electric and a steamdriven auxiliary feed pump.

(c). During start-up and shut-down the feedwater is introduced through the top-feed nozzle for loads below $25 \%$ of full load. Outage of feedwater heaters, coupled with operator error of opening the main feedwater valve, can cause introduction of highly subcooled water through the main feed nozzle. However, the alarm system should alert the operator. if the temperature of the feedwater is below $250^{\circ} \mathrm{F}$.

(d) Above 25\% of the full power, the feedwater is introduced into the steam generator through the main feedwater line. Outage of several feedwater heaters is required to increase the subcooling of the feedwater significantly. Also, the alarm system should be activated if the feedwater temperature falls below $250^{\circ} \mathrm{F}$. 


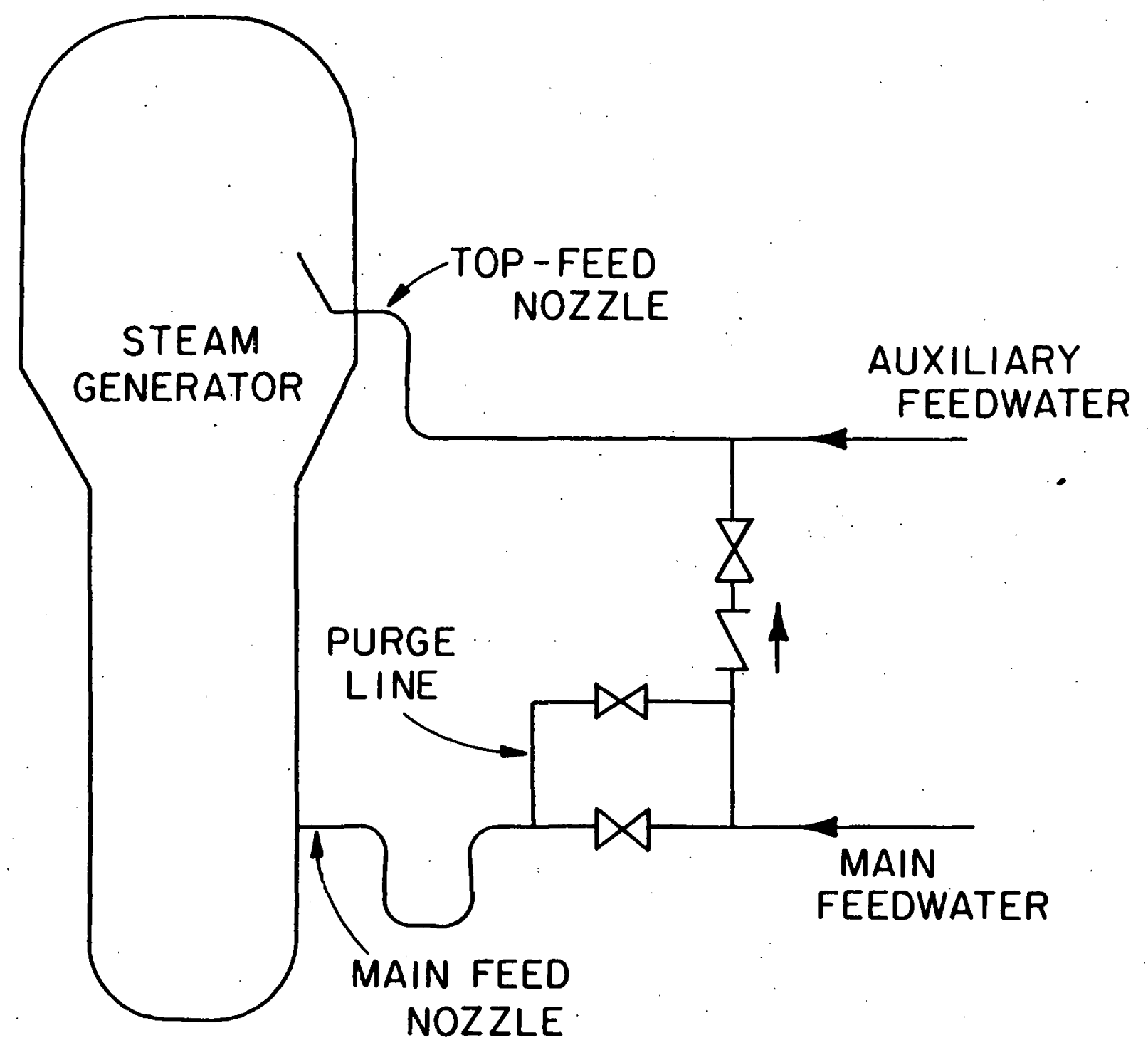

Figure 6.1 Schematic of the McGuire preheat steam generator with the associated feedwater system. (BNL-3-175-80) 
(e) In both the main and the auxiliary feedwater piping, down-turned elbows are placed immediately after the nozzle pieces. Thus the horizontal lengths between the steam generator and the vertical run of the pipings have been minimized as per Westinghouse and Creare recommendations.

With the above information, it appears that the cold (room temperature) water can be injected through the main feedwater nozzle into a voided steam generator only if the failures mentioned in items (a) and (b) occur simultaneously. NRC staff has stated during the meeting that they would consider such a combined failure to be improbable and thus would rule out the possibility of cold water injection through the main feedwater line into a voided steam generator for the McGuire plant. In addition, an operator error of opening the main feedwater valve coupled with outage of several feedwater heaters is required for injection of highly subcooled feedwater through the main feedwater nozzle during start-up and shut-down at loads less than $25 \%$ power. NRC staff stated that plant operation with outage of several feedwater heaters would not be expected because of limitations placed by the plant Standard Operating Procedure and thus need not be considered as a realistic condition for verification testing. However, at approximately $25 \%$ of full load, the feedwater is switched from the top-feed nozzle to the main feed nozzle. It is also known that at low loads, there will be vapor voids at the preheater section of the steam generator. Therefore, the following verification test is suggested for the McGuire plant to ensure that no damaging water hammer will occur in the steam. generator and/or the feedwater system:

- Run the plant at approximately $25 \%$ of full power by using feedwater through the top-feed nozzle at the lowest feedwater temperature that the plant Standard Operating Procedure (SOP) allows. Switch the feedwater at that temperature from the top-feed nozzle to the main feed nozzle by following the SOP. Observe and record the transient that follows.

We, at BNL, feel that a review of the type presented in this report of the feedwater system is needed for each and every plant with Westinghouse preheat steam generators. Out of these reviews, the worst probable situation(s) for. water hammer will evolve for each plant, and the specific situation(s) should then be tested in full-scale steam generators in actual plants. This is particularly important since the other plants. with Westinghouse preheat steam generators may not implement the Westinghouse suggestion regarding the injection of auxiliary feedwater. Besides, the feedwater piping and control systems may vary from plant to piant. 


\section{EVALUATION OF COMBUSTION ENGINEERING DESIGN}

Three meetings were held among NRC, BNL and Combustion Engineering (CE) personnel on September 28, 1977, October.7, 1977, and June 28, 1979, to review the design of the CE preheater steam generators from the standpoint of condensation induced water hammer. A schematic of the CE preheater steam generator is shown in Figure 7.1. Notice that there are two feedwater nozzles. One at the economizer or the preheater section at the lower part of the steam generator, and another at the top or the downcomer section of the steam generator. CE representatives stated that the cold auxiliary feedwater in CE system is designed to be injected only through the downcomer nozzle at the top section. The downcomer nozzle is connected to a feedring which is provided with " $J$ "-tubes or Tees and also a loop seal. Moreover, there are $90^{\circ}$ downward sloping elbows immediately off the downcomer as well as the economizer nozzle. In short, the recommendations for the feed-ring type steam generators have been incorporated in the feed-ring for auxiliary feedwater, and therefore, CE claims to have eliminated the possibility of having any damaging water hammer.

Other relevant design features of CE preheat steam generators are the following:

(1) All feedwater to the economizer nozzle is ceased when S. G. water level falls below 26 feet from the tube sheet. Thereafter, the feedwater and/or emergency feedwater is fed only through the downcomer nozzle.

(2) Two check valves need to fail for cold emergency feedwater to go to the economizer section. This is shown schematically in Fig. 7.2.

Therefore, introduction of cold emergency (auxiliary.) feedwater through the economizer nozzle can be considered to be a low-probability event.

A review of the CE feedwater flow control system revealed that from zero to $15 \%$ of full load, feedwater is injected only through the downcomer nozzle. At around $15 \%$, the feedwater is switched from the downcomer nozzle to the economizer nozzle. A CE representative mentioned that the initial gush of water into the economizer at this switchover point could be at ambient temperature $\left(\sim 70^{\circ} \mathrm{F}\right)$. Results from CE computer code HELIOS (a three-dimensional, steady-state, homogeneous equilibrium two-phase flow codel indicated that at 15\% operating power, significant amount of voids (15-20\%) can be expected near the preheater (distribution) box before the feedwater starts to flow through the economizer nozzle. Therefore, at the switchover point, i.e., at $15 \%$ of full load, a condensationinduced water hammer in the preheater box region is a definite possibility. However, the severity of the water hammer, if it occurs, cannot be predicted with the current state-of-the-art.

Unlike Westinghouse, Combustion Engineering has not conducted any experiment, even in small scale, to study the condensation-induce water hammer in their preheat steam generator. Nor have they reported any analysis for the preheater region. Some analysis was done for the pipe geometry. However, the results transmitted to $N R C$ and $B N L$ do not contain any description of the CE 


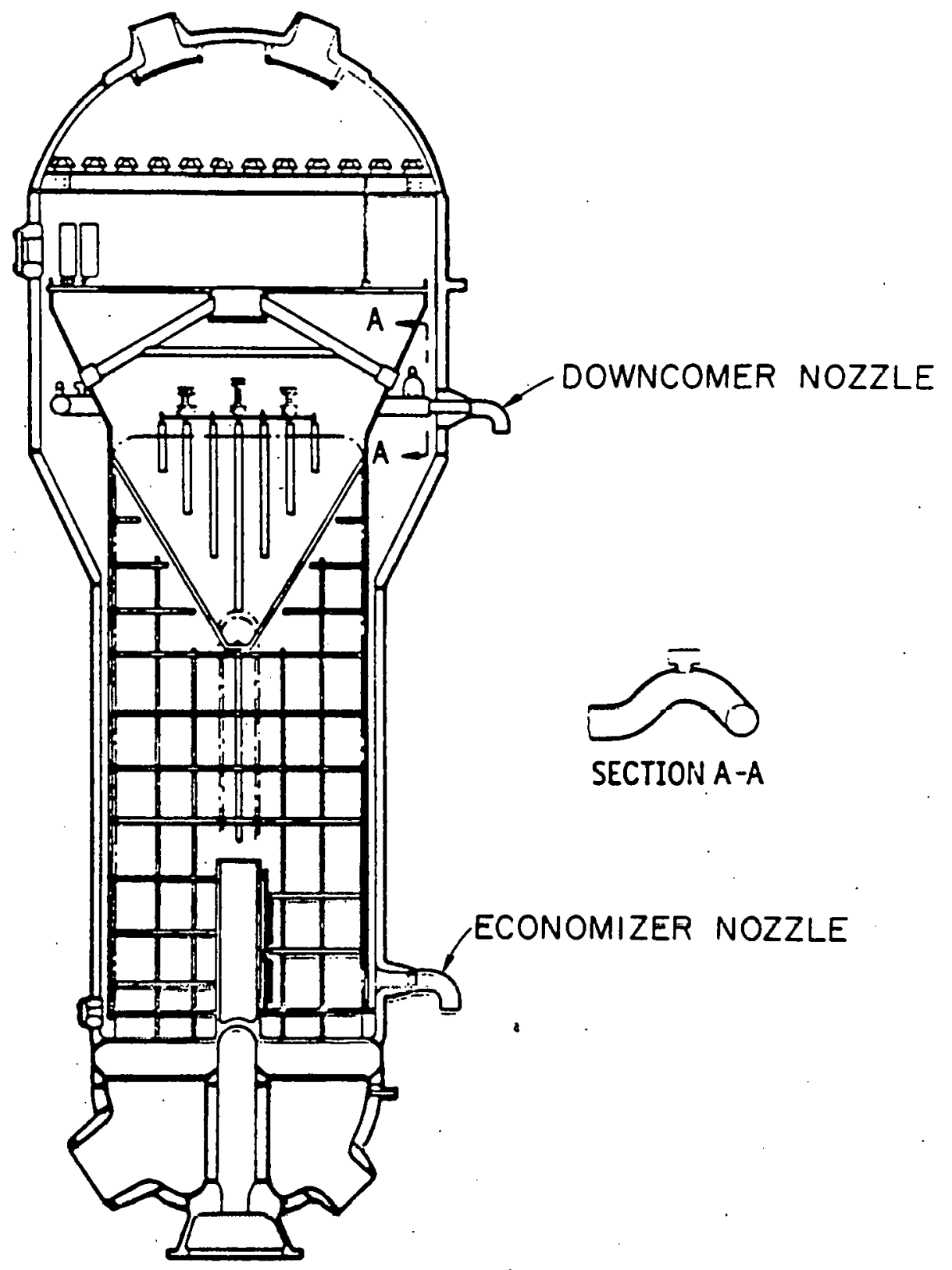

Figure 7.1 CE integral economizer steam generator (axial flow). (BNL-3-173-80) 


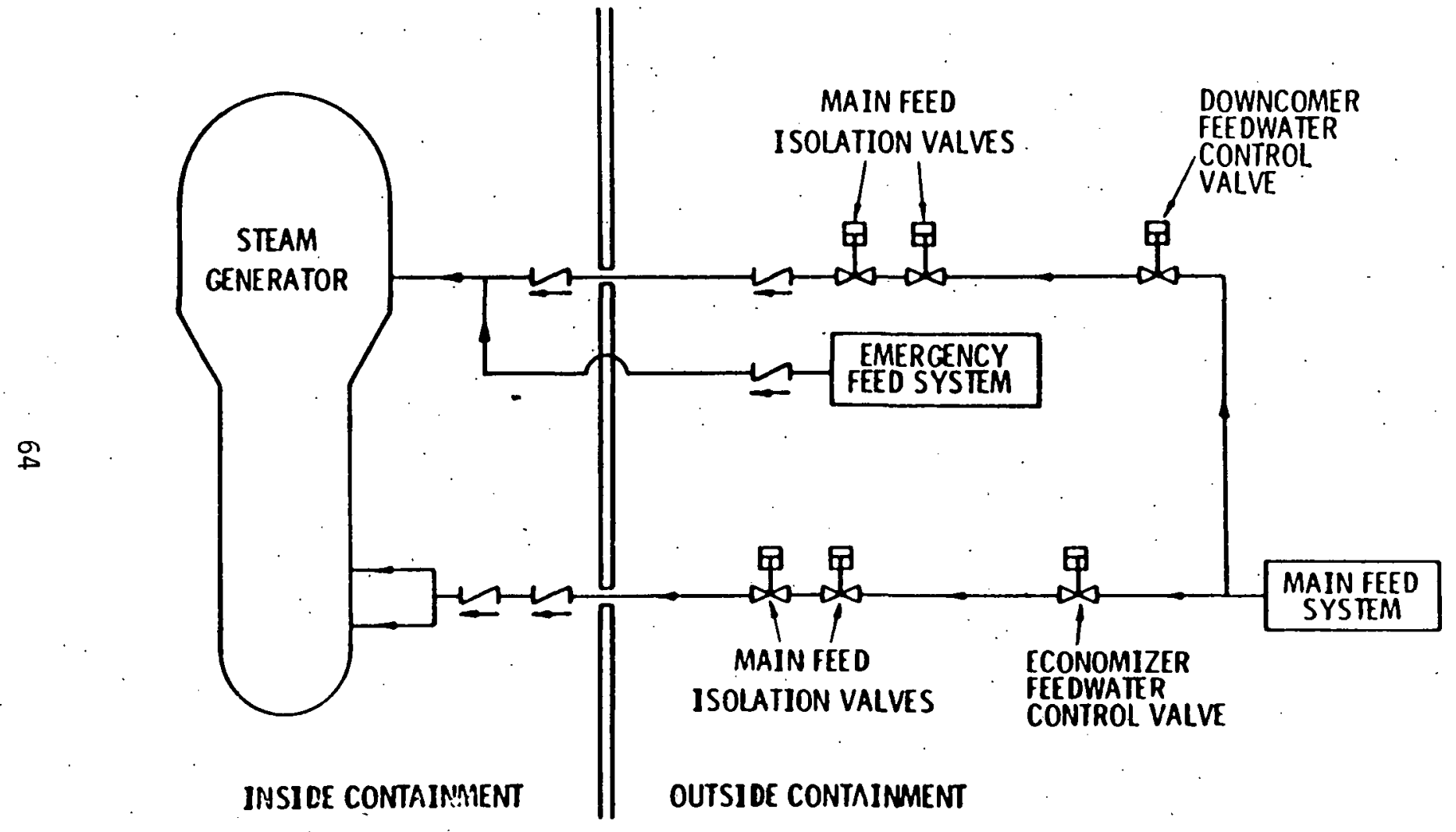

Figure 7.2 CE main feed system flow diagram. (BNL-3-178-80) 
model and the assumptions used in the analysis. The analysis appears to be parametric in nature and was able to produce results similar to the experimental results obtained at Tihange and Doel plants. Figures 7.3 and 7.4 serve as examples. Notice that different values of condensation rate, $K_{c}$, initial slug lengths and horizontal runs are used. No justification for the numbers used for the analysis are given. As such, the analysis does not seem to be more sophisticated or powerful than those of Westinghouse or BNL.

In view of the above findings, it is concluded that in the $C E$ design, under low power ( $215 \%$ of full power) condition, highly subcooled water could be introduced into the preheater. The preheater could contain significant amounts of voids and thus could be susceptible to water hammer. As no experimental or analytical results are available, verification tests in actual plants are needed. The test should be similar to that suggested for the McGuire plant with the exception that the plant be run at around 15\% of full load during the switch of feedwater from the downcomer nozzle to the economizer nozzle. 
LEGEND:

$K_{C}=104$ (VARIABLE)

$--K_{C}=200$ (VARIABLE)

SLUG LENGTH - 6'

HORZ. RUN LENGTH - 8'

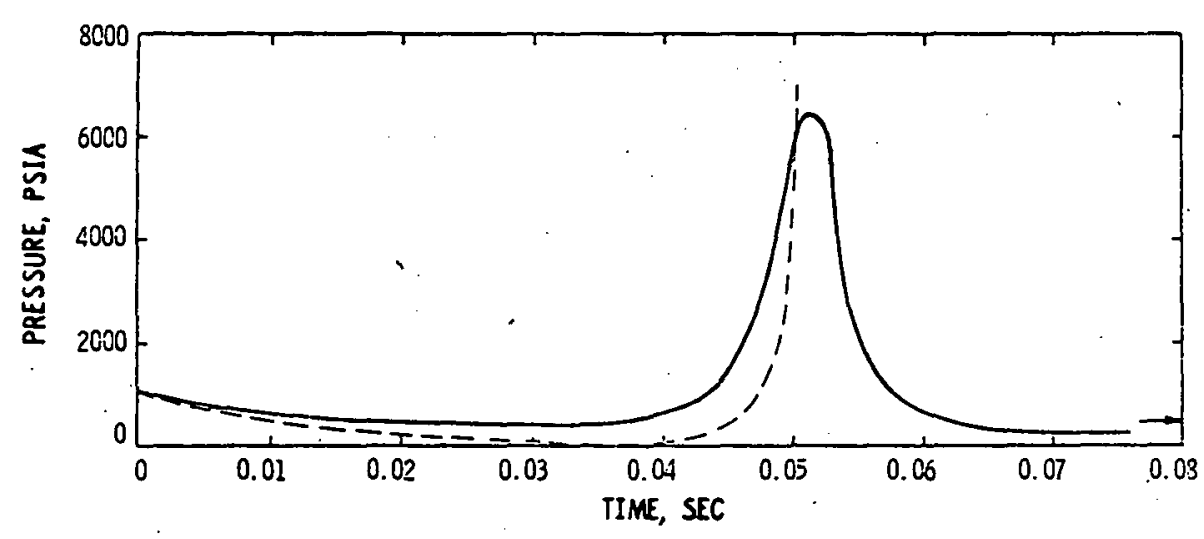

Figure 7.3 CE analytical results. Pressure vs. time - Tihange incident. Variable condensation rate $\left(K_{C}\right.$ in $\left.1 \mathrm{bm} / \mathrm{sec}-\mathrm{ft}^{2}\right)$. (BNL-3-169-80)

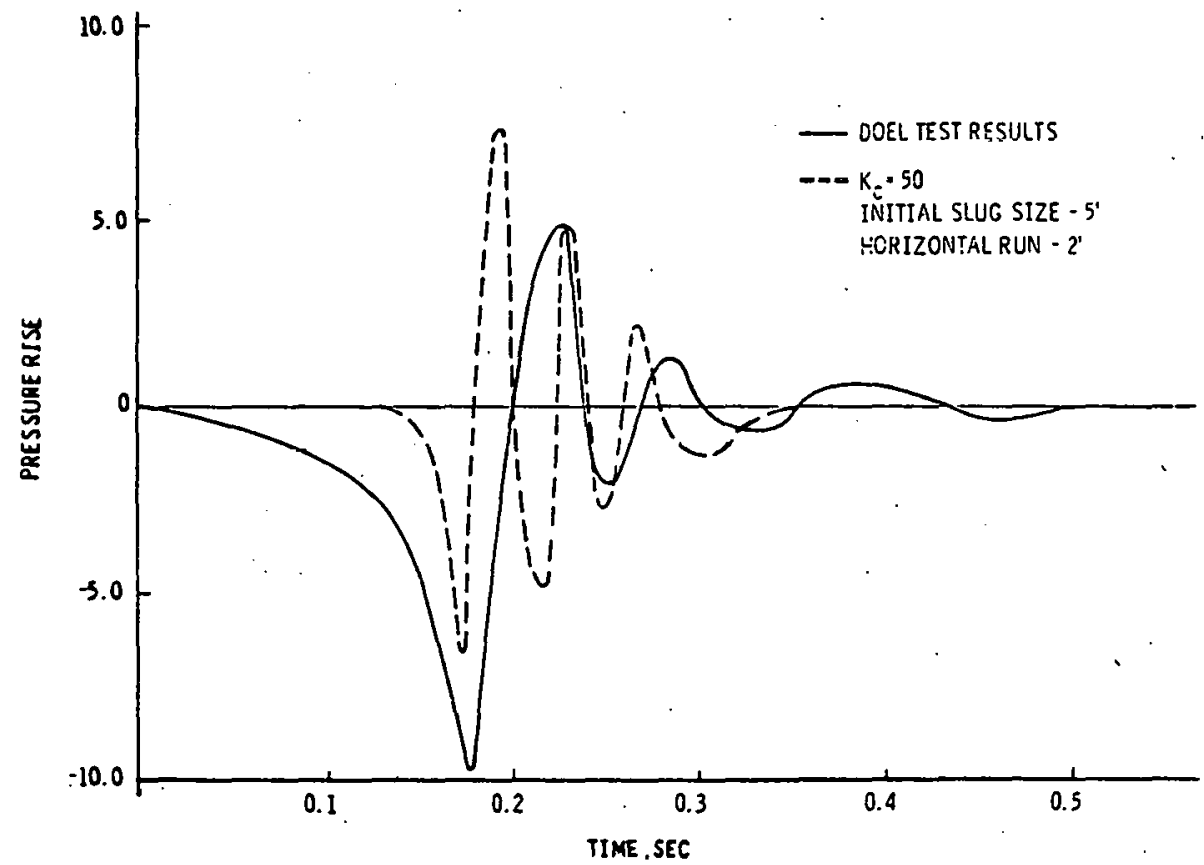
Figure 7.4 Doel test results vs. CE analytical results ( $k_{C}$ in $1 \mathrm{bm} / \mathrm{sec}-\mathrm{ft}^{2}$ ).
(BNL-3-168-80) 


\section{CONCLUSIONS AND RECOMMENDATIONS}

The following conclusions can be drawn from the BNL evaluation of the work done at Westinghouse, Combustion Engineering and BNL, and the review of Westinghouse and CE preheat steam generators:

(a) "Mild" water hammers were recorded in the feedwater pipe of the Westinghouse $1 / 8$ th scale test facility. No significant magnitude pressure pulses were recorded at the periphery of the preheater section. However, the uncertainties in the pressure attenuation characteristics of two-phase media with internals, together with the uncertainties in the effects of noncondensibles, precludes a clear conclusion that no significant water hammer activity occurred in the interior of the preheater.

(b) Westinghouse scaling laws cannot be substantiated becaúse of the uncertainties in the condensation heat transfer coefficient, interfacial area for condensation, initial sizes of the water slug and the vapor cavity, and the effective area over which the pressure difference acts

- on the water slug. Westinghouse assumed without substantiation, that these parameters are scale-independent.

(c) Condensation-induced void collapse could be an oscillatory process. This can cause the water hammer phenomenon to be random at certain operating conditions. This is seen from the BNL analytical study as well as the large scatter in the Westinghouse and Creare experimental results.

d) Because of the lack of definitive experimental and analytical results, the full-scale verification test.s are needed to ensure that no damaging water hammer will occur in any part of the steam generators and the connecting feedwater pipings. Because of the possible randomness of the water hammer phenomenon, a "sufficient" number of tests should be performed.

In view of the above conclusions, the following recommendations are made:

(i) The feedwater system of each plant with Westinghouse and Combustion Engineering preheat steam generator should be reviewed carefully. This is important in understanding the flow path of the cold auxiliary feedwater and the worst condition(s) for having a possible water hammer in the preheater area.

(ii) If NRC is convinced that the probability of introducing the cold auxiliary feedwater into the preheater area is very low because of the design of the auxiliary feedwater system, attention should be focused to the condition when the most subcooled feedwater might be injected into the preheater with significant voids. Such is the case in the McGuire plant and in the Combustion Engineering design. Verification tests in full-scale steam generators must be done for these conditions.

(iii) If the cold auxiliary feedwater is designed to be injected into the preheater area, as might be done in some plants with Westinghouse steam 
generators, appropriate verification tests must be performed. This means injecting room temperature water into a completely or partially voided preheater.

(iv) For the Combustion Engineering design, the feed-ring for the auxiliary feedwater should be tested in accordance with the NRC requirement for feedring type steam generators.

(v) Each verification test should be performed several times. This is important in view of the random nature of condensation-induced water hammer.

(vi) Research should be sponsored in order to enhance our understanding in the area of condensation-induced water hammer. This includes experimental programs directed at measuring condensation heat transfer coefficients, interfacial area for condensation, initial vapor cavity volume and the mass of accelerating water slug in simple geometry like round tubes. The mechanism of vapor cavity formation and liquid slug motion in a more complex geometry like tube bundles must be understood before we can even attempt to analyze water hammer phenomenon in the preheater region. Finally, the question of possible pressure pulse attenuation in a two-phase medium with internals, and with or without phase change, should be resolved. 


\section{y. REFERENCES}

Bankoff, S.G. and Mason, J.P. (1962), "Heat Transfer from the Surface of a Steam Bubble in Turbulent Subcooled Liquid Stream, "AIChE Journal, Vol . 8, No. 1, pp. 30-33.

Block, J.A., Rothe, P.H., Crowley, C.J., Wallis, G.B., and Young, L.R. (1977), "An Evaluation of PWR Steam Generator Water Hammer," NUREG-0291 .*

Brucker, G.G. and Sparrow, E.M. (1977), "Direct Contact Condensation of Steam Bubbles in Water at High Pressure," Int. J. Heat Mass Transfer, Vol. 20, pp. $371-381$.

Cahill, W.J. (1974), "Feedwater Line Incident Report - Indian Point Unit No. 2," Consolidated Edison Co., AEC Docket No. 50-247, Jan. 14, 1974.

Carlson, R.W., et al. (1978a), "High Pressure Water Hammer Test Program for the Split Flow Preheat Steam Generator," WCAP-9232, Jan. 1978.

Carlson, R.W., et al. (1978b), "Water Hammer Data Acquisition System Response Tests," October 1978.

Cumo, M., Farello, G.E., and Ferrari, G. (1978). "Direct Heat Transfer" in Pressure-Suppression Systems," 6th Int. Heat Transfer Conference, paper No. NR-18, Toronto.

Eckert, E.R.G. and Drake, R.M. (1972), Analysis of Heat and Mass Transfer, McGraw-Hill Book Co., New York, p. 387.

Florschuetz, L.W. and Chao, B.T. (1965), "On the Mechanics of Vapor Bubble Collapse," Journal of Heat Transfer, Vol: 87C, pp. 209-220.

Ishii, M. (1975), Thermo-Fluid Dynamic Theory of Iwo-thase flow, Eyrolles, Paris.

Rudinger, G. (1969), Nonsteady Duct Flow: Wave Diagram Analysis, Dover, New York.

ÆAvailable for purchase from the NRC/GPO Sales Program, U.S. Nuclear Regulatory Commission, Washington, DC 20555, and the National Technical Information Service, Springfield, VA 22161. 
APPENDIX A

BNL EXPERIMENTS: PRESSURE PULSE ATTENUATION IN TWO-PHASE VAPOR-LIQUID MEDIA WITH NO INTERNALS

\section{A.1 Introduction}

The Westinghouse experiments were instrumented with piezoelectric pressure transducers located on the walls of the preheater test vessel. Pressure events which occurred in the test vessel were sensed with these transducers. The inside diameter of the vessel is $15.56 \mathrm{in}$. A pressure pulse which originates within the preheater test vessel had to travel approximately 8 inches before it could be observed by a transducer. The possibility exists, therefore, that a pressure pulse could be attenuated by a combination of mechanisms before it reached the transducer location.

A pressure wave generated by a sudden deposition of a finite amount of energy at a given point will be attenuated simply because the wave spreads out as it progagates into the undisturbed medium. Geometrical attenuation of waves with spherical wave fronts follows an inverse-square law with distance from origin. In addition, irreversible processes in the two-phase medium may also lead to significant attenuation of the strength of the pressure waves.

Attenuation due to irreversible processes within the preheater may have occurred as a result of two mechanisms:

First, the two-phase medium could attenuate the pressure pulse and, second, the presence of the preheater internals (tubes, baffie plates, support structure) could also influence the attenuation.

In order to obtain an order-of-magnitude estimate regarding the potential for significant attenuation of the strength of shock waves in two-phase mixtures, a two-phase shock tube experiment was devised and undertaken for both bubbly and slug flow conditions. One-dimensional propagation of plane waves in a cylindrical pipe is not subject to geometrical attenuation and the attenuation by irreversible processes may be singled out. A one-dimensional experiment, performed using a circular pipe as a shock tube, was therefore chosen for the study.

The basic objectives of the experiment were:

(i) To create a two-phase flow of known and controllable void fraction in which a pressure pulse could be generated and,

(ii) To measure the attenuation of the pulse as a function of distance from a reference location.

It is the purpose of this section to describe the experimental apparatus and the results obtained. In the experiments described here, the attenuation characteristics of the two-phase flow were investigated. The impact of internal structure on the attenuation mechamisms were not studied due to limitations in available time and resources. 


\section{A.2 Experimental Apparatus}

\section{A.2.1 Test Section}

The apparatus consisted of two major parts:

(i) A shock generator or driver tube, and,

(ii) A test section.

As shown in Figure A.I, the shock generator consisted of a length of $2.5 \mathrm{~cm}$ I.D. stainless steel pipe with a rupturable diaphragm at the bottom end, and an ability to measure the internal pressure. The test section consisted of a length of Lexan plastic pipe having a porous plate at the bottom through which air could be injected into the liquid column above. A funnel-shaped device was mounted at the top of the test section to focus the shocks into the test section. Fast response piezoelectric pressure transducers were located at 3.81 , $13.97,26.67$, and $39.37 \mathrm{~cm}$ from the top of the test section. The porous plate was located in a union approximately $14 \mathrm{~cm}$ below the lowest transducer, $53 \mathrm{~cm}$ from the top. Figure A.2 shows the entire test apparatus, including the test section and the instrumentation. Figure A.3 presents the Lexan plastic pipe with the four transducers mounted along its length. The funnel and the lower portion of the shock generator are also visible. The test column is shown under bubbly flow conditions. Figure A.4 is a closeup view of the test section showing a bubbly flow. The porous plate is located in the union at the bottom of the photograph.

\section{A.2.3 Inslrumenlaliun}

The instrumentation used in the experiments to measure the pressure pulses consisted of

(i) Four piezoelectric pressure transducers,

(ii) Charge amplifiers, and,

(iti) A storage oscilloscope.

These are shown in Figure A.2.

The transducers and amplifiers were supplied on loan by Westinghouse to BNL. The transducers are PCB Model 112A04 High Temperature Pressure Transducers. Their range, according to vendor specifications, is 0-5000 psi. The charge output of these transducers was converted to voltage output using Unholtz-Dickie Model D22 charge amplifiers. The amplifier output voltage was recorded on a Tektronix Model 7633 memory-type oscilloscope, operated in the external trigger mode. Photographs were taken of the stored pressure traces.

Also shown in Figure $A .2$ are 


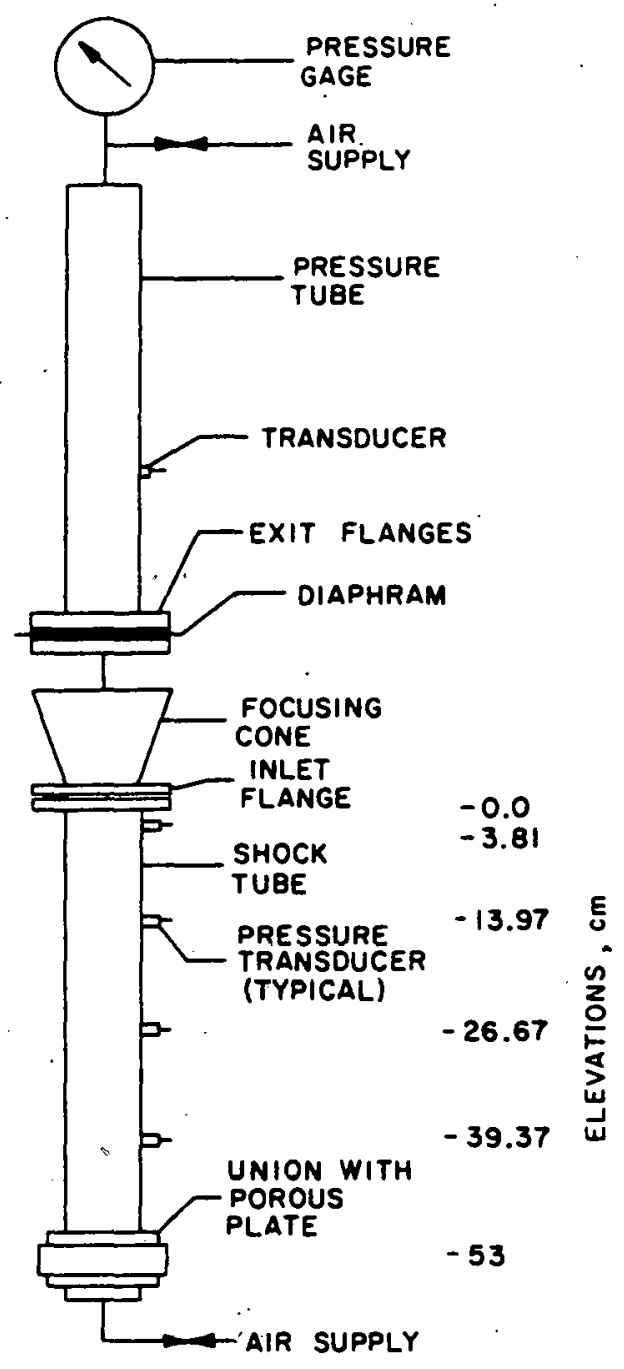

Figure A.1 Schematic of BNL two-phase shock attenuation test section. $(B N L-2-1128-80)$ 


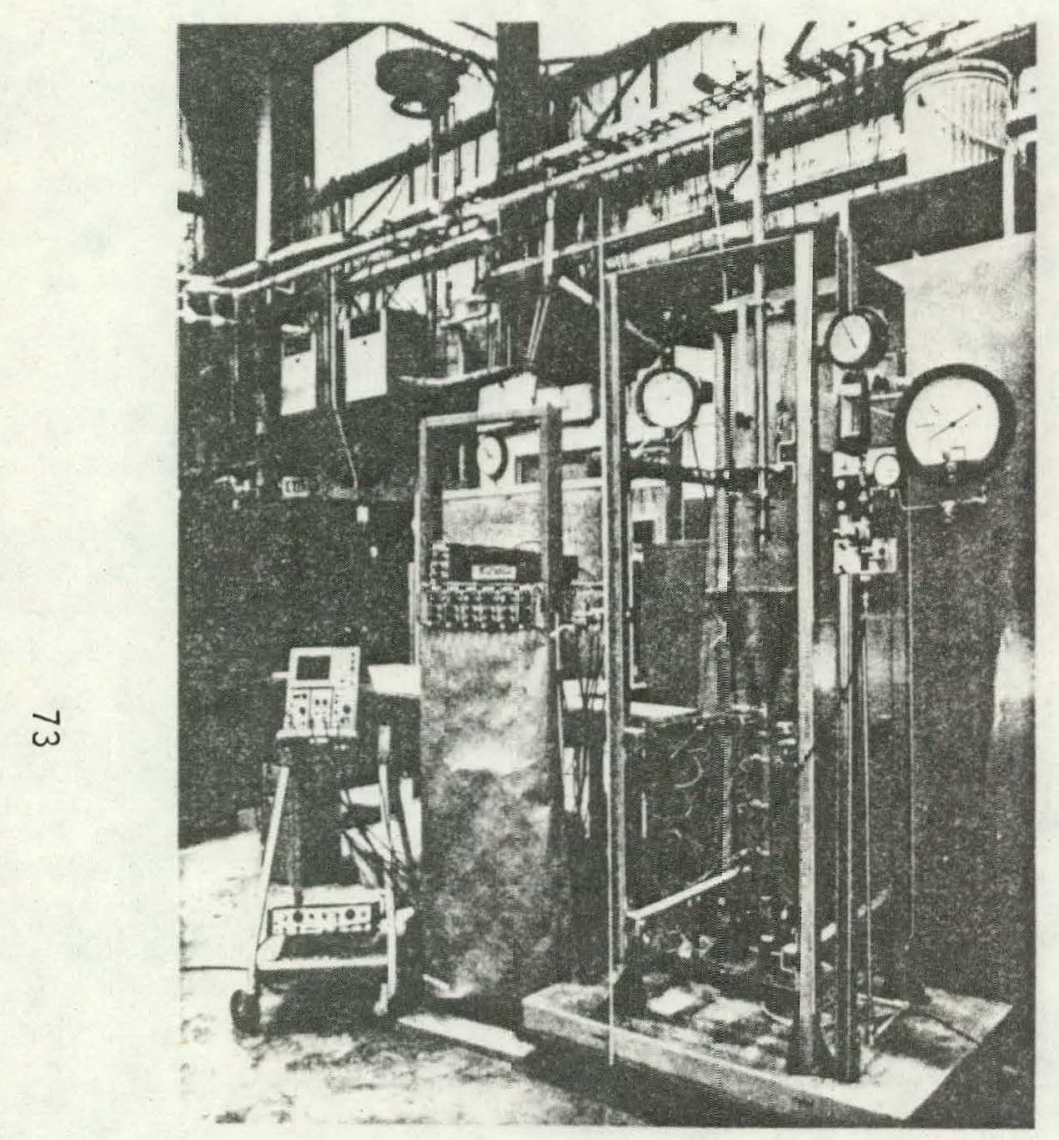

Figure A.2 Overall view of shock attenuation apparatus: Test section and instrumentation. (BNL-6-1076-79)

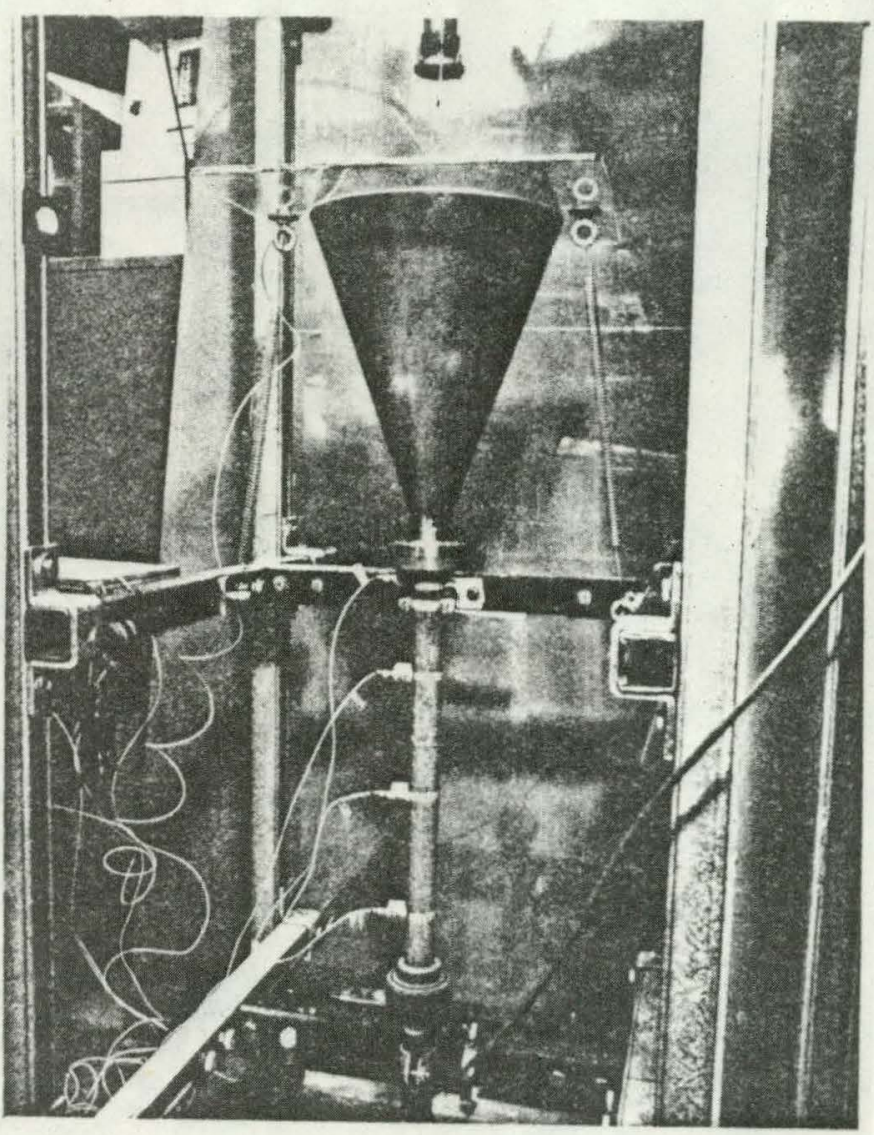

Figure A.3 View of test section: Pressure transducer, focusing cone, tip of shock generator. (BNL6-1075-79) 


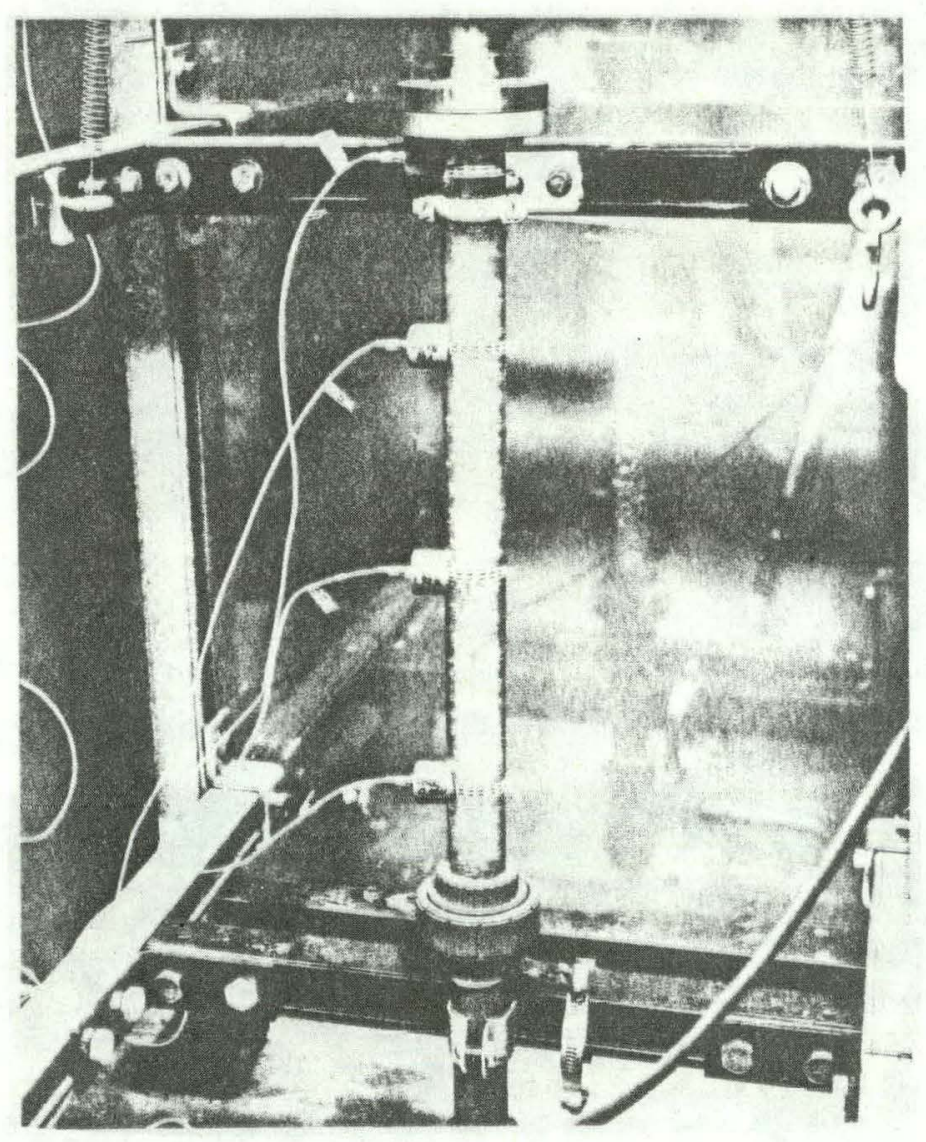

Figure A.4 Close-up view of test section: Two-phase conditions. (BNL-6-1077-79) 
(i) The pressure gauge used to monitor the pressure in the shock generator, and,

(ii) The valving, flow meter and pressure gauges used to monitor the flow of gas to the test section.

\section{A.3 Experimental Procedure}

The experiments were carried out in two parts. First, the transducers were calibrated using an in-situ procedure. Then, the two-phase pressure pulse attenuation measurements were carried out. These two steps are described below.

\section{A.3.1 Transducer Calibration}

The pressure transducers were calibrated using a modified version of the apparatus shown in Figure A.3. For this purpose, the funnel was removed from over the Lexan test section. A flange was placed over the top test section flange, with a rupture diaphragm sandwiched between them.

The transducers were calibrated by first pressurizing the test section statically and recording the pressure. The diaphragm was then ruptured, and the resulting series of pressure traces was recorded. The transducer nearest the upper flanges was used to trigger the oscilloscope. The three lower transducer outputs were recorded on the scope. The pressure pulse propagates down the Lexan tube as a rarefaction wave. The pressure in front of the wave is the initial pressure in the tube, and the pressure behind the wave is atmospheric pressure. This is true because the outflow from the test section is subsonic (Rudinger, 1969). The presence of the tail of the expansion wave in the test section as observed in the pressure traces assures that the outflow is subsonic in the calibration runs.

Figure A.5 shows a typical calibration signal response from the three lower transducers. The zero level of all three signals is at 5 psig. The zeros have been slightly shifted to provide readability. The lower plateau level corresponds to atmospheric pressure. The calibration was performed by measuring the recorded voltage magnitudes on the scope photographs and recording the corresponding pressure prior to breaking the diaphragm. Calibration results are presented in Section A.4.

\section{A.3.2 Pressure-Pulse Attenuation}

The attenuation measurements were carried out using the test section as shown in Figures A.2-A.4 and the instrumentation discussed in Section A.2.3.

A test was initiated by first creating a two-phase flow with the desired void fraction. This was accomplished by filling the Lexan tube with water to some level $H_{0}$. The gas flow was then adjusted so that the mean liquid pool level rose to a new position $H$. The average void fraction, $\bar{\alpha}$, in the test column is then computed as 


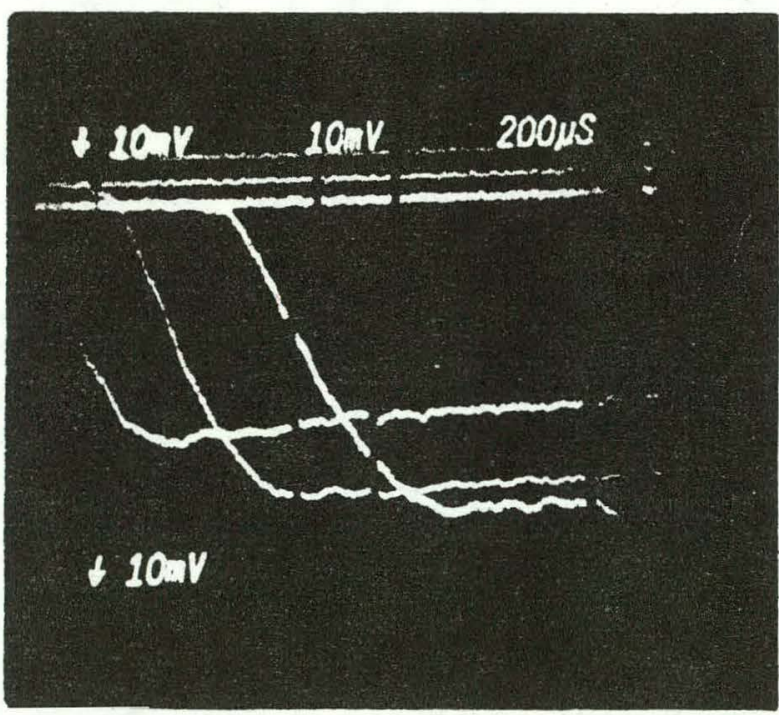

Figure A.5 Calibration pressure traces. 


$$
\bar{\alpha}=1-\frac{H_{0}}{H}
$$

Liquid was then poured into the column, to raise the level up to just within the funnel. The gas flow was kept constant during an experiment. It was assumed that since the gas and liquid velocities were not changed upon addition of water, then the average void fraction was not affected.

A diaphragm was then positioned in place at the base of the driver tube. The driver was then lowered until the diaphragm was submerged in two-phase fluid. The driver tube was then pressurized to the desired level.

The driver tube pressure was recorded, along with the initial and final liquid levels. A photograph of the two-phase flow field was taken to give a visual indication of the flow regime. The diaphragm was then ruptured manually by insertion of a sharp object. This initiated the pressure pulse which traversed the test section. A pressure transducer located in the driver section was used to trigger the oscilloscope. The lower three transducer signals were stored on the scope, and were subsequently photographed.

\section{A.4 Experimental Results}

\section{A.4.1 Transducer Calibration}

Typical calibration experiment pressure traces are shown in Figure A.5. The calibration data were extracted from the traces as described in Section A.3.

Figures A.6-A.8 present the transducer calibration results. The data are compared with the manufacturer's calibration curve for each transducer. The in-situ calibration at BNL covered the range 0-20 psig. It was in this range that the two-phase attenuation measurements were made. The calibration data are scattered $+20 \%$ around the vendor-supplied calibration. This scatter corresponds to less than $0.1 \%$ of full scale of the specified range ( 5000 psi) of the transducers. The accuracy of the pressure measurements reported in this work, therefore, is taken to be $+20 \%$, since the calibration uncertainty is the largest surce of error.

\section{A.4.2 Pressure Pulse Attenuation in Two-Phase Flow}

The initial experiments were performed in single-phase media, in order to develop an understanding of the behavior of the experimental system. Singlephase shock tube behavior is discussed in many textbooks [e.g., Rudinger (1969)]. These initial experiments, therefore, permitted comparison with known analytical results. They were used to check the performance of the overall measurement system before initiation of the two-phase experiments.

Figure A.9 presents typical pressure traces showing shock wave propagation in single-phase air and single-phase water. Looking first at the air results, a 


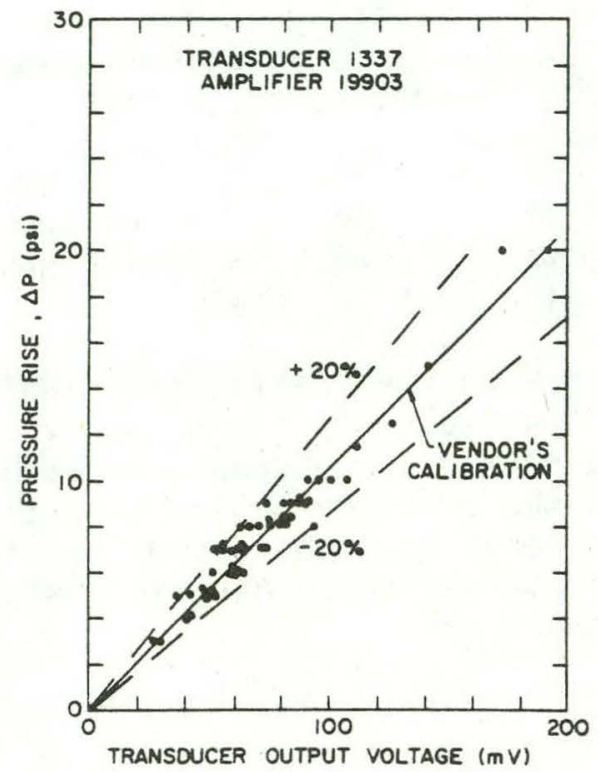

Figure A.6 Pressure transducer calibration data. (BNL-2-1126-80)

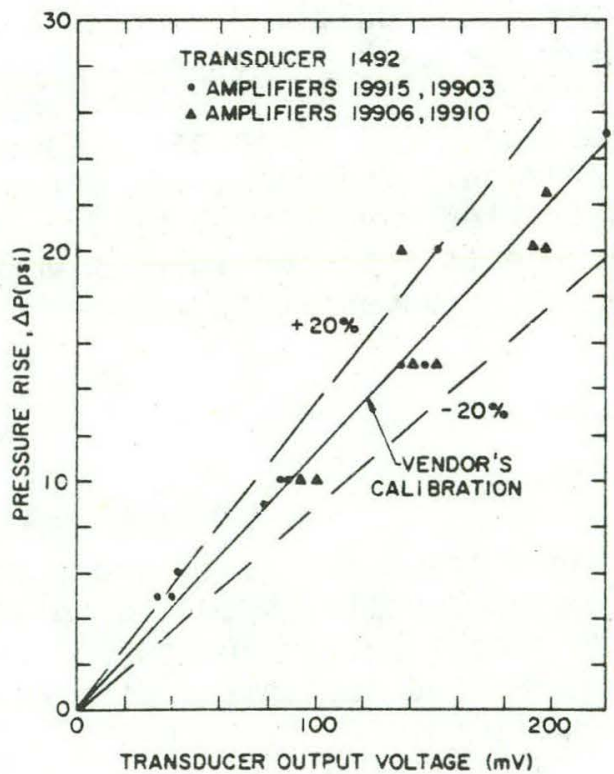

Figure A.8 Pressure transducer calibration data. (BNL-2-1125-80)

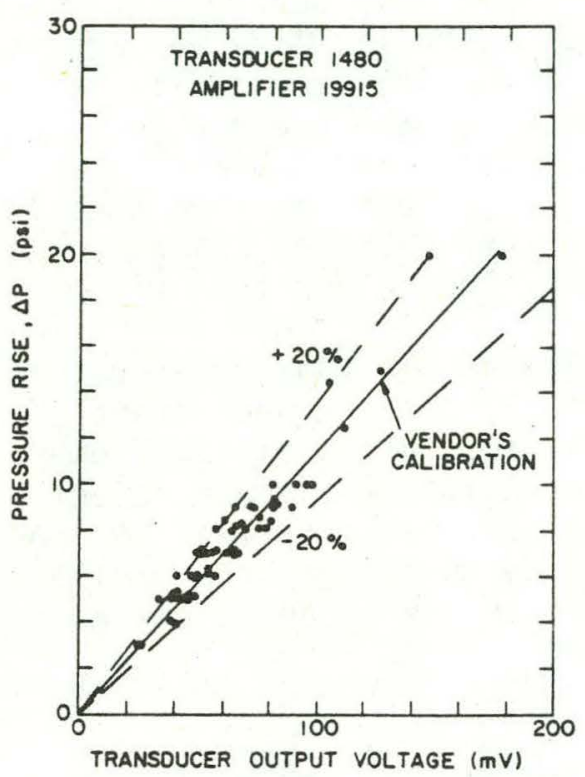

Figure A.7 Pressure transducer calibration data. (BNL-2-1124-80) 


\section{WAVES IN SINGLE PHASE}

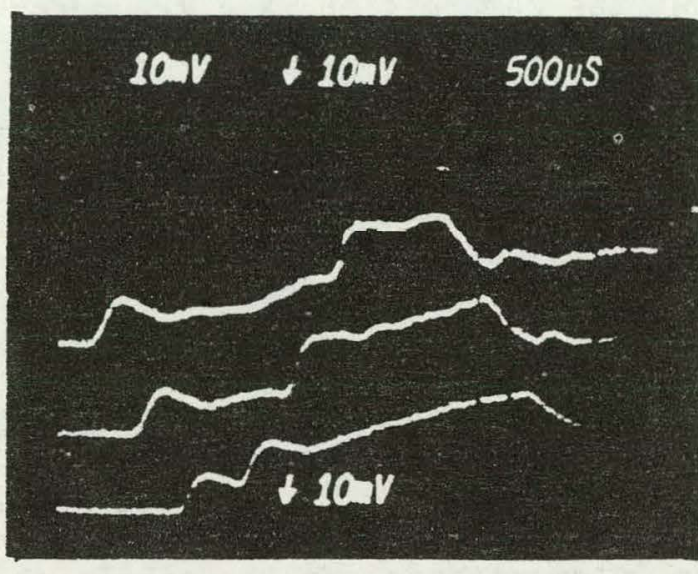

$$
\begin{gathered}
\text { AIR } \\
P_{4}=7.5 \text { PSIG }
\end{gathered}
$$

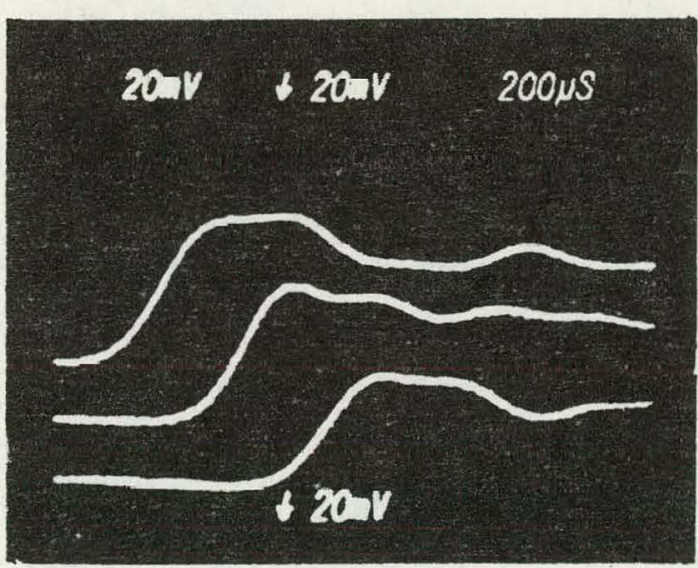

WATER

7 PSIG

Figure A.9 Pressure pulses of waves in single phase air and water. (BNL-7-80.3-79) 
delay time is observed before the pressure wave reaches the transucer measurement stations. Calculations indicate that these delay times correspond closely to the time for a sonic disturbance to traverse the distance between transducers. Following the pressure rise due to the arrival of the shock wave, a small reduction in pressure is observed. The reason for this reduction is not known. A plateau region is then observed in all three traces, albeit with different time scales. This is then followed by another pressure rise. This behavior is explained by the fact that the compression wave traverses the length of the test column, reaches the porous plate and is reflected back. This reflection of a compression wave from a solid surface is accompanied by a pressure rise. This second pressure rise is observed in all transducers as the reflected compression wave traverses up the column. The relatively slow rise in pressure following the arrival of the reflected wave cannot be accounted for at present. A generally similar behavior is observed for the case of water, as shown in Figure A.9. No significant attenuation in pressure is observed in the single-phase experimental data.

The single-phase measurements described above are explained by classical shock theory, at least qualitatively. The signals, however, are not "clean" and some of their characteristics are not understood. If time had permitted, it would have been desirable to attempt several system modifications which may have led to "cleaner" signals and easier interpretation of the single-phase signals. It was decided, however, that a sufficient understanding of the system had been attained, and that two-phase measurements could proceed.

Two-phase pressure pulse attenuations were carried out at two void fraction ranges. In the first $0.16<\alpha<0.19$, and in the second $0.26<\alpha<0.29$. The first range is in the bubbly flow regime, the second in the slug flow regime. Typical pressure traces, together with photographs of the flow field, are presented in Figures A.10 and A.11.

The pressure pulses observed in Figures A.10 and A.11 are "noisy" and difficult to interpret in detail. The first pressure rise is observed in all cases, as in the case of the single-phase results. In some cases, however, and in particular in the uppermost trace, a pressure drop is observed before the sharp rise in pressure. The reason for this behavior is not understood. This makes it difficult to judge the magnitude of the pressure pulse in the uppermost measurement station. Following the sharp rise in pressure due to the arrival of the shock, a fluctuating pressure response is observed, instead of an expected plateau region indicative of constant pressure conditions. The reason for this behavior is also not understood. This behavior also makes it difficult to estimate the magnitude of the pressure pulses.

The above-mentioned difficulties notwithstanding, a judgement had to be made with respect to whether or not, and how much pressure signal attenuation was observed in the two-phase shock tube tests. The poorly-understood details of the pressure traces were, therefore, overlooked. The pressure traces of Figure A.10 and $A .11$ are representative of a total of 14 two-phase experiments. It was concluded that, within the experimental error in pressure of $+20 \%$, attenuation of pressure pulses in the two-phase experiments was not detectable. 
WAVES IN BUBBLY FLOW $0.16<\alpha<0.19$
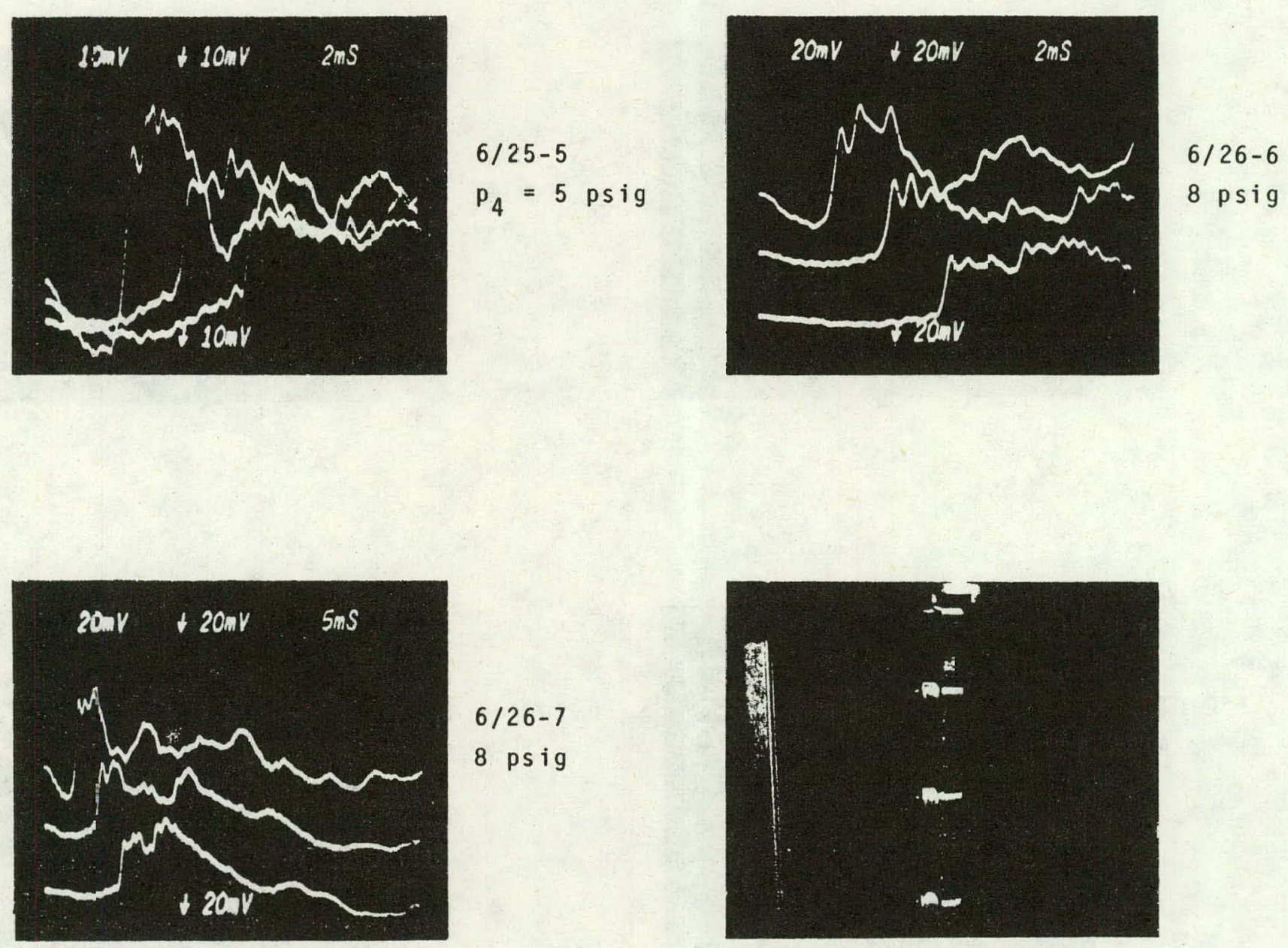

$6 / 26-7$

8 psig

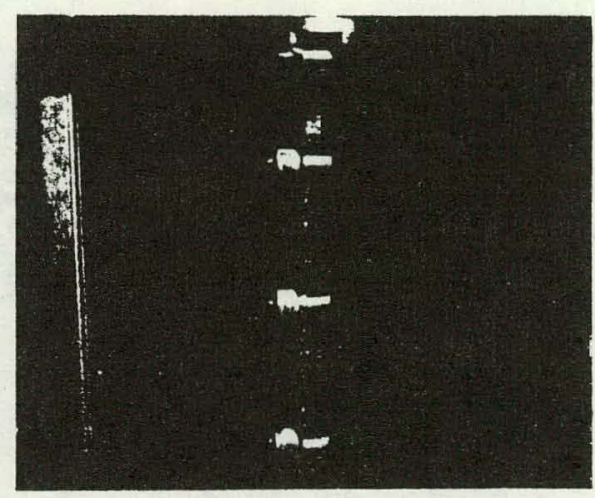

Figure A.10 Pressure pulses of waves in two-phase butbly flow. (BNL-7-802-79) 
WAVES IN SLUG FLOW $0.26<\alpha<0.30$
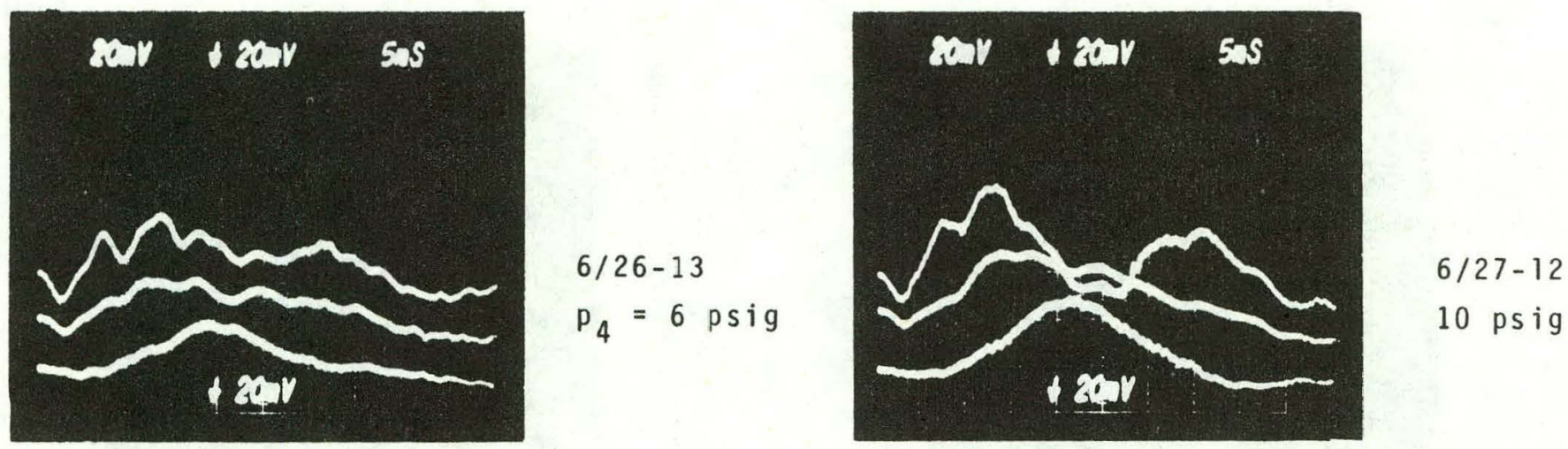

10 psig

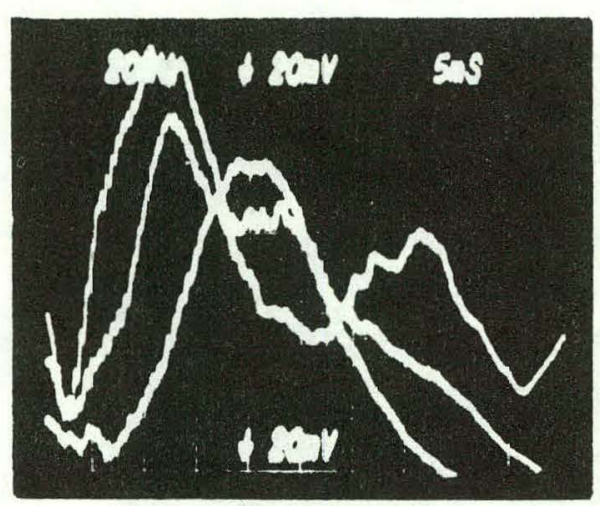

\section{$6 / 27-8$}

26 psig

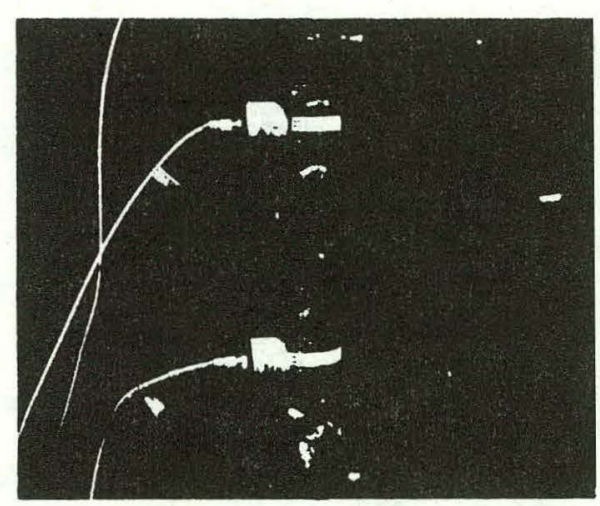

Figure A.11 Pressure pulses of waves in two-phase slug flow. (BNL-7-801-79) 


\section{A.5 Conclusions}

On the basis of the two-phase experiments described above, and within the experimental error in pressure measurement, it is judged that pressure pulse attenuation in two-phase flow (in a tube with no internal structures) is negligible over distances of approximately 1-2 feet. Certainly, order of magnitude attenuation is not to be expected on the basis of the experimental results. This conclusion is meant to apply to flows with void fractions up to approximately 0.30 , and to the bubbly-and slug-flow regimes. It applies to lowpressure (near atmospheric) conditions.

The above conclusion is difficult to extrapolate to the conditions existing within the Westinghouse preheater vessel. The major uncertainty is judged to be the effect of the internal structures (tubes, baffles, supports) on the attenuation characteristics. While the results of this experiment suggest that pressure pulse attenuation in two-phase flow is small over distances on the order of 1-2 feet, the possible effects of internal structures cannot be discounted. Further experimental investigation is required in order to determine the effects of internal structures on pressure pulse attenuation in two-phase media. 


\section{NRC.F ORM 335 (7.77)

4. TITLE AND SUBTITLE (Add Volume No., if appropriate)

An Evaluation of Condensation-Induced Water Hammer in Preheat Steam Generators

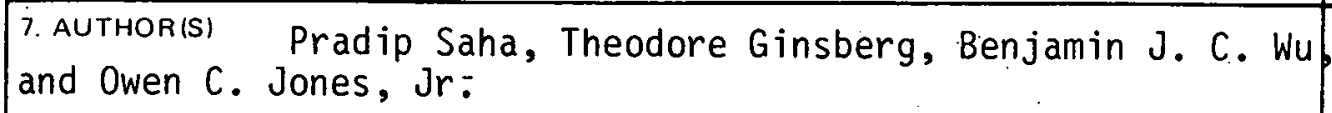

2. (Leave blank)

5. DATE REPORT COMPLETED

\begin{tabular}{|l|l}
\hline MONTH & YEAR
\end{tabular}
\begin{tabular}{l|l}
\hline ONTH & YEAR \\
JunE & 1980
\end{tabular}

\begin{tabular}{l|l} 
DATE REPORT ISSUED \\
\hline MONYH \\
September & YEAR 1980
\end{tabular}

6. (Leave blank)

8. (Leave blank)

12. SPONSORING ORGANIZATION NAME AND MAILING ADDRESS (Include Zip Code)

Division of Systems Safety

Office of Nuclear Reactor Regulation U.S. Nuclear Regulatory Commission Washington, DC 20555

FIN No. A3115

16. ABSTRACT 200 words or lessAt the request of the Division of Systems Safety of USNRC, BNL evaluated the potential of condensation-induced water hammer in preheat type steam generators.

Westinghouse 1/8-scale water hammer tests and data añlys is were reviewed. BNL has concluded that water hammers occurred in the feedwater line during many of the 1/8-scale tests and were probably caused by steam bubble entrapment and collapse in the partially-filled feedwater line. The Westinghouse scaling laws were also independently reviewed. The present state-of-the-art on the condensation heat transfer and the mechanism of vapor cavity formation precludes us from deriving any credible scaling criteria. However, under certain operating conditions the condensation-induced void collapse could be an oscillatory process. This may partially explain the apparent randomness of the water hammer phenomenon seen in most experimental studies.

The full-scale preheat type steam generators of both the Westinghouse and the Combustion Engineering design have been reviewed from the viewpoint of condensation-induced water hammer. It is recommended that each plant should be reviewed separately to identify the worst situation(s) for the condensation-induced water hammer, and the appropriate verification test(s) should be performed in plants. In addition, basic research should be sponsored in order to enhance our understanding in this area:

Water Hammer, condensation-induced

Feedwater line steam bubble collapse 
NUCLEAR REGULATORY COMMISSION

WASHINGTON, D. C. 20555

POSTAGE AND FEES PAID

OFFICIAL BUSINESS

U.S. NUCLEAR REGULATORY COMMISSION 